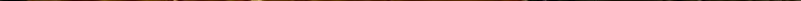




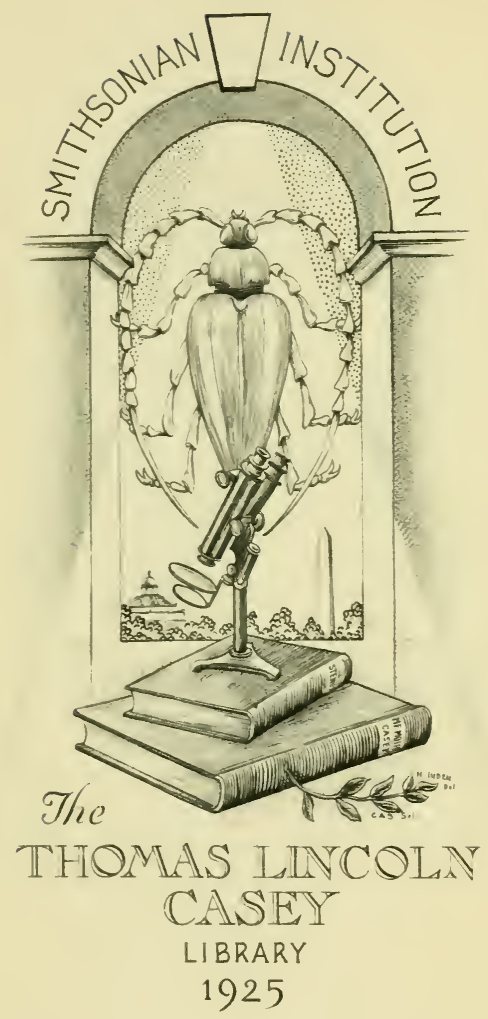








\section{DES ENDOMYCHIDES}

D'EUROPE ET DES CONTRÉES LIMITROPHES;

\section{Par M. So-1. DE MARSEUL.}

A la suite des Érotyles, que M. Louis Bedel a étudiés avec tant de soin et dont la monographie inaugure avec succès les travaux de ce jeune entomologiste, vient se ranger tout naturellement la petile famille des Endomychides. Ces deux groupes ont des rapports intimes de forme, partagent le même genre de vie fongicole et noclurne et établissent une transition des Chrysomèles aux Coccinelles. Dans ces derniers temps, deux savants entomologistes se sont occupés des Endomychides ou Sulcicolles : l'un, le $D^{r}$ Gerstæker, a fait sur la famille entière un travail de haute valeur; l'autre, M. Mulsant, a décrit minutieusement les espèces de France. En donnant la monographie de ces insectes, je n'ai donc pas la prétention de faire une œuvre originale, de débrouiller une famille négligée, comme l'étaient les Erotyles d'Europe ; mais j'ai voulu faire profiter les entomologistes français des recherches du professeur allemand et compléter le cadre du premier historien des Coléoptères de France. Quand j'aurai bien fait connaitre les genres et les espèces, par une exposition claire et précise et à l'aide de tableaux synoptiques rigoureux el faciles à consulter, mon but sera rempli. J'ai bien aussi rectifié certains genres et publié quelques nouvelles espèces, grâce à trois de nos notabilités entomologiques, MII. Chevrolat, Perris et lieiche. Ces savants trouveront leur récompense, moins dans nos remerciments, que dans les sentiments de gratitude qui animent tous ceux qui profitent de leurs communications scientifiques.

Abeille, v. 1867. 


\section{CARACTÉRES ET ÉTUES DES PARTIES EXTÉRIEURES DU CORPS.}

La famille des Exdourchides, appelés par Latreille Fongicoles, de leurs habitudes, et par M. Mulsant Sulcicolles, des sillons que présente leur pronotum, se compose, dans les limites que je leur assigne à l'exemple de M. Gersłæker, d'especes réunissant les caractères suivants :

Tête rétrécie au-devant des yeux et allongée en museau. Epistome bien séparé du front. Dernier article des palpes maxillaires sub-cylindrique.

Antennes insérées sur le front, allongées, non rétractiles, de 11 articles, terminées par une massue.

Pronotum marqué à sa base de 2 sillons longitudinaux, reliés pour l'ordinaire par un autre transversal. Nẻsépimères rhomboïdales, métépisternes tronquées obliquement en devant. Hanches antérieures globuleuses; cuisses non cannelées le long de leur bord interne; jambes libres; ongles simples. Nlélasternum et premier segment de l'abdomen dépourvus de fossettes ou plaques coxales.

Differences sexuelles ordinairement visibles. - Larves fongicoles.

Le corps des Endomychides est de moyenne ou de petite taille, de nature solide, cornée, à surface plutôt glabre que pubescente. Sa forme est entre l'ovale oblong ou même allongé el le cercle, avec une convexilé faible dans le plus grand nombre, mais alleignant dans des cas rares la hauteur d'une demi-sphère.

La têle est enfoncée à sa partie supérieure jusqu'aux yeux dans le prothorax et enclavée entre ses angles antérieurs saillants, mais en dessous non-seulement les parties de la bouche, mais encore les parties progéniales restent libres. Le front est large, tombant obliquement en devant, et se rétrécit fortement de chaque côté à son point de jonction avec l'épistome. Celui-ci est beaucoup plus étroit que la tête et n'égale souvent qu'un tiers de sa largeur; il est séparé du front par un sillon fin, quoique tonjours distincl. Ordinairement plus large que long, quelquefois très-court, il est arrondi ou coupé droit par devant. Il ne couvre pas 
entièrement en dessus les parties de la bouche, mais il laisse déborder latéralement les mandibules, qui sont inséyées sur la même ligne transversale que lui. Cette disposition donne à la bouche la forme d'un museau.

Les yeux sont placés sur les côtés de la tête, derrière et en dehors des antennes, sur une ligne verticale si on les regarde de profil, en ovale oblong, légèrement sinués en devant. Dans les Endomychides propres, où ils sont plus grands, ils s'avancent sur le front et entourent par derrière l'insertion des antennes. Dans les Endomychides annexés, ils sont petits, en ovale ou même en cercle (Mycetca), sans échancrure, et finissent en dehors des antennes, de manière à laisser le front libre dans toute sa largeur. Leur surface est glabre et composée de grosses facettes cornées; ces facetles varient de grosseur dans de certaines limites entre cerlains genres: mais ces variations ne peuvent fournir de caractères génériques, comme dans les Erotyles. On ne trouve d'ocelles dans aucune espèce.

Les antennes sont insérées à la partie inférieure du front près de la limite de l'épistome et au bord interne de l'œil. Le bord du front s'élève à leur insertion et forme deux espèces de tubercules frontaux. Leur longueur varie peu; elle atteint au plus celle de la moitié du corps et n'est pas en rapport avec sa forme plus ou moins allongée; c'est ainsi que les Leicstes ont des antennes courtes. Le nombre normal des articles est de 11 , et il n'y a d'exceptions que dans peu de genres exotiques. Le $1^{\text {er }}$ article est allongé et épaissi au bout; 4-8 sont ordinairement plus longs que larges, quelquefois courts et transverses. La longueur lelative des 3 ou 4 premiers articles du funicule est fort variable et a beaucoup de valeur pour séparer les genres et même les groupes. Ainsi, dans la première section, le $3^{\text {e }}$ articie est allongé comme le $1^{\mathrm{er}}$, tantôt beaucoup plus long que le $2^{\mathrm{e}}$ (Ancylopus, Dapsa, Endomychus, Mycctina), tantôt à peine plus long ou seulement aussi long que le $2^{\mathrm{e}}$ (I.ycopcrdina, (ieramis, Perrisia, Polymus), et les suivants vont en décroissant. Dans la deuxième section, le $\mathbf{1}^{\mathrm{r}}$ article est le plus long. et à partir de là les suivants vont en diminuant. Les 3 derniers forment une massue qui subit de nombreuses moditications soit dans son ensemble, soit dans ses parties. 
Tantôt elle est peu prononcée et les articles s'élargissent graduellement, plus (Mycetina) ou moins (Lycoperdina); tantôt elle est forte et abrupte (Ceramis). Les articles sont, dans les Ancylopus, par exemple, longs et làclies; dans les Perrisia, plus larges que longs et serrés. Enfin, ces articles varient aussi beaucoup entre eux de taille et de forme : le premier ordinairement plus petit, souvent à peine plus fort que le precédent, est quelquefois très-gros; le dernier est la plupart du temps le plus grand; arrondi au bout, allongé ou transversal, aussi long que les deux précédents ensemble ou bien moindre que le 10 e.

Ia bouche, rétrécie en forme de museau, présente dans ses organes des caractères importants : le labre transversal, de consistance cornée, souvent avec une bordure membraneuse qui nait du bord antérieur et se trouve garnie de soies, varie peu de forme, seulement il est coupé droit en devant ou distinctement échancré avec les angles arrondis. Les mandibules commencent sur la même ligne transverse que l'épistome; fortes, cornées, convexes en dessus et concaves en dessous, elles se courbent en dedans et forment une pointe plus ou moins aiguē. A leur bord interne, elles sont entaillées et munies, à partir de la base, d'une membrane garnie de cils et armées d'une dent vers le bout, plus ou moins près de la pointe.

Les mâchoires ont la liampe cornée, de forme irrégulièrement carrée et portant deux lobes distincts, dont l'externe est toujours le plus grand, moins corné et ordinairement le plus long. Le lobe interne étroit, allongé, linéaire, d'ordinaire tronque obliquement au bout, rarement en pointe presque droite (Dupsa), est toujours garni de poils épais et roides à son bord interne, ou sur une assez grande étendue seulement; ces poils, dans la plupart des cas également longs et forts, sont serrés l'un contre l'autre en touffes; rarement ce sont des soies isolées, remarquables par leur raideur et leur longueur (Dapsa). Le lobe externe varie beaucoup de taille, de forme et de consistance, mais ces variations peuvent être ramenées à deux types tranchés : ou il est très-long et alor's corné seulement tout-à-fait à la base, et la plus grande partie forme une queue membraneuse garnie de poils soyeux, épais (Dapsa), ou bien il est beaucoup moins long, et en ce cas 
entièrement corné ou coriacé, arrondi ou obliquement tronqué par devant et garni seulement au bout d'un panache de longs poils (Endomychus et Endomychides annexis).

Les palpes maxillaires sont également assujeltis à de nombreuses variations sous le rapport de la longueur; car tandis que d'ordinaire les trois derniers articles paraissent allongés, il éprouvent aussi (Endom. annexés, elc.) un raccourcissement considérable et quelquefois même l'avant-dernier devient transversal. Le dernier article, ordinairement plus long que les autres, n'est jamais sécuriforme comme dans les Coccinellides, mais souvent subuliforme, dans certains cas en ovale plus long ou plus court, et dans les Endomychus où il est largement et profondément tronqué, il conserve toujours la forme cylindrique.

Le menton, de consistance cornée, est beaucoup plus large que long, coupé droit ou très-légèrement arrondi par derrière, coupé droit ou un peu avancé sur les côtés el rarement au milieu par devant; à l'exception des Endomychus, où il est parallèle; il est rétréci aux deux bouts et élargi de chaque côté après le milieu en un angle obtus ou aigu.

La languelte est cornée et au moins coriacée à la base, membraneuse à la partie apicale, la plupart du temps sur une grande étendue, rarement sur une très-petite (Mycetcea). Chez les Dapsa et autres genres du même groupe, elle est plus large que longue et plus souvent échancrée que droite par devant, tandis que chez les Endomychus, elle est plus longue que large et arrondie au bout, ce qui leur donne une analogie prononcée avec les Coccinelicles.

Les palpes labiaux qui prennent naissance à la base de la languelte et toujours près l'un de l'autre, sont épais el serrés. Leur premier article, petit el très-court, ne présente pas de notable différence, non plus que le deuxième qui est transversal et largement tronqué en devant; mais le troisième est d'une importance toute particulière : court et transverse avec la troncature apicale orbiculaire et droite dans les uns, il alteint en longueur jusqu'au carré on à la forme sphérique dans d'autres el va même dans quelques cas jusqu'à l'ovale allongé.

Le prothorax, de taille petite ou an plus moyenne, adopte des formes diverses : ordinairement il est plus large que long 
et rétréci par devani, quoique ce soil le contraire dans quelques cas; son bord antérieur est entaillé profondément pour recevoir la tête, el les angles sont fort avancés. Le pronotum présente un caractère saisissant qui distingue nettement la famille el fournit en même temps un moyan sûr el facile de reconnaltre cerlains genres. C'est un systeme de sillons particuliers, toujours bien imprimés, quoique de différentes manières, et offrant partout une analogie parfaile. Deux sillons longitudinaux partent de la base, un de clıaque côté en dedans de l'angle postérieur, el remontent ver's le milieu qu'ils n'alteignent pas, si ce n'est dans quelques Endom. anncxés où ils vont presque jusquau bord antérieur. Ils sont reliés par un troisième sillon côloyant transversalement la base, qui disparaît quelquefois. Le propectus ou face infẻrieure du prothorax ne forme qu'une seule pièce, les sutures qui séparent le prosternum, les épisternes el les épimères élant complèlement effacées. Il est coupé droil à son bord antérieur jusqu'à la ligne de rencontre du prosternum avec les côtés rabaltus du prothorax, où il se brise en formant un coude pour se lerminer aux angles antérieurs. Il présente, à son bord postérieur, une double échancrure profonde pour loger les hanches. Ainsi les cavités colyloïdes sont formées en dedans et en devant par le prosternum et en dehors par les épisternes el les épimères rẻunies, el ouvertes par derrière, de sorte que les hanches s'appuient sur le mésosternum. L'arance prosternale, ou pour abréger, le prosternum, affecte trois disposilions qui sont d'une importance majeure, car elles se lient étroitement à la forme du corps et particulièrement a l'inclinaison plus ou moins grande du prothorax : tantôt il s'avance entre les hanches qu'il sépare dans loute leur élendue, et alors ou il les dépasse el vient appliquer sa pointe arrondie ou obluse sur le bord anlérieur du mésosternum, ou bien il s'arrête sur la mène ligne ; tanlôt il s'avance en pointe entre les lranches et les laisse se loucher dans toute leur partie moyenne et postérieure.

Le mésothorax est comme d'habitude peu étendu. L'écusson toujours apparent est médiocre, ordinairement plus large que long, en triangle ou en demi-cercle. Le mésosternum dépend, pour la forme, de celle du corps, étroile ou ramassée. Iorsque le prosternum dépasse les hanches, il présente, $\dot{ }$ 
son bord antérieur, un enfoncement pour le recevoir ou au moins une inclinaison; à son bord postérieur, entre les hanches intermédiaires, il est coupé droit ou légèrement échancré et rencontre une avance saillante du métasternum. Les épisternes bien distinctes forment un triangle dont le côté antérieur est transversal; l'interne va droit par derrière et l'externe obliquement de dehors en dedans et d'avant en arrière.

Les épimères, de forme rhomboïde ou trapézoïde, ont le côté postérieur oblique et égal à l'antérieur, ce qui fournit un caractère qui distingue très-nettement les Endomychides des Coccinellides, où elles affeclent la forme d'un triangle dont le côté postérieur est droit-transversal et répond aux métépimères qui sont tronquées droit par devant.

Le métathorax est beaucoup plus dẻveloppé que l'anneau précédent. Le métasternum en occupe presque toute la face inférieure, côtoyé par les épisternes longues, étroites, linéaires, subparallèles et coupées obliquement par devant, largement et peu profondément entaillé de chaque côté par derrière pour clore le devant des cavités cotyloïdes qui sont distantes l'une de l'autre et formées en grande partie par le premier segment abdominal.

L'abdomen se compose de cinq segments apparents, toujours mobiles les uns sur les autres; le prennier est allongé, quelquefois au point d'égaler la longueur des quatre autres ensemble. Dans le $\sigma^{x}$, très-souvent on voit saillir au bout du cinquième, un sixième petit segnent.

Les élytres couvrent l'abdomen jusqu'au bout et l'enchássent étroitement sur les còtés. Elles sont de consistance cornée, serrées l'une contre l'autre à la suture sans être soudées, finement rebordées en dehors, et leur bord infléchi assez large d'abord, diminue peu à peu au point de devenir une simple ligne vers l'extrémité. Pour la forme, elles passent par tous les degrés, depuis l'ovale allonge jusqu'au cercle court et tronqué par devant, et de la convexité d'une demi-sphère à la forme presque aplatie. Leur surface est plus ou moins, mais irrégulièrement ponctuée el quelquefois sans points. Les ailes complètement développées se plient en travers et ont deux fois la longueur des élytres. Elles sont raccourcies dans quelques espèces de Lycoperdina et manquent exceptionnellement dans les Mycetca. 
Les paltes sont étroites, allongées et dépassent de beaucoup les côtés du corps, dans les genres qui ont le prothorax petit et séparé; elles sont, au contraire, serrées et peu ou point visibles en dessus dans ceux ou le prothorax est large el étroitement ajusté contre les élytres. Les trois paires s'insérent par des hanches qui se meurent librement. Toutes en rapport avec deux segments, puisque les cavités cotyloïdes sont ouverles par derrière, elles ont une grande mobilité, surtout les quatre antérieures qui sont globuleuses. Les intermédiaires sont plus distantes à leur insertion que les antérieures, même lorsque celles-ci ne se touchent pas. Les postérieures, transverses, ovales oblongues, aplaties, allénuées en pointe vers les mésépisternes qu'elles alleignenl, sont assez éloignées l'une de l'autre.

Les cuisses sont munies de trochanters petits en triangle pointu qui leur sont solidement mnis et partagent avec elles l'articulation. Généralement comprimées, rarenent cylindriques, menues à la base, renflées vers le milieu, elles sont creuseees en dedans à l'extrémité pour l'articulation des jambes, mais jamais cannelées pour les loger, ainsi qu'il se voit dans les Coccinellides. Elles augmentent de longueur des antérieures aux postérieures.

Les jambes sont en rapport avec les cuisses pour la longueur; toujours comprimćes latéralement et légèrement arçuées ou même sans courbure, elles s'élargissent graduellement vers le bout, où elles sont obtusément arrondies, sans épines terminales, mais densément vêtues d'une molle pubescence soyeuse. Ce sont les jambes, surtout les antérieures et les intermédiaires, qui fournissent les différences sexuelles les plus constantes.

Les tarses ont été donnés comme de trois articles seulement par la plupart des auteurs, tels que Latreille, Leach, Newinann, Germar, de Castelnau, etc. M. Nulsant, prenant un terme moyen, dit: "Tarse de trois articles, le dernier offrant à sa base un nodule ou petit article. "Nais ils sont véritablement de quatre articles dans tous les Endomychides, ainsi que Nac-Leay l'a démontré dans son mémoire sur la structure des tarses dans les coléoptères tétramères et trimères. Seulement, dans les Endomychides propres, le troisième article est'très-petit, soudé avec le dernier qui est 
long et caché dans une fente pratiquée sur le deuxième article, et on peut appeler ces insectes, à cause de cela, Cryptotétramères. Dans ce cas, les deux premiers articles sont grands, quoique de forme variable, garnis en dessous d'un feutre épais et terminés par de longs poils; le deuxième est inséré sur le premier, dans une entaille tout près du bout; il est lui-même creusé en dessus d'un profond sillon longitudinal, et les deux derniers articles, soudés ensemble, $s^{`} y$ insèrent tout-à-fait à sa base : le petil forme, à lui seul, l'articulation; le dernier étroit et cylindrique, un peu épaissi au bout, est logé dans le sillon qu'il dépasse de beaucoup et porle toujours deux crocliels simples et peu forts. - Les Endomychides annexés ont le troisième article des tarses bien distinct et ils sont véritablement Phanérotétramères. Dans les Symbiotes, les articles de un à trois sont presque de même forme et de même laille et s'articulent l'un au bout de l'autre. Nais on trouve des passages de celle disposition extrême à la structure Cryptotétramèrc; par exemple, dans les nycetceu, les deux premiers articles sont dejjà engagés l'un dans l'autre, et le troisième n'est plus dégagé du deuxième en dessous et se rapproche davantage du quatrième par sa forme plus étroile.

Les Endomychides, entre les Erolyles et les Coccinelles, se font remarquer par des empreintes extérieures de caractères sexuels. Les antennes n'en présentent que d'insignifiants. Les jambes, au contraire, sont dans le $\sigma^{\pi}$ non-seulement allongées et visiblement arquées, mais encore souvent munies d'une dent ou d'une dilatation dentiforme. Le plus ordinairement, ce sont les antérieures ou les intermédiaires seules, quelquefois cependant les deux paires à la fois. Enfin l'abdomen fournit un caractère plus important encore dans la présence du sixième segment propre au plus grand nombre des genres.

\section{GENRE DE VIE ET PREMIERS ÉTATS.}

On connait les premiers élats de quelques espèces et les larves ont entre elles une grande ressemblance daris la forme du corps comme dans la struclure de ses parties isolées.

La têle de la larve est subarrondie et aplatie en dessus; 
les yeux petits, arrondis, peu saillants, sont situés sur les côtés de la tête. Suivant Blisson, il y a des ocelles dans celles des Mycetara, mais il n'y en a pas dans les autres espèces. Antennes courtes, de trois articles courts, dans les Lycoperdina et les vycetca, ou bien de deux articles dont le dernier est fort allongé dans les Endomychus; mais, dans ce dernier cas, il existe aux côtés de la tête un enfoncement oú les antennes sont insérées et où l'on peut voir comme un troisième article basal. Mandibules cornées, en pointe aiguē (Lycoperdina, Mycctcea) ou obtusément bidentées, entaillées en dedans et garnies d'une lamelle membraneuse (Endomychus). Mâchoires et lèvre de consistance plus molle, plus membraneuse. Palpes maxillaires de trois articles, labiaux de deux courts et serrés.

Le corps est mou, allongé ou parallèle (Endomychus, Mycetcca), ou bien atténué en pointe à ses deux extrémités (Lycoperdina), aplati en dessous el un peu convexe transversalement en dessus. Il se compose de douze segments. Les trois premiers (thor $(a x$ ), toujours plus longs que ceux de l'abdomen, surtout le premier qui est le plus développé, portent chacun en dessous une paire de pattes, très-courtes chez les Iycoperdina, plus longues et plus étroites chez les Endomychus, terminées par un article long, simple, en forme de crochet. Les seginents de l'abdomen diminuent de largeur vers le bout, et le dernier est inuni, chez les Lycoperdina, de deux appendices en forme de style qui peuvent se diriger en haut. Le dessous du corps est garni dans !e même genre d'élévations charnues, verruqueuses, et dans les Endomychus et les Myceloca de granules nombreux. Dans ces derniers, les segments présentent en outre, sur leurs côtés, des soies particulières, épaissies au bout.

Condannées à vivre d'une vie cachée, ces larves sont d'un blanc sale ou livide; quelques-unes cependant sont parées de couleurs agréables. Les unes dans l'intérieur des Lycoperdons en dévorent la substance; les autres se nourrissent de champignons ou des productions fongueuses qui se développent sous les écorces du peuplier, du saule, du bouleau, du hêtre et du sapin. A l'état parfait, ces insectes conservent les mêmes goûts et les mêmes habitudes; ils vivent en partie dans des champignons, en partie sous 
les écorces; rarement on les trouve rampants çà et là. Ils restent cachés et se meuvent lentement durant le jour; mais quand le soleil disparait sous lhorizon, ils quittent leurs retraites et parcourent les airs.

Les Endomychides sont répandus par toute la terre entre le $65^{\circ}$ de latitude boréale et le $45^{\circ}$ de latitude méridionale. La zone torride est la plus riche: sur 218 espèces connues, elle en possède 110. L'Amérique semble, de toutes les parties du monde, en être la vraie patrie; car elle en compte 111 espèces, tandis que notre monographie n'en compte que 25 , dont 15 propres à l'Europe, réparties entre 12 genres.

\section{HISTORIQUE DE LA SCIENCE.}

Linné, dans sa Fauna suecica (1761), plaça dans les Chrysomèles le seul insecte de la famille connu de lui (Chrysomela coccinea). Dans son Systema naturce (1767), il en décrivit une $2^{\text {e }}$ espèce (Silpha succincta).

En 1783 Schaller fit connaître, dans les Mémoires des

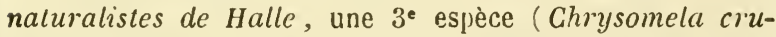
ciata), que peu de temps après Herbst reproduisit sous un nom nouveau et sans savoir à quel genre le rapporter (Lithophilus) dans les Archives de Fuessly ( 1783 ). Gmélin copia l'une et l'autre description de la même espèce et plaça la première parmi les Opatres et la seconde parmi les Chrysomèles. Enfin, cette même espèce a été rapportée au genre Tenebrio par Panzer, dans ses Descriptions de quelques insectes rares ( Naturforscher XXIV. 1789), et puis par Rhen, dans ses Observations sur quelques insecles rares et d'une détermination générique douteuse (1792).

Fabricius qui, jusque-là, avait classé tous les Endomychides parmi les Chrysomélines, les transporta parmi ses Galeruques dans son Enlomologia syslemalica (1792).

Panzer, dans son Entomologia germanica (1795), fit cesser les incertiludes en réunissant ces espèces dans le genre Endomychus, créé par llelwig, qui le premier en avait saisi les caracteres distinctifs. Latreille adopta le genre Endomychus au tome XII ${ }^{e}$ de son Ilistoire naturelle (1804), en sépara le genre Lycoperdina dans son Genera crustaABEILLE, $\vee .1867$. 
ceorum et insectorum (1807) el réunil ces deux coupes dans sa famille des Coccinelatides, d'après la structure des tarses. Mais plus lard, dans le Règne animal (1817), il les sépara en une famille particulière qu'il nomına Foxgicoles; et dans une $2^{\mathrm{r}}$ édition, en 1829 , il caractérisa le genre Dapsa indiqué par Ziegler el l'y réunit. Presque en même temps, Leach élablissait la même famille sous le noun d’ExdouyCHIDES que .. Gerstæker a adoptẻ de préférence à cause du nombre de groupes el de genres auxquels il a été appliqué.

Le premier essai heureux pour répartir en genres les nombreuses espèces d'Endomychides et pour en fixer les limiles naturelles, a élé fail par Dejean dans la $2^{\text {e }}$ édition de son Catalogue (1837). Il s'y tronve bien quelques éléments étrangers, comme Orestia, rangé dans les Alticides par M. Allard, Dasycerus el lé genre exolique Pelinus, qui sout héléromères d'après 11 . Guérin-lléneville; mais le savant créateur de la famille montre qu'il en avait bien reconnu les caractères naturels en réunissant ainsi des genres dont la structure des tarses est si diffèrenle. Les 65 espèces qu'il cite sont réparties en un grand nombre de genres nouveaux.

Après lui, Germar dans l'Encyclopédie de Ersch et Gruber, article Ecsorpruss, a publié un tableau synoptique des genres d'Endomychides, mais il omel les genres Phanérocétramères que Dejean avait compris dans la famille. Les autres travaux qui ont suivi consislent surtout dlans des faunes spéciales, tels que les Sulcicoles de France, par M. Mulsant, 1\&46; les Endomychides du royaume de Naples, par Cosla, ,1549; ou traitent spécialement des exotiques, comme les Eumorphides que II. Guérin-Néneville a publiés dans les Archices entomologiques de 11. Thomson (I, 237-280, I'l. Xill \%. On y trouve des espèces nouvelles et mème quelques coupes génériques.

Enfin, le $D^{r}$ Gerslæker est venu dire pour longtemps le dernier mot sur celle intéressante famille. Sa monographie, si complète el si savante, est un modele et une mine où je n’avais qu’à extraire: recherches analomiques, détails sur les mœurs et les premiers élals, sages apprécialions des travaux de ses devanciers, discussions sur la composition et les limites de la famille, exposition claire et méthodique 
des genres et des espèces, description nelle et précise des caractères figurés dans d'excellentes planches, rien n'y manque. Dans un travail aussi restreint que le mien, ce serait un hors-d'œuvre de m'étendre sur le plan de ce grand onvrage, qui décrit 38 genres et 218 espèces. Il me suffit de dire que je l'ai suivi pas à pas, et qu'il divise ses Endomychides en trois groupes, de la manière suivante:

I. ENDOMYCHIDES GENUINI. - Tarses cryptotétramères, $3^{e}$ article petit, enfoncé dans le précédert.

A. Languette transverse, échancrée ou tronquée au bout.

B. Nassue des artennes dilatée, comprimée; $3^{e}$ article allongé. - Abdomen ơ composé de 5 seg-

ments. . . . . . Eusiorphis (exotiques).

B' Massue des antennes non comprimée; $3^{\text {e }}$ article variant de longuenr. - Abdomen or ordinairement composé de 6 segments. . Dapsixr (Ancylopus, Dapsa, Lycoperdina, Ceramis, Mycetina).

A' Languelte oblongue, arrondie au

bout. . . . . . . . . Ехромуснімі (Endomychus). 1I. FNDOMYCHIDES ADSCITI. Tarses tétramères, $3^{\text {e }}$ article visible libre (Leiestes, Symbiotes, Mycetcea).

\section{I.IMITES ET CIRACTÈRS DISTINCHIFS DE LA FAMILLE.}

Il nous faut d'abord mettre de côté plusieurs genres comptés par diver's auteur's parmi les Endomychides et qui ne peuvent en faire partie. Dasycerus Brongn. et Holoparamccus Curt. compris dans cette famille, l'un par Dejean, l'autre par Erichson, par leurs tarses linéaires et trimères, ont leur place naturelle, comme Lacordaire l'a reconnu, parmi les Lathridides dont ils possedent les caraclères essentiels. Il en est de même dı genre Merophysia, établi par Lucas et placé par lui entre les Lathridides et les Endonychides; ses tarses trimères et sa ressemblance avec les Iloloparamecus et les Cholovocera le raltachent aux premiers.

Le genre Orestia Chevrol. a élé mis par Dejean dans la 
famille actuelle et par Redtenbacher dans les Cryptophages. Germar, qui l'a caractérisé plus exactement, a d'abord décrit l'espèce sous le nom de Lycoperdina alpina, mais plus tard il a reconnu qu'il est étranger aux Endomychides et qu'il se doit raltacher, au contraire, aux Erolylides. Selon Gerstæker, les tarses cryptopentamères de ce genre, comme ceux des Chrysomélides; les organes buccaux analogues aux leurs, en particulier la lèvre el ses palpes latéraux (comme dans les Galcruca et les Eumolpus), détermine sa place parmi les Chysomélides; et d’après ses antennes insérées aux côtés du front et au-devant des yeux, ainsi que d'après la forme bilobée du $3^{\text {e }}$ article des tarses, il appartiendrait au groupe des Eumolpides, et en particulier aux genres dont les ongles sont simples et non fendus. M. Allard l'a compris dans sa monographie des Alticides,

Ainsi débarrassée de ces genres, la famille des Endomychides reste, pour Mulsant, composée d'espèces à tarses cryptotétramères, formant un tout parfaitement homogène. J'y joins cependant, avec Gerstæker, les genres Mycctcea. Symbiotes, Clcmmus et Leicstes, qui sont distinctement tétramères. D'ailleurs, ces genres ayant 4 articles à tous les tarses et élant dépourvus d'épines aux jambes, ne peuvent rester dans la famille des Cryptophages, telle que Erichson en a fixé les limites; et la petile famille des Mycéléites, oủ J. Duval les a jetés avec d'autres genres incerla scdis, ne peut être conservée, car c'est un pêle-mêle de formes disparates, de caractères opposés, n'ayant de commun que le nombre des articles des tarses; ainsi les lithophilus sont de vraies Coccinelles à dernier article des palpes fortement sécuriforme, avec des plaques fémorales et des ongles bifides, voisines des Coccidula. Les Alexia ont le lobe interne si petit que Redtenbacher n'a pu le voir, et des plaques fémorales; les Myrmichixcnus ont une massue de 3 articles et une forme étroite et allongée qui contraste avec la forme ovalaire ou arrondie des genres auxquels on les a associés; et tous les trois sont dépourvus de ces sillons prothoraciques qui sont l'apanage de nos Endomychides annexés.

Ces derniers se rapprochent beaucoup de certaines tribus. Les Colydides ont le même nombre d'articles aux tarses, mais ils se distinguent par les $4-5$ premiers anneaux de 
l'abdomen paraissant soudés ensemble, par la massue des antennes, composée d'articles courts, serrés fortement en bouton, par les sillons plus distincts sur le pronotum et par une forme extérieure très-différente. Le genre de vie et les habitudes carnivores des larves viennent à l'appui des caractères organiques.

Les Triplacides et les Engides ont avec eux une grande ressemblance non-seulement pour la forme générale, mais encore pour la structure des antennes; mais dans ceux-ci ces organes sont insérés sur le bord du front au-devant des yeux, l'épistome n'est séparé du front par aucun sillon, les hanches antérieures sont logées dans une cavité fermée par derrière et les tarses sont de 5 articles. - Ce dernier caraclère sert aussi à distinguer les Cryptophages qui leur ressemblent souvent beaucoup pour le faciès, et ont comme eux les hanches antérieures logées dans des cavités ouvertes par derrière; de plus, ils manquenl d'épines terminales aux jambes et de sillons longitudinaux sur le pronotum.

C'est avec les Coccinellides que les Endomychides, surtout les Endomychides proprement dits, offrent le plus de points de contact. Voici les caractères différentiels les plus saillants qui les séparent:

1. La tête est forlement étranglée à l'origine de l'épistome, qui est étroit et distinclement séparé du front, et elle s'allonge en museau; $-2^{\circ}$ les antennes sont allongées, terminées par une massue de 3 articles, insérées entre les yeux à la partie inférieure du front, et non enfoncées par en dessous; $-3^{\circ}$ les palpes maxillaires ont l'article terminal plus ou moins cylindrique et jamais élargi en forme de hache; - $4^{\circ}$ le pronotum est pourvu de deux sillons longitudinaux; $-5^{\circ}$ les épimères du mésothorax sont coupées obliquement par derrière, ce qui les rend rhomboïdales; chez les Coccinellides, elles sont au contraire coupées droit et par là même triangulaires; $-6^{\circ}$ les épisternes dı métathorax qui leur correspondent sont coupées obliquement en dedans et avancées en delıors contre les épisternes; dans les Coccinellides, elles sont coupées droit; $-7^{\circ}$ le métathorax, aussi bien que le $\mathbf{1}^{\text {er }}$ segment de l'abdomen, inanque de ces plaques fémorales, limitées postérieurement par une fine bor- 
- dure, qui sont propres aux Coccinellides; $-8^{\circ}$ les jambes ne sont pas reçues lans une coulisse creusée au bord inlerne des cuisses $;-9^{\bullet}$ les hanches antérieures ne sont pas en cylindre transverse el insérées dans des cavités cotyloïdes closes, mais globuleuses, très-saillantes, et leurs cavités cotyloïdes sont ouvertes par derrière; $-10^{\circ}$ les crochets des tarses ne sont pas dentès, mais simples et en pointe aiguë; $-11^{\circ}$ les insectes parfaits présentent pour l'ordinaire des différences sexuelles extérieures bien saisissables; $-12 \cdot$ les larves ne sont pas aphidiphages ou herbivores, comme celles des Coccinellides, mais elles se nourrissent de champignons et de matières fongueuses.

\section{TABLEAU SYNOPTIQUE DES GENRES.}

A. Tarses à $3^{e}$ article très-petit, renfermé dans le précédent. Endosychides propres.

B. Prosternum non visible entre les lıanches qui sont contiguës.

C. Antennes allongées; $2^{e}$ article beaucoup plus court que le $3^{e}$, les suivants plus longs que larges; massue déliẻe.

D. Lisse, luisant, glabre. - Pronotum subparallèle. - Dernier article des antennes allongé, acuminé. 1 Axcruopus Costa.

D' Densément et fortement ponctué, pubescent. - I'ronotum subcordiforme. - Dernier article des antennes arrondi, obtus.

C' Antenncs épaisses; $2^{\text {e }}$ article égal au 3 , les suivants moniliformes, plus larges que longs; massue courte et forte.

D. Glabrc. - Pronotum subparallèle. $9^{e}$ article des antennes à peine plus large que le précédent et beaucoup moins que le $10^{\mathrm{e}}$. . . .

5 Darsa Latr.

D' Pubescent. - Pronotum subcordi-

4 Ly COPERdina Latr. forme. $-9^{\mathrm{e}}$ article des antennes fortement dilaté, plus robuste même que le $12^{e}$.

8 Hylaid Guẻr.

B' Pronotum éleré entre les hanches et les séparant nettement. 
C. Elytres en orale-oblong. - Abdomen de 5 segments seulement. - Mésosternum en ogive, en demi-cercle ou allongé, parallèle.-Massue des antennes courte ou composée d'articles inégaux.

D. Massue des antennes courte, à diernier article pas plus long que le précédent - Sillons longitudinaux du pronotum bien marqués et assez longs. - Hésosternum arrondi et rétréci en derant.

F. Etroit, pubescent. $-2^{c}$ article des antennes subégal au $3^{\mathrm{e}}$.-Mésosternum plus long que large.-Prosternum sans rebords tranchants, peu sailiant au-delà des hanches. Fond noir de poix uniforme. .

E' Large, lisse et glabre. $-2^{\mathrm{e}}$ article deș antennes de moitié plus petit que le $3^{\text {e }}$ - Yésosternum plus large que long. - Prosternum à bords élevés tranchants, dépassant de beaucoup les hanches.-Fond jaune tacheté de noir. . . . . .

D' Massue des antennes déliée, à dernier article plus long que les deux précédents réunis. - Sillons longitudinaux du pronotum obsolètes - Mésosternum en carré long, subparallèlc.

C' Elytres larges et arrondies. - Abdomen de 6 segments. - Mésosternum en trapèze court, très-élargi en devant.Massue des antennes très-longue, les 3 articles égaux. . . . . .

A' Tarses à $3^{\text {e }}$ article libre et visible. Exuowychides axvexés.

B. Plus grand, luisant, glabre, noir, avec le pronotum rouge. - Prosternum non visible entre les hanches qui sont contiguës. - Mésosternum très-longr, acuminé en devant. - Antennes insérées sous le bord du front au derant des yeux. . . . . . . . .

7 Perrisia il.

3 Mrcetixa Muls.

6 Polrues Muls.

2 Endowychus Panz.

9 Leiestes liedt. 
B' Très-petit, pubescent, d'un ferrugineux uniforme. - Prosternum élevé entre les hanches et les dépassant par derrière. - Mésosternum court, tronqué en devant. - Antennes insérées sur le front en dedans des yeux.

C. Ovale-oblong. - Mésosternum plus long que large.

D. Sillons prothoraciques très courts. Une strie suturale aux élytres, forte et arquée à la base. . . . . .

D' Sillons prothoraciques paralleles au bord latéral et complets. - Pas de stric suturale aux élytres. . .

C'Arrondi. - Mésosternum plus large que long. - Sillons prothoraciques profonds, arqués, complets. . . .

10 Symbiotes Redt.

12 Mусгтґ Steph.

11 Clemurs Hamp.

\section{TIIBU. ENDOMYCHIDES PROPRES.}

Tarses à $3^{e}$ article très-petit, renfermé dans le précédent.

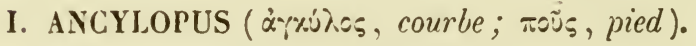

Costa, Fauna di Napoli, Monographia di Coccinellidei ed Endomichidei del Regno di Napoli, 14. 1850. - Gerstæk., Endom. $183,13$.

Ovale Irès-allongé, peu convexe, lisse luisant, glabre, pointillé, rouge ferrugineux avec la tête, les paltes et des taches sur les élytres noires.

Tête transverse, enfoncée dans le prothorax; front plan, un peu élevé sur les antennes, séparé de l'épistome par un sillon transversal ; ce dernier bombé, coupé droit au bout, en carré large; labre court, largement sinué au bout, avec les angles arrondis, frangé de jaune. Yeux latéraux, assez distanls, globuleux, grossièrement granulés. Mandibules arrondies, débordaut fortement, convexes en dessus, à bord externe mince, très-aiguês mais dépourvues de dent in- 
terne. Menton tronqué au bout, avec une élévation en forme d'angle dont le sommet touche au milieu du bord antérieur; langueite très-dégagée, profondément échancrée en cercle par devant avec ses lobes latéraux paraissant tronqués obliquement. Palpes labiaux courts et larges, à dernier article largement tronqué. Mâchoires insérées en dehors du menton. Palpes maxillaires allongés, peu épais; 'e article long, un peu épaissi au bout; $3^{\text {e }}$ plus court en triangle, dernier ovale, un peu plus long, tronqué obliquement au bout.

Antennes longues et déliées, jnsérées au bord interne et antérieur des yeux sous le bord du front, assez écartées, de 11 articles, tous plus longs que larges; $1^{\mathrm{er}}$ ovale, épais, assez long, $2^{e}$ petit, $3^{e}$ subcylindrique, trois fois plus long, à peine renflé au bout, 4-6 de mème forme, de moitié plus courts, égaux entre eux, $7^{e}$ obtriangulaire, $8^{e}$ moins dilaté au bout que le $7^{\mathrm{e}}$ et le $9^{\mathrm{e}}$, les 3 derniers formant une massue peu serrée, 9-10 en triangle oblong, dernier aussi long que les 2 précédents, ovoïde terminé en pointe.

Pronotum en carré transverse, un peu aplati, subparallèle, tronqué droit à sa base, très-largement et bisinueusement échancré en devant avec les angles obtus peu saillants, bordé étroitement dans tout son pourtour, largement et fortement à sa base; sillons longitudinaux bien accusés et raccourcis un peu avant le milieu. Écusson large, arqué. Élytres plus larges à la base et 3 fois plus longues que le pronotum, avec l'épaule saillante, médiocrement convexes, s'élargissant peu à peu sur les còtés jusqu'aux 2/3, obtusément arrondies à l'extrémité, avec l'angle sutural arrondi; entourées d'un étroit rebord qui se continue un peu et légèrement le long de la suture; bord infléchi concave, s'étendant presque jusqu'au bout. Propectus court, tronqué en devant, sans saillie prosternale; hanches antérieures arrondies, contiguẻs, s'appuyant sur le mésosternum, creusé à cet effet de 2 larges cavités, séparées par une étroite carène; celui-ci rétréci par derrière, tronqué postérieurement et appuyé contre l'avance du postpectus. Ilanches intermédiaires fortes, globuleuses, assez rapprochées; postérieures transverses, distantes. Abdomen de 5 segments, $\mathbb{1}^{\text {or }}$ un peu plus long que les 3 suivants, dernier en demi-cercle. 
Paltes assez robustes et assez longues; cuisses renflées vers le milieu ; jambes forles; tarses de 4 articles, e $^{r}$ triangulaire, $2^{e}$ un peu plus long que large, muni de forles palelles; angulaire long, arqué, inseré par le $3^{e}$ sur la base du $2^{\text {e }}$ el terminé par 2 petits onglets.

Les sexes se distinguent extérieurement par les dents des jambes antérieures et la courbure plus ou moins forte des postérieures. Il y a aussi quelquefois une différence sensible dans la longueur des antennes.

Les espèces de ce genre sont peu nombreuses, à peine conuues; elles habitent les contrées les plus chaudes de l'ancien continent; une seule se retrouve en Europe.

Ce genre, comme on le voit par la description, se distingue bien de tous ceux de la famille. Le prosternum ne pénètre pas entre les hanches qui sont contiguès, ainsi que dans les Dapsa, Hylaiu, Leiestes, Lycoperdina, tandis qu'il forme un avance saillante, dépassant les hanches plus ou moins, mais les isolant loujours bien (Perrisia, Mycetina. Polymus, Endomychus).

Le mésosternum est long, rétréci postérieuremient, élargi en devant et marqué d'une carene entre deux cavités propres à recevoir les hanches antérieures, au lieu d'être petil, étroit, pel saillant, comme dans les Lycoperdina, les Dapsa et les Hylaia, qui sont d'ailleurs pubescentes; ou en longue bande acuminée, rebordée, comme dans les I.eiestes, si dislincts en outre par les profondes cavités triangulaires du pronotum

Enfin ses antennes déliées, à articles allongés, la structure des jambes, etc., ne laissent pas d'hésitation possible.

1. Aneylopus melanocephalus Oliv., Ent. VI. 1073, 3. Pl. I, 3 † (Endomychus) 1808. - Costa, Faun. Napl. Endom. 14. Pl. VIII, 3 б. 1850. - Gerst., End. 190, 1.

Oblongus, rufo-ferrugineus, capite, antennis, clytris basi, sulura, maculis 2 , una media, altera postica, pedibusque basi excepta nigris.

Allongé, ovale, faiblement convexe, poli luisant, d'un jaune ferrugineux avec la tête, les antennes, les paltes et les taches sur les élytres noires. Tête noire, transverse; front inegal, ponclué, séparé de l'épistome par un fin 
sillon; yeux noirs, assez gros, bombés. Parties de la bouche ferrugineuses ou d'un brun de poix. Antennes noires, déliées, de la longueur de la moitié du corps; $1^{\text {er }}$ article

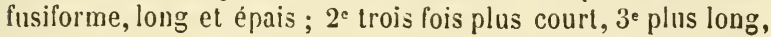
subcylindrique, un peu renflé au bout; 4-6 et 8 égaux entre eux, faiblement obconiques, à peu près de la moilié du 3 e ; $7^{\text {e el }} 9^{\text {e }}$ presque de la mème longueur, mais plus élargis et triangulaires; $10^{\circ}$ un peu plus court que le précédent, dernier lurbiné, long et fort, terminé en pointe mousse; un peu plus courtes, avec les trois derniers articles un peu plus élroits of que $\delta$. Pronolum en carré transverse, peu convexe, vaguement ponctué, bordé dans tout son pourtour, étroitement sur les côtés qui sont à peine auguleux au tiers antérieur, ainsi qu'au bord antérieur qui est bisinueusement et faiblement échancré, avec les angles obtus peu avancés; la strie marginale s'éloigne du bord au milieu; longé à sa base d'un profond sillon, interrompu de chaque côté aux sillons longitudinaux qui sont bien marqués, droits, et n'atteignent pas tout-à-fait le milieu; moins longs et courbés en $S$ l'un vers l'autre, et n'étant séparés au milieu que par un court sillon longitudinal $q$; bord postérieur un peu plus large que l'antérieur, tronqué avec les angles droits, marqué souvent dans son milieu de deux taches noires carrées. Ecusson concave, large, arrondi au bout, brun. Elytres beaucoup plus larges que le pronotum a la base, 2 fois $\mathbf{1 / 2}$ plus longues que larges, subparallèles, également convexes et pointillées, avec les épaules élevées, un peu élargies par derrière, obtusément arrondies au bout, étroitement et finement marginées latéralement et à la partie postérieure de la suture; d'un blond-roux, avec une bande basale transverse, se prolongeant le long de la suture jusque près de l'extrémité, et sur le bord infléchi jusqu'au milieu; ornées, en outre, chacune de 2 taches: l'une carrée, vers le milieu, presque contiguẻ à la marge : l'autre, vers l'extrémité, un peu ovalaire. Nésosternum en forme de triangle, dont la base présente des cavités superficielles pour la réception des hanches antérieures, linilées par une crête et séparées par une saillie dentiforme, et dont le sommet tronque re. présente une bande rectangulaire, séparée du reste par un sillon en arc, et placé entre les hanches intermédiaires. 
Aldomen pointillé el à peine pubescent, les 4 premiers segments assez longs, subégaux; le dernier arqué et rebordé au bout, sinué au milieu $\sigma^{\star}$ : pattes assez longues, brun de poix, avec la base roussâtre comme le dessous; cuisses renflées au milieu; jambes antérieures dilatées en dedans peu à peu jusquau milieu où se trouve une dent trèsforle, puis entaillées circulairement jusqu'au bout, intermédiaires de même forme, mais saillie obtuse, postérieures un peu épaissies au tiers et garnies de dentelures droites tout le long du bord interne $\sigma^{\star}$. - Long., 6 mill. - Larg., 2,5 mill.

M. Gerstæker signale une variété de couleur décrite par Wriedemann (Zool. Mag. II, 1. 78, 121 q) sous le nom d'Eumorphus pictus des Indes-Orientales, de Java et de Ceylan, qui ne se distingue du type que par la bande noire basale qui s'étend quelquefois même sur l'écusson el laisse libres les bosses humérales, et par les taches noires qui se dilatent plus ou moins, de sorte que la postérieure se lie souvent avec la suture.

Celte espèce a un habitat des plus étendus : outre les exemplaires de sicile répandus par Helfer sous le norn de Solani, on en trouve des Indes-Orientales, de Java, de Ceylan, de Port-Natal.

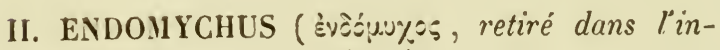 térieur).}

(Helw.) Panz., Ent. Germ. 175. 1795. - Payk., Faun. Suec. II. 112. 1798. - Fab., Syst. El. I. 504, 86. 1801. - Latr., in Illig. Mag. III. 1804. 134. - Latr., Gen. Crust. et Ins. III, 72. 1807. - Règne an. 1829, v. 160. - Gyl., Ins. Suec. IV, 217. 1827 - Redt., Faun. Aust. 587, 590. 1849. - Muls., Sulc. 11.-Gerst., Endomych. 368, 32.

Orale arrondi, assez convexe, lisse el luisant, à peine pointillé, glabre en dessus, avec de fins petits poils rares en dessous.

Tête courte, enfoncée fortement, déprimée sur le front; yeux petits, arrondis, latéraux. Bouche formant un mu- 
seau étroit avancé; épistome sub-tronqué au bout, sans sillon qui le sépare bien distinctement du front; labre court, transverse. Mandibules grandes, terminées par une pointe bifide et dirigée obliquement en dedans, assez profondément entaillées au bord interne avec une lamelle d'égale largeur, densément pubescente. Mâchoires cornées à la base, à deux lobes presque membraneux; l'externe un peu plus long que l'interne, 3 ou 4 fois aussi large, élargi par devant, légèrement arrondi et densément villeux, sinué au bord externe; l'interne très-étroit et allongé, en forme de lancette à pointe obtuse, et garni en dedans de poils courts. Palpes maxillaires assez longs, de 4 articles; $1^{\text {er }}$ court et petit, $2^{\text {e }}$ allongé, épaissi graduellement, oblique au bout, 3 e large transwersal, 2 fois moins long, dernier comprimé, à peine plus long et un peu moins large que le précédent, tronqué obliquement au bout et un peu sécuriforme, ou seulement ovalaire. Menton 2 fois plus large que long, un peu rétréci par derrière, arrondi sur les côles ; languelte membraneuse, plus longue que large, rétrécie par derrière, arrondie en devant avec une légère sinuosilé au milieu, brièvement ciliée au bord. Palpes labiaux de 3 articles; $1^{\text {er }}$ petit, $2^{\text {e }}$ assez long, épaissi au bout, dernier ovalaire à pointe tronquée.

Antennes assez forles, à peu près de la longueur de la moilié du corps, insérées à nu sur le front un peu en avant et en dedans des yeux; de 11 articles ; $1^{\text {er }}$ obconique, un peu plus long que le $2^{\mathrm{e}}$, les suivants $2-8$ subcylindriques, plus longs que larges, $3^{\text {e }}$ un peu plus long que les autres qui sont d'égale longueur; les 3 derniers sont plus longs et plus épais et forment une massue allongée; 9-10 obconiques, dernier ovalaire, plus ou moins arrondi au bout, tronqué ob!iquement en dehors.

Prothorax plus large que long, obliquement rétréci par devant, ordinairement convexe sur le dos, avec les parties latérales larges et aplaties; côtés bordés d'un étroit bourrelet; bord antérieur largement échancré, avec les angles avancés el assez pointus; base partagée en trois portions, médiane arquée, longée par un sillon assez éloigné du bord, limilé de chaque còté par un sillon longitudinal en arc qui n'atteint pas le milieu; les deux latérales, un peu moins larges, Abeille, v. 1867. 
sont aplaties, finement rebordées; angles postérieurs aigus, étroiternent appliqués contre l'angle huméral. Ecusson en demi-cercle. Elytres en ovale arrondi, convexes, dilatées, arrondies sur les côlés avec un étroit rebord élevé angles huméraux assez marqués, mais bosses à peine visibles, extrémilé arrondie; bord infléchi assez large à la base, diminuant graduellement et disparaissant ver's le tiers postérieur; la coloration est constante: deux grosses taches noires sur un fond rouge.

Prosternum élevé entre les hanches, rétréci en devant, élargi et saillant par derrière en forme de spatule, aplati. llésosternum en carré transverse, avec le bord antérieur arrondi, tronqué droit par derrière et entouré d'un petit rebord élevé dans tout le reste de son pourtour. Abdomen de 6 segments dans les deux sexes, $1^{\text {er }}$ de la longueur des 4 suivants ensemble, ceux-ci courts, égaux entre eux, Ge en arc de cercle très-court.

Pattes médiocres et assez robustes; hanches antérieures globuleuses assez rapprochées, intermédiaires de même lorme, un peu plus distantes entre elles, rapprochées des premières, postérieures transverses mais pas très-longues, insérées loin des précédentes et guère plus écarlées. Cuisses un peu comprimées, légèrement épaissies au milieu. Jambes arquées à leur base et élargies vers le bout. Tarses assez larges, $2^{\mathrm{e}}$ article beaucoup plus large que le $\mathbf{1}^{\mathrm{er}}$, le suivant inséré en dessus jusqu'à sa base, le dernier assez long, terminé par deux petils crochets.

Les différences sexuelles ne se traduisent pas extérieurement. Il existe un $6^{\text {e }}$ segment abdominal visible dans les deux sexes; cependant il est plus long et plus fortement arrondi dans le $\delta^{x}$ que dans la $q$ oủ il parait très-court et très-obtus.

Des quatre espèces dunt se compose actuellement ce genre, trois sont propres à notre faune. Limitées à la zone tempérée de l'hémisphère boréal, elles sont très-voisines en taille comme en forme et en couleur. Le Coccineus, qui est le plus commun, se trouve pour l'ordinaire en société sur les troncs d'arbres couverts de champignons; les différents états de celle espèce sont connus et nous les décrivons en détail à la suile de sa description particulière. 
Linné avait réuni ces insectes aux Chrysomelides. Rhen, le premier, considerant leur genre de vie, pensa qu'ils devaient en être séparés. Bientôt après Panzer publia le nom d'Endomychus que leur avait donné Helwig, et Paykul, dans sa Faune de Suède, caractérisa celle coupe d'une inanière plus précise.

On reconnaitra aisément ce joli genre, en outre de sa forme ovaire, de ses élytres convexes, glabres et luisantes, d'un rouge brillant, et parées de leur quatre grosses taches noires, aux caractères suivants :

Antennes à massue de 3 articles allongés et légèrement dilatés, dernier ovoïde, obliquement tronqué au bout.

Mandibules bifides au bout.

Prosternum en spatule, saillant derrière les hanches, aplani.

.lésosternum en carré plus large que long.

Palpes maxillaires à dervier arlicle ordinairement large et coupé obliquement.

\section{TABLEAU SYNOPTIQUE DES ESPËCES.}

A. Pronotum débordé par les élytres à la base, rouge au moins en partie. - Dernier article des palpes élargi, sécuriforme, tronqué obliquement au bout. - Tache noire basale des élytres plus petite, plus éloignée du bord externe que de la suture.

B. Plus allongé. - Pronotum plus étroit, bombé sur le dos, noir au moins en partie. - Prosternum parallèle. — Pattes noires.

1 coccineus L. Eur.

B' Plus élargi. - Pronotum plus large, déprimée sur le dos, entièrement rouge.- Prosternum triangulaire. - Pattes rouges.

2 armeniacus Mots. Cauc.

A' Pronotum aussi large à la base que la base des élytres, noir. Dernier article des palpes ovale. - Tache noire basale des élytres beaucoup plus large, aussi près du bord externe que de la suture . . . . . . . . 3 thoracicus Charp. Hongr.

1. Fndonyehus coceineus Lin., Faun. Suec. 166, 532. 1735. - Syst. Nat. II. 592, 43 (Chrysomela). - Fab., Syst. Ent. 105, 59. - Spec. Ins. I. 131, 83. - Mant. Ins. I. 75, 109 
(Chrysomela). - Ent. Syst. II. 20, 31 (Galeruca). - Ent. Syst. Suppl. 100, 2. - Syst. El. I. 505, 2. - Oliv., Ent. $91^{\circ}$, pl. 1. 10 , et VI. 1072,1 pl. 1, 1. - Enc. méth. V. 715, 114. - Marsh., Col. Brit. 477, 10 (Tenebrio). - Panz., Naturf. XXIV, 20, pl. 1, 20. - Ent. Germ. I. 175, 1. - Faun. Ins. Germ. 44, 17. - Payk., Faun. II. 112, 1. - Latr., Crust. Insect. XII. 77, 1. pl. 93, 10. - Cast., Col. II. 523, pl. 55, 7. - Gyl., N. act. Upsal VI. 128, 18. - Ins. Suec. IV. 217, 1. - Zett., Faun. Lap. 240, 1. - Steph., Illust. IV. 399, 1. Man. Brit. Coleop. 320, 2524. - Curt., Brit. Ent. XII. pl. 570. - Redt., Germ. Zeit. V. 120. - Faun. Aust. 587. - Küst., Kæf. Eur. III, 09. -Muls., Sulcicol. 12, 1. - Gerstæk., End. 370,1. - -maculatus De Geer., Mém. V. 301, 10. pl. 9, 1, 1755 (Chrysomela). - Var. Coccineus Krynk, Bull. Mosc. V. 1832. 178.

Ovalis, coccineus, clytrorum, maculis 2 rolundis submediis, una antica, altera postica, nigris, capite, antennis pronoti dorso, pectore pedibusque srepius fuscis.

Ovale-oblong, d'un rouge écarlate vif, poli et luisant. Têle à peine visiblement pointillée, d'un noir luisant; front avec une légère impression entre les yeux ; labre brun, les autres parties de la bouche d'un jaune ferrugineux. Antennes Iongues, noires, avec les 2 premiers articles bruns et l'extrémité du dernier transparent de rouge; $3^{\mathrm{e}}$ article aussi long que le $1^{\text {er }}$ el de moilié plus long que le $2^{\text {e }} ; 4-8$ courts, égaux; $9-10$ de moilié plus longs el un peu plus gros, égaux entre eux, dernier ovalaire de la même longueur ; ces 3 articles formant une faible massue. Pronotum de moitié plus large que long, arqué au milieu de la base et bordé d'un profond sillon jusqu'à l'échancrure latérale, d'où part un sillon arque en dedans, qui n'alteint pas la base, puis droit et finement rebordé, avec les angles logés dans un pli de l'épaule; còtés en ligne oblique, bordés d'un bourrelet ; rétréci, rebordé et largement échancré en devant, avec les angles avancés, arrondis au bout; faiblement bombé sur le dos, noir sur une plus ou moins grande étendue, parfois entièrement rouge. Écusson plan, en arc, brun de poix, noir ou même rouge. Élytres en ovale arroudi, assez convexes, avec leur plus grande largeur au milieu, étroitement re- 
bordées dans leur pourtour el sur la moitié postérieure de la sulure, finement pointillées, d'un rouge vif avec 2 taches noires, ovalaires, l'une au liers antérieur, l'autre au tiers postẻrieur sur le milieu, variant de forme et de taille. Dessous d'un rouge ferrugineux, avec, les côtés de la poitrine noir ou brun de poix. Pattes noirâtres. - Long., 3,6-5,8 mill. - Larg., 3 mill.

Cette espèce varie beaucoup de taille et de couleurs, du rouge vif écarlate au jaune ronge terne. Les taches sont tantôt plus grandes, tantôt plus petites, en ovale ou en triangle. Krynicki mentionne une variété à élytres sans taches. Le dos du pronotum, au lieu d'être noir, est souvent brun de poix; et le noir, au lieu d'être bien limité, empiète sur la bordure latérale rouge; quelquefois le pronotum est entièrement rouge. La couleur de la poitrine est encore plus variable; rarement d'un noir profond, elle est beaucoup plus souvent d'un brun de poix plus clair ou plus foncé; dans le premier cas, le mésosternum est d'un brun de poix , ainsi que le milieu du postpectus; dans le deuxième, d'un rouge-clair sur une plus ou moins grande étendue.

Celte espèce est communement répandue en Europe ; son habitat s'étend du Nord (Laponie, Suède) à la Méditerranée, et s'avance jusqu'en Russie ; elle est commune en Angleterre. Je ne sais si elle se trouve dans le Banat avec le Thoracicus el dans le Caucase avec l'Armeniacus.

La larve de l'Endomychus coccineus, que Kirby et Spence avaient fait connaitre dans l'Introduction (III, 160). a été figurée par Curtis (British Ent. XII , 579) et aussi par Westwood dans son Introduction à la classification (I, 394, fig. 49), et décrite par ces auteurs au moins dans sa forme extérieure. Nais dans son excellente Monographie de la famille, II. Gerstæker donne d'intéressants détails que je lui emprunte.

Cet entomologiste a trouvé en avril un grand nombre de ces larves sur un tronc de hêtre coupé, qui était couvert de petits champignors. Elles n'étaient nullement cachées, mais au contraire rampaient librement à la surface ou se rassasiaient de champignons. Leur forme ressemble essentiellement à celle des larves de Lampyres, seulement elles paraissent plus courtes et plus ramassées. La couleur fon- 
cière, d'un brun-rouge, était, pendant la vie, saupoudrée de bleuâtre, et les angles latéraux des $1^{\mathrm{er}}, 4^{\mathrm{e}}, 5^{\mathrm{e}}$ et $9^{\mathrm{e}}$ segments étaient d'un jaune d'or. Le corps allongé, presque parallèle, déprimé en dessus, légèrement convexe en dessous, se compose en toul de 13 segments dont 1 pour la tête, 3 pour le thorax el 9 pour l'abdomen. Tête ronde un peu plus large que longue, à peine du tiers de la longueur du premier segment thoracique, faiblement convexe sur sa surface avec deux impressions en sillon, latérales, transverses, entre les antennes; les ocelles manquent. Antennes insẻrées à peu près au premier tiers de la longueur sur les côtés, n'ayant pas en longueur plus de la moitié de la largeur de la tète; de 2 articles: le $1^{\text {er }}$ court, mais cependant plus long que large; le $2^{\mathrm{e}}$ allongé, étroit, environ 4 fois aussi long que le $1^{\text {er }}$, mince, cylindrique, en pointe, couvert dans toute sa longueur de soies courtes, éparses. Le labre, les mandibules el les mâchoires sont cornés; la lèvre, au contraire, est molle, mince et membraneuse dans toute son étendue. Labre court, arrondi, très-légèrement sinué au milieu de son bord antérieur. Nandibules petites, courtes, fortes, épaissies au bord externe, avec la pointe divisée, plus large et plus obtuse. Màchoires allongées, subparallèles; la portion antérieure, qui est l'analogue du lobe externe, est très-légèrement arrondie en devant, coupée droit et garnie au bout d'une couronne de poils courts en forme de frange. Palpes maxillaires en triangle court, les deux premiers articles courts, transverses, le dernier pyramidal. Nenton très-court, en forme de bande transversale; languelte un peu plus longue, ayant de chaque côté un bourrelet épais, sur lequel s'appuie le palpe de deux articles; $1^{\text {er }}$ article deux fois aussi large que long; $2^{\mathrm{e}}$ petit, presque carré.

Le $1^{\text {er }}$ des trois segments du thorax est en demi-cercle, presque deux fois aussi long que les deux suivants, qui ne sont guère plus larges que celui-là au bord postérieur. La surface, tant des segments du thorax que des segments de l'abdomen, est densément et finement granulée, mais ils sont marqués au milieu d'une ligne lisse longitudinale, plus pále, fine et élevée en carène sur le $1^{\mathrm{er}}$ segment thoracique, plus large, aplatie el traversée par un léger pli transversal 
sur les suivants; cette ligne devient peu à peu plus indistincte par derrière et disparaît tout-à-fait sur l'avant-dernier segment abdominal. Tandis que les segments du thorax sont étranglés de chaque côté à la base, et dilatés par delrière en un appendice court et obtus, ceux de l'abdomen, de moilié plus courts que les premiers, envoient de chaque côté une saillie large et obtuse, en crochet recourbé, dont les bords paraissent fortement dentés en scie, ceux des segments thoraciques n'étant que légèrement crénelés.

Les segments abdominaux, à partir du 5 e, diminuent sensiblement de largeur, sont parcourus par un sillon superficiel transverse, et leur saillie latérale, de plus en plus forte, est dirigée en arrière; le dernier segment est en carré transverse, deux fois et demie aussi large que long, coupé droit par derrière, avec les angles postérieurs arrondis.

Les trois paires de pattes sont étroites, insérées non loin de la ligne médiane, mais séparées par un intervalle distinct. Hanches coniques, allongées ; cuisses près de deux fois aussi longues; jambes unies avec celles-ci par un article articulaire distinct, à peu près de lá longueur des cuisses, fortement élargies au bout ; tarses longs et grêles, subcylindriques, légèrement rétrécis vers la pointe, et, après deux étranglements, se terminant par un crochet fin et arqué.

Nyniphe d'un jaune clair, paraissant un peu plus grande que l'insecte parfait, auquel elle ressemble complètement pour la forme; les élytres sont rléhiscentes, de la moitie de la longueur de l'abdomen; les pattes, comme d'ordinaire, sont baliantes sous le ventre l'une contre l'autre; les bords de l'abdomen sont, comme ceux du prothorax, ciliés de poils fins.

2. Endomyehus armeniaeus Mots., Mosc. Nouv. mém. IV. 1835. 321, 17. Pl. XI, K. - Gerstrk., End. 375, 3. Scovitzi Fald., Faun. transc. II. 411, 582. Pl. XV, 8. 1837.

Ovatus latior, thorace deplanato latissimo, rufus, antennis basi excepta, clytrorumque maculis 2 incequalibus nigris.

Ovale, élargi, peu convexe, luisant, rouge ferrugineux clair; antennes, yeux et deux taches sur les élytres noirs. 
Tête à peine distinctement pointillée, impressionnée de chaque côté sur le front ; yeux noirs globuleux ; dernier article des palpes maxillaires court, large, tronqué droit au bout. Antennes longues, noires, avec les deux premiers articles rouge ferrugineux; $1^{\text {tr }}$ renflé, triangulaire, court;

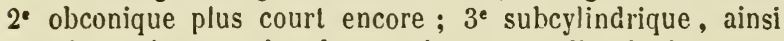
que les suivants, plus long qu'eux, 4-7 d'égale longueur entre eux, plus longs que larges, 8 plus court, 9-10 épaissis, deux fois plus longs que ceux du funicule, obconiques, formant une massue allongée. Pronotum deux fois plus large que long, imperceptiblement pointillé, aplati sur le dos, largement et bisinueusement échancré, finement rebordé en devant, árec les angles assez avancés, à pointe obtuse, creusés en dessus d'une fovéole; rebordé sur les côtés avec la marge relevée en bourrelet, s'élargissant pen à peu presque en ligne droite par derrière; base sinuée de chaque côté, arquée entre les sinuosités el bordée d'un sillon transverse limité par un sillon longitudinal qui n'atteint pas le milieu du pronotum; angles postérieurs aigus. Écusson plan, en demi-cercle. Élytres en ovale arrondi, larges, peu convexes, dépassant à la base les côtés du pronotum, avec l'angle arrondi, dilatées arrondies sur les côtés avec une marge étroite qui se continue le long de la suture jusqu'au tiers antérieur, atténuées au bout avec l'extrémité arrondie, marquées de points espacés excessivement fins, d'un rouge ferrugineux pâle, ornées de deux taches noires subarrondies, l'antérieure plus petile, beaucoup plus éloignée du bord latéral que de la suture, près de la base, la postérieure après le milieu, presque à égale distance du bord extérieur el de la suture. Prosternum triangulaire, large, aplati. Abdomen rembruni a la base de chaque segment, finement pointillé et pubescent. Pattes assez grèles. - Long., 6 mill. -- Larg., 4 mill.

Sa forme large, peu convexe, sa couleur générale rouge ferrugineux pâle, son pronotum aplati sur le dos, moins rétréci en devant, à angles postérieurs presque droits et débordés par les angles huméraux des élytres, son pronotum plus élargi et aplati el le dernier article des palpes maxillaires largement tronqué au bout, font reconnaitre aisément cette espèce. 
Motschulsky prétend que Faldermann a décrit son Scovitzi sur un individu immature du Coccineus.

Arménie ; Géorgie ; Caucase.

3. Endomyehus thoracicus (Koll.) Charp., Hor. ent. 245. 1835. - Germ., Faun. Eur. XX, 13. 1837. - Küst., Kæf. Eur. IV. 100. - Muls., Sulc. 14. - Gerst. Endom. 374, 2.

Ovalis, niger, pronolo postice latiori, elytris coccineis maculis 2 magnis subtrigonis basis et apicis nigris, subtus in medio obscure rufus.

Ovale oblong, poli et luisant. Tête noire, à peine visiblement pointillée; front uni ; yeux arrondis; épistome rétréci, sans sillon qui le sépare du front; dernier article des palpes maxillaires ovale brun. Antennes de la longueur de la moitié du corps, noires; $1^{\text {er }}$ article renflé, avec une transparence brune; 2.8 cylindriques, plus longs que larges ; $2^{\circ}$ rouxbrun, $3^{\mathrm{e}}$ d'un liers plus long que le précédent, $4^{\mathrm{e}}$ un peu plus court, 5-8 à peu près d'égale longueur, 9-11 épaissis et plus longs, formant une massue allongée; 9-10 obconiques, dernier ovalaire. Pronotum noir, deux fois plus large que long, égalant en largeur la base des élytres, rétréci fortement et presque en ligne droite par devant, finement rebordé, largement et profondément échancré au bord antérieur, avec les angles avancés, à pointe obtuse, creusés; épaissi en un étroit bourrelet le long des cótés; bordé au milieu de la base d'un sillon transverse assez éloigné de la marge, limité de chaque côté par un sillon longitudinal arqué qui ne va pas jusqu'au milieu, et, en dehors, d'une fine strie jusqu'à l'angle qui est aigu; un peu bombé sur le dos; très-finement pointillé. ḱcusson lisse, plan, noir, en demi-cercle. Elytres convexes, en ovale court, finement mais distinctement pointillées, ne dépassant pas les angles du pronotum, avec l'angle huméral bien marqué, dilatées-arrondies au milieu, marginées d'un étroit rebord élevé sur les cótés; arrondies séparément au bout, avec un angle sulural rentrant, d'un rouge foncé; ornées chacune de deux grandes taches noires, l'une antérieure et l'autre postérieure, en forme de triangle arrondi, opposées l'une à l'autre par leur base et séparées par une 
bande transverse de la couleur du fond, à peu près à egale distance du bord externe et de la sulure. Dessous noir, ainsi que les pattes, avec le inilieu de la poitrine et l'abdomen d'un rouge ferrugineux, finement pubescent el peu visiblersent pointillé.

Dans les individus dont la coloration n'est pas parfaite, les bords du pronolum et les côtés de la poitrine sont d'un brun de poix plus ou moins clair - Long. , 6 mill. Larg., 3 mill.

Celle espèce ressemble beaucoup à la précédente par la distribution des couleurs et le faciès, mais elle est plus élargie; son pronotum s'élargit bien davantage à la base, dont les angles plus saillants ne sont pas débordés par ceux des élytres; ses taches noires sont triangulaires et bien plus dilatées en deliors; enfin, le dernier article des palpes maxillaires est ovale et non tronqué obliquement.

Hongrie, Transylvanie.

\section{MYCETINA (}

Muls., Sulcicol. 15. 1846. - Redt., Faun. Aust. 1849. 587, 591. -Gerstæk., Endom. 226, 20. - Lycoperdina Sch., Syn. II. 324. 115. - Gyll., Ins. Suec. IV. 219. 1827. - Redt., Tent. 13 ; in Germ. Zeit. V, 120. - Endomychus Panz., Ent. Germ. 175. - Payk., Faun. Suec. II. 114. - Fab., Ent. suppl. 100 ; Syst. El. I. 505. - Latr., Hist. nat. XII, 77. - Chrysoneela Schall. Hall. Gesel. I. 273. - Fab. . Mant. I. 75. Galleruca Fab., Ent. Syst. II, 20._Panz., Faun. Germ. VIII. 5.

Ovale courte, convexe, lisse el luisante, presque glabre, finement ponctuée, rougeâtre avec des taches noires.

Tête assez petite, transverse, fortement enfoncée dans le prothorax; front plan; yeux latéraux, très-distants entre eux, arrondis, assez convexes ; épistome assez allongé, convexe, tronque au bout, bien séparé du front et beaucoup audessous de son niveau; labre large el court, échancré au bout, à deux lobes arrondis, ciliés. Mandibules larges, débordant, profondément divisées à la pointe. Mâchoires à 
lobe externe large, allongé, atténué au bout, barbu ; interne etroit, 2 fois $1 / 2$ plus court que l'externe, garni en dedans d'une brosse terminee par deux fortes et longues soies et commençant par une. Palpes maxillaires ciliés, plus courts que le lobe externe; $1^{\mathrm{er}}$ arlicle court et petit, $2^{\mathrm{e}}$ assez long, obconique, $3^{\mathrm{e}}$ transversal plus court, dernier subuliforme, de la longueur du $2^{\circ}$. Menton transversal, rétréci à la base, dilaté, arrondi sur les côtés, échancré au bord antérieur; lèvre angulairement échancrée en devant. Palpes labiaux courts, épais; $1-2$ articles transverses, $3^{e}$ long, largement tronque au bout.

Antennes insérées sur le bord du front, un peu en devant des yeux el entre eux, robustes, assez longues, ciliées, de 11 articles; $^{\text {er }}$ inédiocre, obconique; $2^{e}$ petit, $3^{\mathrm{e}}$ au moins de la longueur du $1^{\text {er }}$ et deux fois plus long que le $2^{\mathrm{e}}$, subcylindrique; 4-5 de même forme, décroissant ; 6-8 plus larges que longs; $9-11$ élargis surtout en dedans, formant une massue comprimée; $9 \mathrm{e}$ en triangle équilatéral, $10^{\mathrm{e}}$ en triangle large, dernier transverse, arrondi, tronqué au bout.

Pronotum beaucoup plus large que long, convexe sur le dos, abaissé dans son pourtour, largement échancré et finement marginé en devant, avec les angles rentrés à pointe obtuse, arrondi en devant sur les côtés, avec le rebord élevé, élargi à la base qui est sinuée de chaque côté, avec les angles assez aigus, bordé d'un fort sillon entre les sinus, d'oủ partent de courts sillons longitudinaux. Ecusson plan, semi-ovale. Elytres en ovale arrondi, bombées, avec les angles huméraux saillants, dépassant ceux du prothorax; dilatées au tiers antérieur, arrondies au bout, entourées d'un étroit rebord élevé, et dans sa partie postérieure d'une fine strie le long de la suture.

Prosternum étroit, élevé, dépassant les hanches, entouré d'une strie raccourcie seulement en devant. Mésosternum en trapèze transversal, creusé, avec les bords latéraux relevés. Nétasternum grand, rétréci en devant et bien séparé du mésosternum.

Abdomen de 5 segments; $1^{\text {er }}$ long, $2-4$ courts, tous coupés droit; dernier en arc court obtus. Ailes complètes.

Pattes assez robustes, pubescentes: hanches antérieures arrondies, rapprochées sans se toucher, intermediaires de 
même forme, un peu plus distantes; postérieures transverses, très-éloignées des intermédiaires et aussi distantes entre elles; cuisses renflées un peu au-delà du milieu ; jambes élargies peu à peu vers le loul, arquées $\delta^{x}$, presque droiles $q$. Tarses de 4 articles; $1-2$ à lobes assez longs,

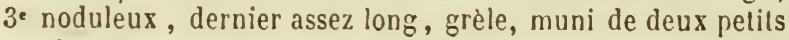
crochels.

Les différences sexuelles extérieures consistent dans un élargissement en forme de dent aux jambes antérieures et dans une échancrure aux postérieures vers le boul du bord interne dans le $\sigma^{*}$, mais elles n'existent pas dans toutes les espèces.

Ce genre, formé par M. Mulsant en 1846 , pour la Chrysomela cruciala de Schaller, qui, d'abord ballollée par les auteurs anciens dans les genres Chrysomela, Galleruca el Tenebrio, enfin Endomychus, faisait partie du genre $I . y$ coperdina pour Gyllenlial et les modernes. Il se compose d'une dixaine d'espèces décrites, réparties en Europe, en Asie et en Amérique, dont deux seulement sont de notre domaine. Ce sont de jolis insectes fongicoles, à la forme élégante, aux couleurs el au dessin simple el tranclié, à la surface polie et luisante, se rapprochant de la Golgia succincta pour les uns el de la Lycopcrdina bovistce pour les autres. La plus grande parlie des organes sont bális sur le même plain, mais le proslernum forme une bande élevée dépassant les hanches antérieures el les séparant, tandis que dans les Lycoperdina il est mince el les hanches sont en contact.

1. Mycetina eruciata Schall., Abhand. Hall. nat. Gesel. I. 273. 1783 (Chrysomela). - Fab., Mant. Ins. I. 75, 110 (Chrysomela) ; Ent. Syst. II. 20, 32 (Galleruca); Ent. Syst. suppl. 100, 3 (Lindomychus); Syst. El. 1. 505, 3. - Rhen in Schneid. Mag. 1, 2, 237, 5 (Chysomela). - Oliv., Enc. mélh. V, 716, 115 (Chrysomela). - Panz., Faun. Germ. VIII, 5. (Galleruca). - Cast., Coléopt. II, pl. 55 (Galleruca). Panz., Naturf. XXIV, 35, 49, pl. 1, 50 (Tenebrio). - Scriba, Jour. Liebl. Ent. I, 20, 40. - Panz., Deuts. Ins. 175, 3 (Endomychus ). - Payk., Faun Suec. II, 114, 2. - Latr., Hist. Crust. Ins. XII, 77, 2. - Walken., Faun. Paris. I, 146, 2. - Gyll., Ins. Suec. IV, 219, 1 (Lycoperdina). - Redto, 
Germ. Zeits. V, 120, 1 (Lycoperdina). - Küst. Kæf. Eur. II, 100. - Muls., Sulc. 15, 1. - Redt., Faun. Aust. 587. -

Costa, Faun. Nap., Endom. 8. - Gerst., Endom. 229, 1.

Lithophilus Herbst., Fuesl. Arch. IV, 37, pl. 21, a. 1783.

Var. binotata Dahl. Col. Verz. 80. 1823 (Lycoperdina).-Costa,

Faun. Nap., pl. 8, 2. 1850.

Ovalis, convexa, late rufa, antennis, pectore pedibusque piceis; elytris vitta suturali postice abbreviata fasciaque transversa media nigris.

Un des plus jolis Coléoptères d'Europe, avec le corps poli, luisant, d'un rouge intense, orné d'une croix noire sur les élytres, ovale convexe. Tête finement pointillée, d'un brun-rouge luisant, peu convexe sur le front; yeux arrondis, globuleux; parties de la bouche rouges. Antennes d'un brunnoir, avec le dernier article rougeâtre, aussi longues que la moitié du corps; $1^{\text {er }}$ article obconique, épais; 2 e petit, $3^{\text {e }}$ de la longueur du $1^{\text {er }}$, subcylindrique, à peine élargi, ainsi que les 2 suivants, qui vont en décroissant, quoique plus longs que larges; 6-8 courts, plus larges que longs, presque en bouton; 9-11 en massue large et comprimée, $1^{\mathrm{e}^{\mathrm{r}}}$ en triangle équilatéral, $2^{\mathrm{e}}$ et $3^{\mathrm{e}}$ plus larges que longs. Pronotum deux fois plus large que long, bombé sur le dos, abaissé fortement dans sun pourtour, surtout en devant, vaguement pointillé sur toute sa surface, d'un rouge intense, avec le bord basal noirâtre ; fortement échancré el finement rebordé au bord antérieur, avec les angles abaissés, rentrés, à pointe obtuse; arrondi, avec un rebord élevé sur les côtés ; plus large que devant à la base, sinué légèrement de chaque côté, avec les angles un peu aigus débordés par les élytres; sillons longitudinaux bien marqués, n'atteignant pas le tiers, rapprochés du bord latéral, reliés par un sillon profond qui longe la base. Ecusson en triangle arrondi, noir. Elytres un peuplus larges à la base que le pronotum, en ovale court, bombées sur le dos, distinctement pointillées avec de petits poils très-courts, ayant leur plus grande largeur avant le milieu, arrondies ensemble au bout, avec l'angle sutural marqué ; élevèes à l'épaule, entourées d'un fin rebord élevé, et le long de la suture d'une petite strie qui ne reisonte guère au-delà du milieu; d'un rouge de minium ABEILLE, V. 1867. 
clair , avec une croix noire commune, dont la traverse placée au milieu s'élargit extérieurement sans couvrir la marge externe; la bande longitudinale, placée sur la suture, s'élargit à la base qu'elle occupe, se rétrécit au milieu, se dilate de nouveau par derrière en triangle, un peu avant l'extrémité qu'elle n'atteint pas. Dessous d'un rouge ferrugineux, avec le milieu du post-pectus et du $1^{\text {er }}$ segment abdominal d'un brun de poix noirâtre, ainsi que les cuisses et les jambes. — Long , 4 mill. — Larg., 2,3 mill.

On signale une variété de couleur propre au Banat et qui paraît constante. La bande noire suturale, fortement élargie en triangle aux deux bouts, est réduite dans le milieu à une ligne étroite, iandis que la bande transverse est largement interrompue et réduile à une tache latérale quadrangulaire sur cliaque élytre.

Dans le $\sigma^{7}$ les jambes antérieures s'élargissent jusqu'au dernier tiers oủ elles forment un angle obtus, à la suite duquel elles se rétrécissent vers le bout; les intermédiaires sont distinctement arquées; enfin, les postérieures sont échancrées en dedans au-delà du milieu.

Cette espèce est assez répandue, quoiqu'elle manque dans plusieurs parties de l'Europe. Elle parait avoir pour habitat les montagnes non-seulement du milieu et du sud de l'Europe, mais encore celles du nord, celles de Suède, par exemple. un la trouve à la Grande-Chartreuse, dans d'autres parties des Alpes, et en général dans les parties froides de la France. Elle s'étend jusque dans le bassin de la lléditerranée (Naples), et en Orient jusqu'au Caucase.

Cette espèce a été décrite la même année 1783, sous deux noms : Cruciata et Lithophilus; on lui a conservé le premier, tandis que le dernier a élé employé et est reçu comme nom générique.

2. Mycetina apicalis Mots., Nouv. mém. Soc. des Natur. Mosc. IV, 1835. 321, 18 (Endomychus).

Oralis, lata, late rufa, pectore medio infuscato; elytris sutura fasciisque 3 transversis basi, medio latiori et apice, marginem lateralem tenentibus nigris; pronoto postice parallelo margine incrassato. 
Ovale dilatée, convexe, polie luisante, finement pointillée, jaune-rougeâtre, un peu rembrunie sur le milieu de la poitrine; élytres noires, avec deux taches sur chacune et l'extrémité rougeâtres. Tête courte ; front plan, finement pointillé, relevé sur la base des antennes; yeux noirs, ronds. Antennes assez longues, peu épaisses, rouge ferrugineux; $1^{\mathrm{er}}$ article médiocre, assez épais; $2^{\mathrm{e}}$ petit, $3-8$ filiformes, décroissant en longueur, toujours plus longs que larges, un peu élargis au boul; $3^{\mathrm{e}}$ deux fois plus long que le $2^{\mathrm{e}}$, $4^{\mathrm{e}}$ à peine plus court, 9-11 beaucoup plus larges, formant une massue peu serrée, un peu comprimée; $9^{\mathrm{e}}$ en triangle équilatéral, $10^{\text {e }}$ en triangle plus court et plus large, dernier en ovale transversal. Pronotum assez court, deux fois au moins plus large que long, convexe sur le dos, avec un pointillé très-fin, rabattu dans son pourtour, surtout en devant, où il est échancré en arc, fort rétréci et bordé d'une fine strie non interrompue, avec les angles peu avancés à pointe obtuse, arrondi antérieurement, puis sinueusement élargi avec un rebord élevé, épaissi et rembruni par derrière, élargi et bisinué à la base, avec les angles aigus mais à pointe arrondie; de chaque sinus part un sillon longitudinal profond et court, à la base duquel on voit un petit tubercule; entre ces sillons règne parallèlement au bord basal, qui est noir, un sillon transversal. Ecusson semi-ovale, lisse, plan. Elytres en ovale large, régulièrement convexes sur le dos, densément pointillées, plus larges à la base que le prothorax, avec l'épaule élevée, fortement dilatées au tiers, arrondies au bout ensemble, avec l'angle obtus; entourées d'un rebord étroit, élevé, avec une petite strie suturale à peine visible dans la moitié postérieure ; noires, ornées chacune d'une tache humérale transverse, large, qui couvre le bord externe et n'atteint pas la suture, et d'une autre vers l'extrémité, ovalaire, ne joignant ni la suture ni le bord externe; enfin d'une bordure apicale, jaune-rougeâtre. Prosternum plan, subparallèle, brun, entièrement rebordé, sauf en devant. Mésosternum enfoncé, court, avec les côtés relevés. Métasternum large, plan, taché de brun au milieu. Pattes assez fortes, rousses; cuisses renflées vers le milieu, rembrunies à la base; jambes droites, un peu élargies extérieurement. - Long., 4,2 mill. - Larg., 3 mill. 
Cette espèce ne peut être, comme le dit I. Gerstæker, une variété de la précédente; sans parler de la coloration, sa forme beaucoup plus élargie, la structure du pronotum à bourrelet marginal beaucoup plus épais, à base plus large, à ang!es postẻrieurs plus aigus et portés en dehors, et plu. sieurs autres différences de détail, en font bien une espèce distincle.

Je n'ai pas vu le type de Motschulsky, mais j'ai fait ma description sur un individu $q$ de la collection de .1. Reiche, venant de Batoum, en Turquie-d'Asie.

\section{LYCOPERDINA, de Lycoperdon ( hísos, loup; $\pi \hat{\varepsilon} \hat{\varepsilon} \omega$, peter).}

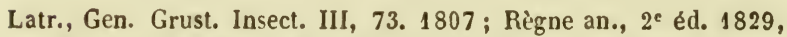
V, 160. - Gyll., Ins. Suec. IV, 218. 1827. - Redt., Germ. Zeit. V, 120, 1. - Faun. Suec. 1849. 588, 592. - Gerst. , Endom. 208, 17.

Lycoperdina et Golgia Muls., Sulc. 20 et 17. - Endomychus Payk., Faun. Suec. II, 115. - Panz., Ent. Germ. I, 175, 41. - Fab., Syst. El. I, 505. - Silpha Lin. - Tenebrio Marsh.

Ovale oblongue, convexe, lisse, luisante, noire ou rougebrun, finement pointillée avec de très-petits poils.

Tête fortement enfoncée dans le prothorax ; front plan ou faiblement convexe, relevé au-dessus des antennes; yeux arrondis, globuleux, forlement granuleux. Épistome étroit, abruptement séparé du front par un sillon transverse; labre court transverse, échancré au milieu et arrondi sur les côtés. Mandibules beaucoup plus longues que larges, courbées en dedans en pointe courte, munies au bord interne d'une petite dent triangulaire peu éloignée de la pointe et d'une lamelle membraneuse, étroile, assez courte et ciliée. Nâchoire à 2 lobes; externe allongé, attẻnué vers le bout qui se termine en pointe aiguē, garni extérieurement de longs poils; interne corné, mince, pas de moitié aussi long que l'externe, en pointe obluse, garni en dedans de poils et de 5 à 6 longues soies raides. Palpes maxillaires dépassant un peu le lobe 
externe, de 4 articles; $1^{\text {er }}$ globuleux petil, $2^{\text {e }}$ épaissi au bout, d'un tiers plus long que le 3 e, dernier le plus long en alène. Nenton transversal, sinué au milieu de son bord antérieur, arrondi sur les côtés, rétréci à la base; languette coriace à la base, membraneuse au bord antérieur, entaillée angulensement avec les lobes arrondis et frangés en dedans de longs poils. Palpes labiaux de 3 articles; $1^{\text {er }}$ petit, globuleux, $2^{\mathrm{C}} \mathrm{cu}-$ puliforme allongé, dernier obovale tronqué au bout.

Antennes insérées sur une élévation du front en dedans et en avant des yeux, pubescentes, robustes, au moins aussi longues que la moitié du corps, de 11 articles; les 3 premiers allongés, $\mathbf{1}^{\text {er }}$ renflé arqué, 2 suivants subcylindriques, un peu élargis au bout, variant de longueur relative selon les espèces ; 4-8 également courts, transverses, plus ou moins serrés, les trois derniers formant une massue peu sensible, un peu plus grands que les précédents; $9^{e}$ guère plus large, croissant peu à peu en épaisseur, plus dilaté en dedans, le dernier le plus grand, tronqué au bout, tantôt droit, tantôt obliquement. Pronotum un peu transverse, dilaté arrondi en devant, puis rétréci par derrière, bordé d'un bourrelet sur les côtés, bisinueusement échancré en devant, avec une fine strie marginale et les angles abaissés et assez saillants, jusqu'au milieu des yeux; base légèrement sinuée de chaque côté, rebordée d'un sillon fort entre les sinuosités. d'une faible strie en dehors, avec les angles droits; surface partagée en trois portions par deux sillons longitudinaux profonds yui ne montent pas au-delà du milieu, le milieu convexe. Écusson arrondi, en demi-cercle ou élargi. Élytres ovales, convexes, débordant la base du pronotum, en ovale tronqué à la base, tantôt enfoncées à la base et le long de la suture et acuminées au bout, tantôt plus arrondies au bout et sans enfoncement à la base et le long de la suture; entourées d'un étroit rebord, quelquefois obsolète le long de la suture. Ailes rarement complètes, souvent arrêtées dans leur développement ou manquant tout-à-fait.

Prosternum très-étroil et invisible entre les hanches, qui sont adossées l'une contre l'autre, et ne les dépassant pas. llésosternum formant une étroite carène peu saillante, incisée par derrière et recevant une pointe du métasternum qui est rebordée en devant. Hanches médianes arrondies, 
comme les antérieures, fort rapprochées; postérieures transverses, distantes. Abdomen de 5 segments $; 1^{\text {er }}$ long, fortenent rétréci en devant par les cavités cotyloïdes, 2-4 courts, égaux entre eux, moins longs ensemble que le $1^{\text {er }}$, dernier assez long en triangle curviligne.

Pattes robustes et assez longues; cuisses épaissies en massue vers l'extrémité; jambes élargies peu à peu vers le bout, tronquées obliquement; tarses de 4 articles ; $1^{\text {er }}$ allongé, $2^{e}$ un peu plus court, $3^{\mathrm{e}}$ noduleux inséré sur la base du $2^{e}$, dernier long, armé de 2 petits crochets menus.

Les caractères sexuels consistent pour les uns en une dent assez aiguë, dont les jambes de devan! sont armées en dedans dans le $\delta$, réduite $q$ à une épaisse saillie, pour les autres dans l'allongement des jambes postérieures qui sont fortement arquées et densément pubescentes de poils jaunes, ainsi que les antérieures, en dedans $\sigma$, tandis qu'elles sont droites, peu allongées et moins villeuses dans la $\$$.

II. Mulsant a divisé ce groupe en 2 genres, que $\mathbf{M}$. Gerstæker a rejelés, parce qu'il re les a pas trouvés appuyės sur des caractères valables; peut être est-ce à tort. En effet, leur faciès est très-différent et permet de les reconnaitre à la première vue; et quand il en est ainsi, le groupe est naturel et ordinairement des caractères viennent le Iraduire.

Les élytres de la Bovisıce enfoncées à la base et le long de la suture qui est parfaitenent rebordée, atténuées régulièrement en arc à partir de la base et terminées en pointe assez aiguē, ne sont-elles pas fort différentes de celles de la succincta, régulièrement ovalaires, arrondies au bout, sans enfoncement à la base et le long de la suture, qui n'est bordée que d'une fine strie obsolète en devant ? ei cette touffe de poils jaunes contre les hanches intermédiaires de la première, dont on ne trouve pas trace dans la seconde; el cette différence dans les caractères sexuels, qui sont ici aux jambes antérieures et là aux postérieures; tout cela ne constitue-t-il pas déjà des caractères suffisants pour valider la séparation de ces genres? Quoi qu'il en soit, ils devront être admis comme groupes.

Les espèces connues sont de petite taille et habitent les zones tempérées des deux hémisphères. Notre faune n'en possède que 6 , qui vivent toutes dans les Lycoperdons el sont fongivores. 
Leur corps a un faciès qui lui est propre et les rend faciles à reconnaître. Les caractères suivants suffiront, du reste, à les déterminer:

Antennes à massue de 3 articles, peu saillante, épaissie peu à peu et à dernier article tronqué.

Mandibules armées d'une petite dent interne. Vlenton sinué au bout; languette bilobée.

Palpes maxillaires à dernier article subulé, celui des labiaux ovale.

Prosternum ne dépassant pas les hanches qui sont adossées. Mésosternum étroit, caréné.

\section{TABLEAU SYNOPTIQUE DES ESPÈCES.}

A. Ovale, régulièrement convexe, arrondi au bout sans étranglement ni enfoncement à la base des élytres et le long de la suture; strie suturale obsolète. - Pas de faisceau de poils contre les hanches intermédiaires; - jambes antérieures $\sigma^{\star}$ dentées au bord interne, légèrement élargies en angle obtus ㅇ. Golgia (nom mythologique) Muls. . 1 succincta L. Eur.

A' Étranglé à la base du pronotum. - Élytres bombées, acuminées par derrière, enfoncées à la base et le long de la suture; strie suturale forte et entière. - Un faisceau de poils jaunes contre les hanches intermédiaires. - Jambes antérieures sans dents, garnies de brosses en dedans $\sigma^{\pi}$; postérieures arquées et allongées $\delta$.

B. Étroit; pronotum non sinué latéralement par derrière, sans pinčau de poils à la base des sillons longitudinaux ; élytres élargies au tiers antérieur . . . 2 bovista F. Eur.

B' Long et trapu. - Pronotum sinué latéralement, avec un pinceau de poils à la base des sillons longitudinaux; élytres plus larges à la base, sans dilatation au tiers antérieur.

3 penicillata M. Alg.

1. Lyeoperdina suceineta Lin., Syst. Nat., 13e éd., 573, 26. 1767 (Silpha). - Payk., Faun. Suec. II. 115, 3. (Endomychus). - Oliv., Ent. VI. 170^. 5. Pl I. 5 (Endomijchus). Gyll. , Ins. Suec. IV. 219, 2. 1827. - Küst., Kæf. Eur. III. 100. - Redt., Germ. Zeit. V. 120, 2 (Endomychus). - Faun., Aust. 588. - Muls., Sulc. 17 (Golgia). - Gerst., Er.dom. 213, 3. - 4-pustulata F. Ent. Syst. I. 2, 20, 33.1792. (Galleruca); Ent., Syst. Suppl. 101, 5 ; Syst., El. I. 505, 4 (Endomyclius),- 
Panz., Faun. Germ. XLIV. 18 ; Ent., Germ. 175, 2 (Endomychius). - Latr., Crust. Ins. XII. 77, 3. - Walken., Faun. Paris. I. 145,3 (id.).

Var. Fasciata F. Syst. El. I. 505, 5. 1801. - Latr., Hist. Ins. XII. 78, 4 (Endomychus). - Redt., Faun. Austr. 588.

Oblonga, subglabra, nitida, rufa, elytris fascia lata media nigra, pectore abdomineque infuscatis scutello transverso.

Ovale subparallèle, allongée, luisante, glabre, rouge-brun, avec le dessous du corps et une large bande transversale au milieu des élytres noirs. Tête pointillée ; front convexe, élevé sur l'insertion des antennes; yeux noirs globuleux. Antennes assez longues, épaisses, pubescentes; $1^{\text {er }}$ article renflé, assez long, $2^{e}$ et $3^{e}$ obconiques, plus longs que larges, celui-là plus court ; 4-8 arrondis transverses; les 3 derniers un peu plus longs et plus épais, croissant peu à peu, dernier assez gros, tronqué au bout. Pronotum à peine plus large que long, pointillé, convexe sur le dos, largement et bisinueusement échancré en devant avec une fine strie marginale interrompue et les angles assez avancés, mais obtus, bordé d'un hourrelet et dilaté arrondi avant le milieu sur les côtés, coupé droit à la base, a vec les angles droits à pointe obtuse; sillons longitudinaux profonds, n'atteignant pas le milieu, réunis par un sillon basal transverse. Écusson en demicercle, lisse et plan. Élytres deux fois et demie plus longues et plus larges à la base que le pronotum, arquées et étroitement rebordées sur les côtés, rétrécies et arrondies ensemble au bout, faiblement marginées le long de la suture, assez convexes et finement pointillées sur le dos, ornées au milieu d'une large bande transversale, qui se dilate ou se rélrécit plus ou moins. Poitrine et abdomen brun-noir avec le bout des segments d'un brun-rouge. Pattes robustes, pubescentes de jaune; cuisses renflées en massue vers le bout : jambes épaissies vers l'extrémité, antérieures munies en dedans vers le milieu d'une dent aiguê $\sigma^{x}$, et obtusément anguleuses q. $^{-}$ Long., 4 mill. - Larg , 2 mill.

Dans les individus typiques, le dessus est d'un rouge-brun, avec les élytres partagées en trois bandes à peu près égales. Quelquefois le noir s'étend le long de la sulure et forme une 
espèce de croix ; d'autres fois, cette couleur s'étend par derrière presque jusqu'au bout. Parfois, au contraire, la bande noire se rétrécit aussi bien en longueur qu'en largeur, de manière qu'elle n'alteint ni le bord externe ni la suture. C'est cette variété que Fabricius a nommée Fasciata. Dahl a établi sa Disca sur des exemplaires qui ont le dos du pronotum légèrement rembruni. On rencontre encore des individus décolorés, d'un brun-rouge unicolore, d'un rouge ferrugineux ou même d'un jaune ferrugineux clair.

Cette espèce habite le nord et le milieu de l'Europe; en France, de préférence les parties froides et tempérées, oủ elle est rare; plus commune et plus répandue en Allemagne. On la trouve en Sibérie; mais elle parait manquer en Angleterre et au moins dans une partie du sud. Elle vit, ainsi que sa larve, dans le Lycoperdon Bovistee Pers., ou aux dépens des substances cryptogamiques sous les écorces des arbres blancs.

La larve décrite, p. 288 et figurẻe pl. IX, fig. 11, par Chapuis et Candèze, est d'environ 4,6 mill. de long, blancjaunâtre, de forme elliptique allongée, garnie en dessus eten dessous de petits poils jaunes courts; il y a sur les segments du thorax, de chaque côté, quelques profonds sillons transverses, et sur ceux de l'abdomen six bourrelets plans, placés sur une rangée transversale, et qui deviennent de plus en plus saillants par derrière. Le dernier segment se termine par deux pointes courtes.

12 Lycoperdina pallida Gebl., Bull. Mosc. 1841. 623, 3. Gerstæk., Endom. 215, 4.

Oblonga, pallida, oculis nigris, fronte transversim sulcata, thorace postice striga angulata impressa, elytris punctulatis. - Long , 3,5 mill.

Cette espèce, dont il n'a été trouvé qu'un exemplaire près de liiddersk, en Sibérie, m'est inconnue, ainsi qu'à M. Gerstæker, qui en parle ainsi : Elle doit avoir la forme de la Succincta et en être très-voisine L'auteur ne donne aucun caraclère importanl qui puisse servir à l'en distinguer ; car la couleur claire et la taille un peu moindre n'ont pas de valeur dans un pareil genre. Ce sillon transversal du front doit être une méprise, à moins qu'il ne s'agisse du sillon 
qui dans toute la famille sépare le front de l'épistome. Il est donc à présumer que cette espèce est établie sur un exemplaire peu développé de la Succincla.

2. Lyeoperdina bovista F., Ent. Syst. II. 20, 34. 1792 (Galleruca) ; Ent. Sỵst. suppl. 101, 5 ; Syst. El. I. 505, 6 (Endomychus). - Panz., Faun. Germ. 8, ४ (Galleruca); Ent. Germ. 175, 4 (Endomychus). - Payk., Faun. Suec. II. 115, 4 (Id. ). - Oliv., Lint. VI. 1703. 3. Pl. I, 4. - Marsh., Ent. Brit. 478, 11 (Tenebrio). - Leac', Edimb. Enc. XV. 116. - Curt., Brit. Ent. VIII. pl. 355, 1-6. - Gyl., Ins. Suec. IV, 220, 3. - Steph., Illust. IV. 400. - Cast., Hist. nat. II. 525. - Redt., in Germ. Zeit. V. 120, 2 ; Faun. Aust. 588. - Mul.s., Sulcic. 21. - Gerstæk., Endom. 216, 5. Immaculıta Latr., Gen. Crust. Insect. III. 73, 1. 1807.

Nigro picea, nitidissima, subglabra, antennis pedibusque rufo-brunneis, pronoto parum antice dilatato; scutello angusto, elytris ad basim et suturam valde depressis.

V'une forme très-élégante, allongée, étranglée au-devant des élytres qui sont convexes et atténuées en pointe, semée de petits points d'où sortent des poils fins et courts, d'un noir luisant et lisse, avec, une transparence brun-rouge vers les bords. Tète brune, déprimée sur le front, plus distinctement pointillée, élevée au-dessus de l'insertion antennaire, avec un faible sillon longitudinal au milieu; yeux arrondis, noirs; parties de la bouche d'un rouge plus clair. Antennes assez épaisses, aussi longues que la moitiẻ du corps, pubescentes; $1^{\text {er }}$ article plus rouge, renflé et arqué, deux fois plus long que les deux suivants; ceux-ci égaux entre eux, plus longs que larges, en tranclies coniques; 4-8 plus courts, de même dimension entre eux, un peu transverses ; 9-11 à peine plus épais et plus longs et formant une massue peu distincte, le dernier un peu plus gros, tronqué au bout. Pronotuın transverse, largement et bisinueusement échancré en devant, avec les angles abaissés, aigus et un fin rebord interrompu, également rebordé et élargi en cercle au quart, puis rétréci sur les côtés, tronqué droit à la base, aver, une petite sinuosité de chaque côté et les angles droits a pointe obtuse; les sillons longitudi- 
naux sont très-profonds, dépassent le milieu et sont réunis par un fin sillon transverse; dos convexe longé par un sillon superficiel, nieux marqué au-devant de l'écusson. Celui-ci petit, arrondi, enfoncé. Elytres en ovale tronqué à la base et terminé en pointe par derrière, bombées sur le dos, rabattues dans tout leur pourtour, enfoncées le long de la suture qui est marginée ainsi que le bord externe, débordant la base du pronotum, élevées à l'épaule, dilatées, arrondies au tiers sur les côtés, puis atténuées par derrière, avec l'extrémité obtuse ; noires, avec la marge basale brune; le bord infléchi rouge et l'extrémité claire. Dessous brun, avec les pattes et le bord des segments abdominaux rougebrun; une touffe de poils jaunes près des hanches intermédiaires. Pattes assez grandes; cuisses renflées en massue vers l'extrémité; jambes épaissies au bout, garnies de brosses de poils jaunes en dedans; postérieures arquées $\sigma^{\star}$ et plus longues que les antérieures, à peu près droites $q$. - Long., 4,5 mill. - Larg., 2 mill.

On trouve des individus en entier d'un rouge ferrugineux plus ou moins clair et évidemment immatures.

Il est toujours aisé, même dans les individus décolorés, de distinguer cette espèce de la Succincta, à sa forme générale étranglée au-devant des élytres et beaucoup plus acuminée postérieurement, à la structure de sa massue antennaire, à son écusson enfoncé ainsi que la suture des élytres, à ses jambes antérieures dépourvues de dents, etc.

Généralement répandue en Europe et plus commune en France que la Succincta, elle étend son habitat au nord jusqu'en Angleterre et en Suède, et au sud jusqu'aux rivages de la Méditerranée et dans le nord de l'Afrique.

Léon Dufour a décrit (Annal. Soc. Ent. de France, 18\%. $647, \mathrm{Pl} .19$, II) les premiers états de cette espèce. Elle vit dans les Iycopercion bovista et pyriforme.

Tête arrondie, assez épaisse, glabre, plus consistante que les autres parties du corps, mais de même couleur blanche. Antennes courtes, conoïdes, assez grosses, rétractiles, de 3 articles, dont le dernier porte d'un côté un article rudimentaire surmonté d'un poil el de l'autre une simple soie. Mandibules cornées, brunâtres, oblongues, aiguẻs, édentées. Mâchoires un peu dilatées à la base externe; lobe antérieur 
arrondi, garni en dedans de soies arquées. Palpe maxillaire court, de 2 articles, avec un poil terminal. Lèvre large, à peine échancrée, glabre. I'alpes labiaux latéraux, de 2 articles, dont le dernier a un poil apical. Thorax de 3 segments glabres, arrondis sur les bords latéraux. Pattes courtes, à ongle terminal grand, non coloré. Abdomen de 9 segments dont le dernier se termine par deux lobes aigus plus ou moins redressés; les 2 séries de tubercules hérissés de leur dos sont difficiles à voir.

Celte larve se nourrit de la poussière du Lycoperdon pyriforme, el change 2 fois au moins de peau; les nymphes se trouvent vers la fin d'avril dans les débris. Elles sont d'un blanc pur, sans en excepter les yeux qui se reconnaissent à leur saillie. Au bout de l'abdomen est collée la dernière dépouille informe et ratatinée de la larve. Les paltes postérieures sont en partie cachées par les élytres rabattues. Les antennes, insérées près du bord interne des yeux, sont couchées le long des flancs du prothorax, droites, pluriarticulées, filiformes.

L'insecle parfait éclòt dans la $2^{\mathrm{e}}$ quinzaine de mai.

\section{Lycoperdina penicillata.}

Nigro-picea, nitidissima, subglabra, antennis pedibusque ferrugineis, pronoto antice valde dilatato, posterius sinuato, sulcis penicillatis, elytris secus basim et suturam depressis.

Ovale oblongue, convexe, acuminée postérieurement, luisante lisse, à peine visiblement pointillée et très-finement pubescente, noir-brun avec une transparence rougeâtre par places. Tête d'un roux-brun, avec les parties de la bouche plus rouges, légèrement convexe avec une dépression au milieu sur le front; yeux arrondis. Antennes épaisses, rougebrun, pubescentes, aussi longues que la moitié du corps ; $1^{\text {ex }}$ article renflé, pas beaucoup plus long que les 2 suivants, ceux-ci égaux, subcylindriques, 4-8 granuleux courts transverses; 9-11 plus longs el beaucoup plus larges, subtriangulaires, dernier tronqué au bout un peu obliquement. Pronolum transverse, noir, brun-rougeatre sur le limbe, convexe sur le milieu du dos, sans canal médian, fortement 
et bisinueusement échancrẻ et finement rebordé en devant, la strie marginale s'éloignant du bord au milieu qui s'avance en pointe et est roussâtre, avec les angles abaissés aigus, bordé dans sa longueur d'un épais bourrelet sur les cotẻs, qui sont dilatés arrondis au tiers antérieur, puis sinueusement rétrécis ; base fortement rebordée et bisinuée, au point de rencontre des sillons longitudinaux, qui sont profonds, raccourcis vers le milieu et garnis à leur origine d'une touffe de poils jaunes ; angles postérieurs aigus. Ecusson en demicercle, enfoncé, plan. Élytres plus larges à la base que le pronotum, avec les épaules saillantes, formant une ogive presque régulière à partir de la base, convexes, entourées d'un étroit rebord, terminées en pointe arrondie au bout; suture élevée, enfoncée seulement derrière l'écusson; noires avec l'épaule et l'extrémité rougeâtres. Dessous noir, avec les bords latéraux du propectus et l'extrémité des segments abdominaux roux ; une plaque garnie d'une brosse de poils jaunes près des hanches intermédiaires. Paltes rouge-brun, assez robusles, pubescentes de jaune ; cuisses renflées en massue un peu avant l'extrémilé ; jambes graduellement épaissies vers le boul. - Long. , 4,3 mill. - Larg. , 2 mill.

Sa forme plus épaisse, plus large et plus courte, son pronotum plus large, sinueusenent rétréci par derrière, ne formant pas un étranglement au-devant des élytres, celles-ci rétrécies à la base, peu enfoncées à la suture, et plusieurs autres détails la distinguent bien de la Bovistce, à laquelle elle ressemble beaucoup.

Algérie.

\section{Eycoperdina validicornis Gerstæk., Endom. 217, 6. $185 \mathrm{~s}$.}

Rufo-ferruginea, nitida, parce pubescens, antennis obscurioribus, elytris ad suturam leviter depressis, oblongo-ovatis, retrorsum sensim attenuat is; scutello transverso, antennis crassis, articulis 2 penultimis subquadratis.

De moitié plus petite que la Bovistae, dont elle a la forme étroite, elle s'en dislingue par plusieurs caractères tranchés. Les antennes se font remarquer par leur épaisseur ; elles ABEILLE, v. 1867. 
sont beaucoup plus obscures que le corps el garnies de poils courts; leurs $2^{\mathrm{e}}$ et $3^{\mathrm{e}}$ articles sont d'égale longueur, mais à peine de moitié plus longs que larges, les suivants tres-serrés les uns contre les autres, en carré transverse; les 3 articles de la massue sont de la même forme, cependant tout aussi longs que larges, les 2 dernier's sont seulement un peu élaigis. La tête est très-finement et vaguement ponctuée; le front aplati ; la ponctuation sur le pronotum et les élytres est également fine et encore plus écartee, et de chacun de ces points sort un petit poil jaunâtre assez long et couché. Le pronotum est très-distinctement élargi par devant, mais à peine arrondi sur les côtés, parce que le bord latéral se courbe à peine en dedans pour former les angles antérieurs qui sont légèrement obtus ; les sillons longitudinaux ne vont que jusqu'au milieu, et la partie antérieure du dos n'est point séparée de la portion latérale. Écusson en demi-cercle, au moins de moitié plus large que long. Les élytres sont en ovale allongé et régulier, très-légèrement et graduellement dilatées, arrondies jusqu'au milieu, et de nouveau rétrécies de la même façon par derrière, sans être en pointe comme daus la Bovista. La sulure, accompagnée dans toute sa longueur d'une fine strie, parait enfoncee seulement dans son tiers antérieur et encore beaucoup moins que dans celui-ci. Tout le corps est d'un rouge ferrugineux unicolore, assez luisant; les bords latéraux du prothorax sont noirs sur leur arête épaissie. Pattes d'un jaune ferrugineux clair, seulement la base des cuisses répond mieux à la conleur rougeâtre de la poitrine. - Long. , 3,8 mill.

Sardaigne.

5. Lycoperdina marginalis Gebl., Ledeb. Reise. II. 227, 2, 1830. - Gerstæk., Endom. 219,8

Nigra, elytris fascia arcuata, margine abdomineque rufis.

Tête polie, Juisanie. Prothorax transverse, arrondi avant le milieu, le dos peu convexe, à peine ponctué. Écusson triangulaire. Élytres peu élargies, largement arrondies au bout, très-finement ponctuées, noires, une bande transversale qui enveloppe toute l'épaule, se dirige en are vers la 
suture el s'étend par derrière jusqu'au-dessus du milieu, d'un ruuge ferrugineux, ainsi que le bord apical. Dessous noir avec l'abdomen rouge, un peu rembruni au premier segment. Paltes étroites assez longues. -- Long. , 4,6 mill. Sibérie, Salair. Une fois.

\section{Lycoperdina humeralis Wollast. Canar. Coleop. 432 ,} 663. 1864.

Elliptique, élargie, déprimée, presque imponctuée, presque glabre, assez luisante (très-finement alulacée), noir de poix. Pronotum plus rougeâtre inégalement sur les côtés, en carré transverse, avec les angles postérieurs droits, marqué de chaque côté à la base d'un sillon longitudinal profond. Élytres dilalées arrondies derrière la base, d'un rouge vif à l'épaule, un peu roussátres an bout, avec une fine strie sulurale. Antennes el tarses d'un ferrngineux obscur. Long., 4,6 mill.

Ténériffe; un seul individu pris, au mois de mai, dans les bois de lauriers humides qui dominent Taganana.

Un peu plus grande, plus large, plus elliptique et plus aplatie qne la Bovistae; elle est aussi moins luisante (étant finement alutacée) et presque sans pubescence ; sa couleur (au moins sur le prothorax) est d'un noir plus rouge. avec les épaules d'un rouge éclatant, el l'extrémité des élytres roussâtre, el sa strie suturale est beaucoup plus fine el moins enfoncée (Ex Wollast).

\section{DAPSA ( ذ่̀ $\alpha \tau \omega$, dévorer).}

Latr., Règne anim., $2^{e}$ éd. 1829. V. 159. - Guér., Icon. $31^{\text {ri }}$, pl. 50. 1839. - Muls., Sulcicoll. 23. - Redt., Faun. Austr. 588. - Gerst., Endom. 196. 14.

Petite, allongée, ponctuée, pubescente en dessus et en dessous.

Tête assez grande, peu ou point enfoncée dans le prothorax; yeux arrondis, granuleux.

Antennes de la longueur de la moitié du corps, plus ou 
moins épaisses, de 11 articles ; $1^{\text {er }}$ ovale épais, $2^{*}$ un peu plus court, $3^{\mathrm{e}}$ de moitié plus long que le $4^{\mathrm{e}}$, les suivants allongés, se raccourcissant à peine; 9-11 un tant soit peu plus épais, formant une massue làche; $9^{c}$ plus long que large, $10^{e}$ en triangle arrondi, dernier ovalaire.

Epistome arrondi, séparé du front par une arête élevée; labre sinué au milieu, corné, avec un large bord membraneux.

Mandibules larges, presque carrées, terminées par une pointe longue et tranchante dirigée en dedans, précédée d'une petite dent triangulaire; garnie en dedans d'une lamelle membraneuse qui part de ce point et s'élargit vers la base.

Mâchoires comme dans les Ancylopus, seulement le lobe interne est terminé par une poinle longue et aiguē, barbu jusquaux 2/3 el muni au-dessous de 3 longues soies écartées. Palpes à dernier article ovale allongé, tronqué tout au bout.

Menton corné, en carré transverse, presque 2 fois aussi large que long, rétréci à la base, coupé presque droit par devant; languette coriace, exceplé les lobes latéraux qui sont membrancux, entaillés très-avant et presque en angle droil, les côtès avancés en pointe aiguẻ el densément ciliés en dedans. Palpes à 2 e article cupuliforme, un peu plus large que long; le dernier paraîl pyriforme avec la pointe tronquée.

Pronotum plus large que long, élargi avant le milieu, rétréci par derrière, sinué de claque côté et rebordé à la base; de chacune de ces sinuosites part un sillon profond qui remonte vers le milieu. Ecusson court, en demi-cercle. Elytres en ovale plus ou moins allongé, presque de la largeur du pronotum à la base, bientôl dilatées, arrondies à l'épaule, finement rebordées latéralement, oblusément arrondies ensemble au bout.

Prosternum non visible entre les hanches, qui sont adossées l'une contre l'autre. Les hanclies intermédiaires sont aussi très-rapprochées, et ne sont séparées que par une lame élroite presque linéaire du mésosternum, qui est élargi en devant, creusé à son bord antérieur d'une cavité superficielle pour recevoir les hanches antérieures, et caréné au milieu dans sa longueur. 
Paltes courtes et robustes; cuisses élargies en massue vers l'extrémité; tarses petits, 2 premiers articles plus longs que larges.

Le $\delta^{*}$ a les jambes antérieures armées en dedans d'une petite dent un peu avant l'extrémité, et les intermédiaires et les postérieures allongées et arquées.

Les espèces de ce genre sont très-semblables pour la taille, la structure et la couleur ; elles habitent le sud de l'Europe et les contrées limitrophes de l'Asie et de l'Afrique, et se trouvent sous les écorces de bois tendre, où les larves vivent sans doute dans les champignons ou le terreau, sous les pierres.

On les reconnaîtra donc aux caractères suivants:

Mandibules presque carrées, armées d'une pointe longue et aiguẽ lournée en dedans et d'une dent un peu au-dessous.

Dernier article des palpes maxillaires ovale, celui des labiaux pyriforme, tronqué au bout.

Nenton tronqué, languette profondément échancrée.

Hanches antérieures contiguēs; mésosternum étroit.

M. Mulsant distribue les espèces en deux sous-genres; il appelle Phylira, ceux dont les angles antérieurs du prothorax ne sont pas courbés en dehors, réservant le nom de Dapsa à ceux dont les mêmes angles sont courbés en dehors en forme de croc.

\section{TABLEAU SYNOPTIQUE DES ESPËCES.}

A. Côtés du pronotum entaillés en arc par devant, avec l'angle en crochet aigu dirigé latéralement; une large tache noire sur le milieu des élytres, plus rapprochée du bord externe que de la suture. . . . . . . 1 denticollis Guér. Al'em.

A' Côtés du pronctum sans entaille arquée au-derant de l'angle, plus ou moins arancée, dirigé en devant et en pointe obtuse; tache noire dorsale nulle ou pas rapprochée du bord externe.

B. Antennes grèles et allongées, à massue guère plus épaisse. Elytres gibbeuses, en ovale, ayant leur plus grande largeur avant le milieu. . . . 2 edentata Wo!lst. Ténérif.

B' Antennes mo:ns longues et plus épaisses, à massue bien distincte. - Elytres en ovale plus ou moins parallèle, faiblement 
convexes, n'ayant jamais leur plus grande largeur avaut le milieu.

C. Pronotum rétréci à la base, arec les angles antẻrieurs avancés et le sillon latéral bien marqué. - D'un blond plus ou moins ferrugineux.

D. Dessus jaune ferrugineux, arec de courts poils jaunes moins serrés, avec ou sans taches noires, mais jamais assez dilatées pour couvrir le dos de l'élytre, et pronotum sans teinte brune; ponctuation moins forte et moins serrée.

E. Pronotum sans crénelures, à sillons latéraux plus courts.Elytres plus parallèles, à angle apical allongé, à trois taches noires, dont l'une suturale, sans tache le long du bord externe . . . . . . 3 trimaculata Mots. Eur.

E' Pronotum crénelé latéralement, à sillons latéraux plus longs. - Elytres plus arrondies sur les côtés, aver l'angle apical droit arrondi; marginées de noir, avec une tache dorsale, mais sans suturale. - Dessous en partie noir.

$$
4 \text { barbara Luc. Alg. }
$$

D' Dessus brun ferrugineux, arec de longs poils jaunes serrés ; une large tache noire sur le dos des élytres. - Ponctuation forte et rugueuse.

F. Sillons du pronotum n'aboutissant pas à une profoncle impression.- Elytres ovales, atténuées en pointe, avec l'angle a pical allongé, assez égal, plus finement ponctué. - Pourtour de l'écusson, épaule et bout vaguement ferrugineux.

$$
5 \text { subpunctaia. Alg. }
$$

E' Sillons du pronotum aboutissant à une profonde impression arquée. - Flytres en ellipse courte, arrondies largement au bout, avec les angles obtus, plus fortement ponctuées, légèrement sillonnées, d'un noir profond, sauf 2 taches ferrugineuses bien accusées à l'épaule el à l'extrémité.

$$
6 \text { sellata. Alg. }
$$

C' Pronotum plus large à la base qu'en devant, avec les angles antérieurs à peine avancés; sillon latéral peu marqué. D'un jaune pâle. . . . 7 pallescens. Alg.

1. Dapsa denticollis Germ., Faun. Insect. Eur. III. 1817. $8^{\circ}$, pl. 8 (Endomychus). - Guér., Icon. 316, pl. 50, 8. 1838. Thoms., Arch. Entom. I. 273, pl. 13, 25. - Redt., in Germ. Zeit. V. 120. 1844. - Fama Austriaca, 588. - Muls. , Sulc. 25, 2. - Gerstrek., Endomych. 197, 1.

Var. Nigricollis Dahl., Col. Verz. 80. 1823.

Convexa, rufa, confertim punctata, flavo pubescens, 
pronoto lateribus denticulatis, angulis anticis uncinatis, elytris macula magna oblongo-quadrata disci parvaque suturali ante apicem nigris.

Peu allongée, convexe, rouge ferrugineux, assez luisante, assez densément ponctuée, plus fortement sur le pronotum, vêtue d'une courle pubescence jaunâtre peu serrée. Yeux noirs assez saillants; front plan, tronqué droit en devant. Antennes assez fortes, de la longueur de la moitié du corps, articles peu serrés, garnis de quelques longs cils; $1^{\text {er }}$ plus gros, 2, 4-8 obconiques, d'égale longueur, $3^{\mathrm{e}}$ de moitié plus long que le $4^{\mathrm{e}} ; 4^{\mathrm{er}}$ article de la massue triangulaire, $2^{\mathrm{e}}$ transverse, $3^{\text {e }}$ ovale. Pronolum plus large que long, subtrisinué et rebordé à la base, avec les angles droits à pointe aiguè, élargi peu à peu et dentelé sur les côtés, entaillé en arc sous l'angle antérieur qui est recourbé en crochet aigu, largement échancré en devant, un peu convexe sur le dos, un sillon longitudinal de chaque côté sur le tiers postérieur. Écusson en demi-cercle large. Élytres ovales, convexes, plus larges que le pronotum à la base, arquées et étroitement rebordées sur les côtés, ayant leur plus grande largeur vers le inilieu, arrondies ensemble au bout avec l'angle oblus, finement aciculées poncluées, avec quelques faibles traces de sillons le long de la suture qui est marginée et un peu enfoncée par derrière, ornées au milieu d'une grosse tache noire ovalaire, plus rapprochée du bord externe, el d'une autre commune triangulaire sur la suture commençant au niveau du bout de la première et qui s'y lie quelquefois. Pattes rohustes, cuisses renflées - Long. , 4 mill. - Larg. , 2 mill.

Var. $a$. Tête, prothorax, poitrine et base de l'abdomen noirs.

Var. b. Immature, en entier d'un ferrugineux clair.

Contrées montagneuses de l'Allemagne méridionale, surtout en Autriche et en Hongrie.

2. Dapsa edentata Wollast., Canar. Coléopt. 432, 664. 186ł.

Fulva, flavopubescens, punctulata, pronoto minori, posterius sinuatim angustato, fortiter sulcato, elytris ovatis subgibbosis, apice valde obtuso, pectore abdomineque fuscis. 
Oblongue, convexe, roux-fatuve, luisante, pubescente de poils jaunes couchés rares. Front avec peu de petits points, plan, tronqué droit au bout; yeux globuleux, noirs. Antennes très-longues et grèles; $1^{\text {er }}$ article ovale, gros; $2^{\text {e }}$ ohconique, menu; $3^{\mathrm{c}}$ au moins deux fois plus long, cylindrique, ainsi que 4-8, ceux-ci à peu près égaux; massue de 3 articles, à peine sensible, $1^{\text {er }}$ affectant la forme et la longueur du précédent, seulement un peu plus épais au bout; $2^{\mathrm{e}}$ en triangle plus court et plus fort, dernier ellipsoïdal. Pronotum plus large que long, à peine circulairement échancré et vaguement rebordé en devant, avec les angles arrondis peu avancés ; dilaté, arrondi au tiers antérieur sur les côtés, qui sont rebordés et sans crénelures, puis presque droit, rétréci, rebordé, biéchancré et subsinué à la base, avec les angles un peu aigus; élevé sur le dos, avec un large canal superficiel au milieu, couvert de gros points avec les interstries finement alutacés; sillons latéraux très-profonds, allant de !a base jusque vers le milieu où ils se terminent par une profonde impression arquée. Ecusson semi-circulaire. Elytres ovales, fort bombées, comme gibbeuses, finement et peu densément aciculées ponctuées, plus larges que le pronotum à la hase, arrondies mais pas saillantes à l'épaule, arquées sur les côtés et finement rebordées, atteignant leur plus grande largeur avant le milieu, atténuées postérieurement, arrondies au bout, avec l'angle sutural droit émoussé ; suture rebordée d'une strie enfoncée. Milieu du médipectus, abdomen, sauf le dernier segment, et base des cuisses noir-brun. Pattes assez longues, cuisses renflées extérieurement. - Long., 4-8 mill. - Larg., 1,8 mill.

Cette espèce, trouvée à 'Ténériffe, tout en ayant le faciès des autres Dapsa, a un cachet particulier qui la distingue de toutes les autres: ses antennes grèles et larges, son pronotum rétréci faisant ressortir ses élytres en ovale bombé, gibbeux.

Canarie, Ténériffe et Palma.

3. Dapsa trimaculata (Koll.) Mots., Nouv. Mém. Mosc. IV. 1835. 322 , 19. Pl. XIX. M. - Guér., Ir.on. Rég. an. 316. Pl. 50, 8. - Guér., Arch. Ent. I. 272. Pl. 13, 24. - Cast., 
Coléopt. II. 523. - Muls., Sulcicol. 23, 1. - Gerst. , Endom. 199, 2.

Parum convexa, sat dense punctata et griseo-pubens, rufo-ferruginea, pronoto antice rotundato, angulis anticis obtusis, elytris subparallelis, macula disci pone medium alteraque suturali sub apicem, scepe junctis, nigris.

Ovale allongée, peu convexe, rouge ferrugineux, assez luisante, ponctuée, pubescente de gris-jaunâtre. Antennes assez longues, assez fortes; $1^{\text {er }}$ article gros renflé, les suivants allongés obconiques, ciliés, $2^{e}$ court, $3^{e}$ de moitié plus long, $4^{e}$ allant à peine en décroissant; massue faible de 3 articles, $1^{\text {ex }}$ en triangle allongé, $2^{\text {e }}$ court transverse, dernier ovale un peu plus long et de même diamètre. Front plan, peu ponctué, tronqué droit en devant; yeux noirs globuleux. Pronotum beaucoup plus large que long, un peu convexe sur le dos, abaissé latéralement, étroitement rebordé et échancré de chaque côté d̀ la base, au niveau des sillons longitudinaux qui sont profonds et ne remontent pas jus. qu'au milieu, avec les angles en pointe très-aiguē, dilaté arrondi antérieurement sur les côtés avec la marge sinueuse sans dentelures, anguleusement bisinné en devant, derrière les yeux, avec les angles avancés à pointe arrondie; parsemé de points écartés assez forts. Ecusson en arc cotirt. Elytres plus larges que le pronotum, 3 fois plus longues, avec l'épaule marquée, poncluées, pell convexes, reborlées étroitement el subparallèles sur les côlés, arrondics ensemble au bout, suture bordée d'un fin sillon enfoncé par derrière, ornées de 2 taches, l'une ovale un peu après le milieu à égale distance du bord externe et de la sulure, l'autre commune en losange très-long, dont l'angle médian correspond à la première el s'y lie quelquefois. Palles assez fortes; cuisses renfleees vers le bout. - Long., 4 mill. - Larg. , 2 mill.

Celle espèce qui a un habilal assez élendu, puisque j'en ai des exemplaires de France. surtout du midi, d'Espagne, de Russie méridionale, du Caucase et de la mer Caspienne, se distingue de la précédente, en outre de ses angles antérieurs du pronolum sans crochet, par ses élytres parallèles, peu convexes, et par la position de ses taches. 
4. Dapsa barbara Luc., Explor. sc. Alg. 552, 1462. Pl. 47, 13. 1842. - Guér., Arch. ent. I. 273. -- Gerstæk., Endom. 200. 3 .

Rufobrunnea, dense fortiter punctata, griseopubescens, pronoto lateribus crenulato, angulis anticis rotundis, elytris parum convexis, ovatis, macula pone medium vaga, parva, nigra.

Ovale allongee, peu convexe, fortement et assez densément ponctuée, vêlue d'une pubescence jaune, luisante, d'un roux ferrugineux obscur. Antennes longues, $\mathbf{1}^{\text {er }}$ article ovale court, $2^{\mathrm{e}}$ obconique, ainsi que les suivants, de la longueur du $\delta^{e}, 3^{e}$ de moitié plus long que le $4^{e}$, ceux-ci allant en diminuant graduellement; massue de trois articles lâches, $1^{\text {er }}$ allongé, triangulaire; $2^{\mathrm{e}}$ court, $3^{\mathrm{e}}$ arrondi. Frront rétréci et coupé droit en devant, sillonné transversalement par derrière; yeux globuleux. Pronotum plus large que long, faiblement bisinué aux deux bouts, fortement rebordé à sa base avec les angles droits, finement el peu distinctement rebordé en devant avec les angles peu avancés obtus, faiblement crénelẻ sur les côtés, qui sont dilatés arrondis au tiers antérieur et largement aplatis en dessus, avec une élévation correspondant à la dilatation, faiblement canaliculé au milieu, avec les deux sillons latéraux profonds, remontant jusqu'au milieu; poncluation forte avec les intervalles finement alutacés. Ecusson en arc, ponctué. Elytres un peu plus larges que le pronotum à la base, 3 fois $1 / 2$ plus longues que lui, peu convexes, densémeut ponctuées, faiblement arquées et rebordées sur les côtés, arrondies au bout, avec la suture bordée postérieurement d'un sillon enfoncé; ornées d'une bande noire après le milieu, à peu près à égale distance du bord latéral el de la suture dilatée en dedans par derrière, et d'une bordure marginale le long des côtés. Dessous noir, avec les bords latéraux du propectus, le bord postérieur des segments de l'abdomen et l'anus rouges. Pattes robustes; cuisses renflees vers le bout, noirâtres à la base. - Long., 4,5 mill. - Larg., 2 mill.

Se distingue de la Trimaculata par la couleur noire du dessous, la bordure latérale des élytres, son pronotum distinctement crénclé sur les côtés, à angles postérieurs moins 
aigus el antérieurs moins avancés, à sillons latéraux plus allongés el à impression médiocre bien marquée: quelquefois les élytres sont entièrement blondes

Alger, Bône, Edough ; en avril, dans les détritus.

\section{Dapsa subpunctata.}

Subdepressa, rufobrunnea, dense cequaliter punctata, griseo-pubescens, pronoto lateribus subcrenulato, anterius dilatato rotundato, sulcis minus profundis, elytris angulo apicali subacuminato, circa scutellum, humero et apice vage rufis.

Ovale oblongue, peu convexe, d'un brun ferrugineux assez luisant, garnie de poils gris-jaune couchés, avec les pattes, palpes et antennes d'un rouge ferrugineux. Front transverse, à points écartés, tronqué droit an bout, relevé sur l'insertion antennaire; yeux noirs ronds. Antennes assez longues et assez fortes, ciliées $; 1^{\text {er }}$ article gros, ossez court, les autres élroitement obconiques, peu serrés, à peu près de même longueur, sauf le $3^{\mathrm{e}}$ qui est le double; massue de 3 articles, peu épaisse, $1^{\text {er }}$ et $2^{\text {e }}$ en triangle large, dernier arrondi. Pronotum densément et fortement ponctué, rugueux, un peu convexe sur le dos avec un canal large el superficiel médian dans toute sa longueur, plus large que long, largement et bisinueusement échancré et étroitement rebordé en devant avec les angles avancés obtus aul bout; côtés déprimés creusés, avec une courte impression tránsverse au uilieu, crénelés obsolètement sur le bord, dilatés, arrondis au tiers antérieur, puis se rétrécissant régulièrement jusqu'à la base, qui est plus étroite que le bord antérieur, trisinuée et bien rebordée; sillons latéraux courts, mais profonds. Écusson en demi-cercle ponctué. Élytres beaucoup plus longues à la base que le pronotum, assez convexes, arrondies, mais peu saillantes à l'épaule, faiblement arquées et rebordées sur les côtés, atténuées en pointe arrondie au bout, l'angle sutural long, en pointe obtuse ; ponctuation assez serrée aciculée, moins forte que sur le pronotum; suture rebordée el en carène fine dans sa moitié postérieure; couleur d'un brun obscur, avec le pourtour de l'écusson, l'épanle et la partie 
postéricure vaguement ferrugineux. Palles robustes, cuisses renflées. - Long., 4 mill. - Larg. , 2 mill.

Celle espèce, également d'Alger, ressemble beaucoup à la Barbara; mais, outre sa couleur bien plus obscure, elle a le pronotum plus fortement et plus densément ponctué, beaucoup plus étroit à la base, plus fortement dilaté sur les côtés; ses élytres, au lieu d'avoir l'angle apical rond et court, l'ont en pointe allongée, seulement un peu émoussée.

\section{Dapsa sellata.}

Subdepressa, rufo-brunnea, dense fortiter rugulosopunctata, flavo-pubescens, pronoto lateribus subcrenulato, anterius dilatato rotundato, elytris subsulcatis, angulo apicali rotundo, nigris, humero apiceque rufo ferrugineis.

Oblongue, peu convexe, fortement el assez densément ponctuée, peu luisante, garnie d'une pubescence d'un grisjaune brillant. Antennes robustes, assez longues, d'un rouge ferrugineux, ciliées ; $1^{\text {er }}$ article court, renflé, les suivants obconiques, $3^{\mathbf{e}}$ de moitié plus long que le $4^{\mathbf{e}}, 9$ et 10 à peu près de même forme, nais plus épais, ainsi que le dernier qui est arrondi, et forment tous trois une massue lâche et peu épaisse. Tète ferrugineuse, large, tronquée en devant, avec le front, l'épistome el les yeux globuleux, noirs. Pronotum court, beaucoup plus large que long, un peu rétréci, étroilement rebordé et biẻchancré à la base avec les angles droits, mais avec une petile pointe, faiblement crénelé, dilaté-arrondi au tiers antérieur sur les côtés, trisinué en devant avec les angles avancés creusés, obtus au bout, rebordés; grossièrement ponctué, convexe sur le dos avec un faible canal longiludinal médian et de chaque còté un profond sillon partant de l'échancrure et n'alteignant pas le milieu. Ecusson transverse presque tronqué, ponctué. Elytres en ovale, arrondies aux épaules et à l'extrémité, assez convexes, finement rebordées sur les côtés, densément ponctuées, marquées sur le dos de faibles sillons, noir-brun, avec une longue taclie humérale et une large apicale ferrugineuses. Dessuus noir; palles ferrugineuses, robusles; cuisses renflées, rembrunies. - Long., 4 mill. - Larg., 1,8 mill. 
Cette espèce ressemble un peu à la Barbara pour les couleurs, dont cependant le noir s'étend bien davantage sur' les élytres; mais elle en diffère par sa taille plus petite, sa ponctuation plus forte et plus serrée, sa villosité plus longue et mieux fuurnie, son pronotum plus court, plus ariondi au tiers antérieur, ses sillons latéraux plus profonds et plus courts, ses élytres plus arrondies, moins saillantes à l'épaule et distinctement sillonnées.

Bône ; mai.

\section{Dapsa palleseens.}

Depressa, pallide testacea, mude punctata, longius flavopubescens, pronoto transverso subquadrato, lateribus vix arcuatis, subcrenatis, sulcis parum profundis, elytris subparallelis, apice rotundatis, inter humeros fuscosignatis.

Assez allongée, subdéprimée, jaune-pâle, mais l'individu paraît immature; garnie de longs poils jaunes couchés. Front plan, large, coupé droit au bout, ponctué; épistome rembruni au bout; yeux globuleux, noirs. Antennes longues, assez fortes, ciliées; $1^{\mathrm{e}^{\mathrm{r}}}$ article globuleux, 2-8 obconiques, étroits, allongés, le 3 e un peu plus long; massue de 3 articles làches : $1^{\mathrm{e}^{\mathrm{r}}}$ en triangle oblong, $2^{\mathrm{e}}$ un peu plus court, $3^{\text {e }}$ arrondi. Pronotum presque en carré, transverse, plus large à la base qu'en devant, faiblement éshancré de chaque côté et subsinué au milieu, obsolètement rebordé, avec les angles aiguisés ; côtés amincis, abaissés, avec quelques crénelures, à peine arqués en devant; bord antérieur à peine largement échancré, ávec les angles arrondis, très-peu avancés; dos un peu élevé, avec une large impression à la partie antérieure ; ponctuation grosse et écartée; sillons latéraux courts et peu inarqués. Écusson courl, ponclué, un peu arqué au bout. Elytres un peu plus larges que le pronotum à la base, arrondies mais peu élevées à l'épaule, vaguement rebordées et subparallèles sur les côtés, arrondies ensemble au bout, avec l'angle sutural marqué, obtus; ponctuées plus densément mais moins fort que le pronotum, déprimées, étroitement rebordées à la partie postérieure de la suture: d'un jaune-pâle uniforme, avec une ombre brune linéaire à peine visible en dedans du calus huméral, suivie d'une autre plus ABEILle, v. 1868. 
rapprochẻe de la suture et placée au tiers. Cuisses assez. minces et longues, un peu épaissies vers le bout. - Long., 4,2 inill. - Larg., 2 mill.

Celle espèce, dont notre regrellable charles Coquerel m'avail donné un exemplaire qui me parait encore immature, se rapproche pour l'ensemble de la Barbara, mais elle est plus déprimée, plus grossièrement et plus vaguement ponctuée, et elle diffère surtout des autres espèces par son pronolum en carré transverse au moins aussi large à la base qu'en devant, à angles anterieurs ronds et à peine avancés vers les yeux, et par ses sillons latéraux courts et peu enfoncés.

Alger.

8. Dapsa limbata Mots., N. Mém. Mosc. IV. 1835. 323, 20, pl. IX, f. N. - Gerstæk., Endom. 202, 4.

Elongata, ovata, testacco-fusca, pubescens, thorace postice angustato, elytris valde convexis, lateribus et postice late nigris.

Un peu plus petite et plus allongée que la Trimaculata, et plus pubescente. Pronotum plus rétréci par derrière et n'ayant que deux impressions latérales (les sillons longitudinaux sont confondus avec elles), celle du milieu manque. Les angles antérieurs sont peu saillants et coupés obliquement vers la tête. Les élytres ont une large bordure latérale qui s'étend parfois sur toute la surface. Dessous du corps et pattes d'un jaune-brun, poitrine plus foncée. - Long., 3,5 mill.

D'après la figure, cette espèce paraît distincte et se reconnait bien par son prolhorax fortement arrondi sur les côtés, considérablement rétréci par derrière, et par la coloration des élytres. Ces dernières sont toutes noires dans la figure, à l'exception d'une grande tache triangulaire allongée dont la base correspond à la largeur de la base des élytres, et la pointe alteint environ le milieu de la longueur de la suture.

Monts Akhalzick, en Arménie. 
9. Dapsa caucaviea Mots., Mosc. Bull. 1845. 111, 328.

Venx lois plus petite que $D$. denticollis, d'un testacé unicolore. (Ex Mots.)

Alpes du Caucase.

\section{POLYIISS (nom mythologique!}

Muls., Sulcic. 10. 1816. - Gerstæk., Fndom. 351. 28.

Corns en ovale allongé, pubescent.

Tête enfoncée dans le prollırax jusqu'aux yeux, qui sont arrondis, saillants et fortement granuleux. Front transverse, termine par une arête, sur le bord de laquelle les antennes sont insérées all-devant des yeux. Epistome plus bas que le front, transverse, coupé droit, arrondi latéralement. Labre court, plus large que l'épistome. Palpes maxillaires grêles, à $3^{\mathrm{e}}$ arlicle plus court que le $2^{\mathrm{e}}$ et le $4^{\mathrm{e}}$ qui est atténué et tronqué au bout. Ilenton en carré transverse; palpes labiaux à dernier arlicle court, subcylindrique, tronqué.

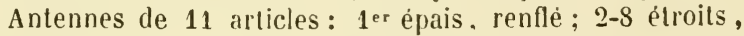
un peu épaissis au boul; '2e el $4^{e}$ presque égaux, $3^{e}$ un peu plus long, les autres diminuant peu à peu de longueur; massue de trois articles plus larges que les précédents, peu serrés, comprimés : $1^{\text {er }}$ el $2^{\text {e }}$ obconiques, de même longueur, $3^{\text {e }}$ ovalaire, presque aussi long que les deux précédents ensemble.

Pronotum plus large que long, convexe sur le dos, avec les côtés ralıattus, rebordés, arrondis en avant, sinneusement rétrécis par derrière, échancré largement en devant avec les angles arrondis peu saillants, tronqué à la base avec les angles aigus, avec un sillon profond margiual, terminé de chaque côté par un enfoncement. Elytres plus larges et beaucoup plus longues que le pronotum, étroitement rebordées, bombées, ovalaires, élevées en bosse à l'épaule, obtuses à l'extrémité.

Prosternum élevé entre les hanches qu'il dépasse pour aller en forme de pointe arrondie senfoncer dans une échan- 
crure du mésosternum; ce dernicr en carré-long, plan, rebordé latéralement, coupé droit à la base, échancré avec les angles arrondis en devant. Métasternum rebordé en devant, entaillé de chaque côté pour recevoir les hanches, large el long, tronqué postérieurement. Quatre hanches antérieures globuleuses, assez rapprochées ; postérieures en virgule, canaliculées, distantes entre elles.

l'altes assez allongées, grêles; cuisses longues, un peu épaissies avant l'extrémité; jambes menues, un peu plus courtes. Tarses à $1^{\text {er }}$ el $2^{\text {e }}$ articles bilobés, garnis de poils épais; $3^{\mathrm{e}}$ petit, caché entre les lubes du $2^{\mathrm{e}} ; 4^{\mathrm{e}}$ étroil, allongé, muni de deux petits crochets.

Abdomen de 5 segments; $1^{\text {ex }}$ long, égal aux deux suivants ensemble; 2-4 transverses, diminuant de longueur; dernier court, en arc de cercle.

La crainte d'endommager l'individu unique de la collec-

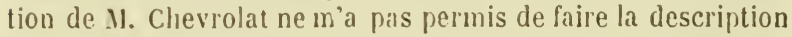
complèie des mandiluules, des mâclioires el de la languelte.

Ce genre a les plus grands rappor's avec les Dapsa: forme du corps, structure des paltes, des antennes même, pubescence, tout les rapproche; mais il s'en distingue par le prosternum moins étroit, visible entre les hanches et les dépassant, pour aller s'enfoncer daus une petite échancrure du mésosternum, qui est en carré allongé ; el par l'absence de sillons prolhoraciques. Les mêmes caractères le séparent des IIylaia (Ceramis) qui leur ressemblent aussi beaucoup.

1. Polymus nignicornis Muls., Sulcicol. 10. 1846. - Gersl., Endom. 352, 1.

Oblongus, rufo-ferrugincus, vix punctulatus, pubescens; antennis basi excepta nigris, femoribus apice obscurioribus, pronolo valde lransierso, sulcis vix dislinctis; elyuris comexis, humeris elevatis.

Ovale-olılong, médiocrement convexe, d'un jaune-roux luisant, presque lisse, garni de duvet jaune. Front légèrement convexe, arqué au bout; yeux assez gros globuleux ; épistome transverse, élargi en devant; labre courl, un peu plus large, arrondi sur les côtés. Antennes longues, gı êles, 3 articles peu serrés : $1^{\text {er }}$ gros ovale, $2^{\text {e }}$ petit el $3^{\text {e }}$ de moitié 
plus long, un peu épaissis au hout, tous trois de la couleur du fond, les autres noirs; 4-8 ovales, de même diamètre, plus longs que larges, décroissant peu à peu en longueur, 9-11 en massue assez épaissie, comprimés, 9-10 égaux, en triangle arrondi, dernier ovale, long. Pronotum deux fois plus large que long, rebordé dans tout son pourtour, fine-ment en devant, fortement sur les côtes dont la marge est relevée el au milieu de la base; largement échancré en devant avec les angles obtus, arrondi en devant sur les côtés, puis rétréci postérieurement, arqué au milieu de la base, avec une petite sinuosité qui correspond à un petit enfoncement longitudinal peu arrêté; angles droits, mais à pointe aiguë. Écusson en demi-cercle. Élytres beaucoup plus larges que le pronotum à la base, elliptiques, fortement élevées en bosse à l'épaule, arquées el très-finement rebordées sur les côtés ; bord infléchi cessant vite el devenant tres-fin , obtusément arrondies au bout, où la bordure continue. Patles gréles, allongées, cuisses un peu épaissies avec les genoux rembrunis. - Long. , \$ mill. - Larg., 2 mill.

France, Loudun.

\section{PERRISIA.}

Ovale-oblongue, convexe, lisse, luisante, à peine visiblement pointillée, noir de poix avec la tête, les antennes, l'abdomen et les pattes d'un rouge ferrugineux et garnie de petits poils jaunîtres.

Tête courte, fortement enfoncée dans le prothorax; front convexe, égal; yeux latéraux, très-distants entre eux, globuleux, fortement granuleux; épistome abaissé, plus large que long, tronqué au bout, séparé du front par une fine strie transversale. Labre court, plus large que long, subsinué au bout, avec les angles arrondis. Mandibules courbées en dec̉ans, débordant le labre. Nâchoires visibles en dehors du menton et le dépassant par derrière; ce dernier transverse, droit devant et derrière, relevé à ses angles antérieurs. Palpes maxillaires assez longs, de 4 articles : $\mathbf{1}^{\text {er }}$ petit, $2^{\mathrm{e}}$ allongé renflé au bout, $3^{\mathrm{e}}$ court en cône tronqué $: 4^{\mathrm{e}}$ en ovale beau- 
coup plus long; labiaux petits de 3 articles, dont le rernier est ovalaire. N'ayant qu'un exemplaire unique sous les yeux, je n'ai pu disséquer la bouche pour en donner une description plus détaillée.

Antennes assez robustes, égalant à peu près en longueur la moitié du corps, ciliees, insérées à l'aide d'un nœud tout contre les yeux, au bord antérieur du front, à une distance assez grande l'une de l'autre, de 11 articles: $1^{\text {er }}$ arrondi, à peine plus épais et pas plus long que les deux suivants, qui sont obconiques, égaux entre eux, les 4-8 moniliformes courts, les 3 derniers formant une massue, assez tranchée dont 1-2 sont en triangle plus large que long, dilatés en dedans, et 3 subarrondi, un peu plus gros.

Pronotum beaucoup plus large que long, plus étroit devant que derrière, un peu élevé sur le dos, abaissé, bisinueusement échancré en devant avec les angles arrondis peu saillants, bordé sur les côlés d'un épais bourrelet quui est arqué en devant, puis sinneusement redressé vers les angles postérieurs qui sont fortement acuminés; base formant une ligne droile entre les sillons longiludinaux qui ne remontent pas au-delà du tiers et sont réunis par un sillon transverse longeant le bord basal; à partir de là, celle ligne se brise et suil l'angle postérieur. F́cusson plan, en cercle. Elytres en ovale court, bombées sur le dos, tronquées à la hase avec les angles huméraux bien marqués, dépassanl ceux du pro-notum auxquels ils fournissent un point d'appui, dilatées arrondies au tiers antérieur sur les côtés, curvilinéairement rétrécies par derrière, avec un étroi: rehord dans tout le pourtour et mème le long de la suture postérieurement; l'extrémilé est arrondie, avec l'angle sutural obtus.

Prosternum fort saillant, surtout entre les hanches antérieures, qu'il ne dépasse pas par derrière, rebordé et élargi à la base, obtus au bout el appuyé sur le mésosternum, qui est plus long que large avec le bord étroitement relevé, arrondi en devant et tronqué droit par derrière, oú il est bien séparé du métasternum. Ce dernier large, lisse, convexe, bisinué et rebordé en devant.

Pattes médiocres . trapues; hanches antérieures et intermédiaires globuleuses, insérées à une pelite distance les unes des autres, les intermédiaires un peu plus éloignées, 
postérieures transverses; cuisses renflées peu à peu en massue vers le bout ; jambes élargies en triangle; tarses de 4 articles, 1-2 bilobés, garnis en dessous de brosses de poils, $3^{\text {e }}$ en forme de petil nœud, le $2^{\text {e }}$ presque à la base soudé au $4^{\mathrm{e}}$, qui est mince, long, arqué, armé de 2 petits crochets.

Abdomen de 5 segments : $1^{\text {er }}$ grand, 2-4 courts, coupés droit au bout, dernier en arc court.

Cette intéressante espèce, découverte par 11 . Ed. Perris, m'a été comminniquée, comme toujours, avec une obligeance si aimable qu'elle double le prix du service. J'ai voulu introduire, dans la nomenclature générique, le nom de cel éminent entomologiste, àqui la science doit de si précieuses découvertes el qui sait si bien surprendre la rature dans ses opérations mystérieuses, comme une faible preuve de ma haute estime pour lui et du prix que j'altache a sa vieille et bonne amitié. Tout d'abord, il a rapporté celle espèce au genre l.ycoperdina, dont elle a le laciès, mais son prosternum saillant entre les hanches ne me permet pas de la faire rentrer dans ce genre. Elle a beaucoup plus de points de rappout encore avec les Mycetina, sauf les couleurs et la pubescence, mais son prosternum no saillant pas derrière les hanches, son mésosternum plus long que large, le deuxième article des antennes presque égal au troisième, l'en distinguent surabondanment. Elle rsemble enfin beaucoup à la IIylaia (Ceramis) rubricollis, qui a, comme elle, les $2^{\mathbf{e}}$ el $3^{\mathbf{e}}$ articles des antennes à peu près égaux, mais se trouve dépourvue de la saillie prosternale entre les hanches antérieures adossées l'une contre l'autre.

1. Perrisia brevis Perris, Soc. Ent. France 1864. 303. Lycoperdina).

Ovata, nigro-picea . griseo-pubescens ; capite, antennis, pedibus abilomineque rufis, pronoto breviter subcordato, margine laterali valde crasso, angulis posticis acutis, "lytris convexis apice dilutioribus.

Orale-oblongue, convexe, noir de poix, luisante, avec la tête el les parties de la bouche, l'abdomen, les antennes et les paltes d'un rouge ferrugineux; garnie d'un duvet jaunâtre assez lung et assez fourni sur toute la surface. Front 
convexe, arrondi, avec quelques points; yeux globuleux, noirs; épistome court el étroit, arrondi au boul, peu nettement séparé du front; labre brun, pelit, arqué. Antennes assez longues, épaisses, ciliées; $1^{\text {er }}$ article court, subarrondi, 2 et 3 obconiques, presque égaux entre eux et au $1^{\text {er }} ; 4-8$ moniliformes, égaux; 9-11 formant une massue peu serrée, de 3 articles, dont le $1^{\text {er }}$ et le $2^{\text {e }}$ triangulaires sont dilatés en dedans, le dernier arrondi. Pronotum beaucoup plus large que long, à peine visiblement pointillé çà et là, légèrement convexe sur le dos, abaissé, rélréci el bisinueusement échancré en devant, avec les angles peu saillants, très-obtus; bordé latéralement d'un fort el large bourrelet, arrondi, sinué au-devant des angles postérieurs qui sont avancés en angles aigus, tronqué droil el rebordé à la base, jusqu’au point de lépart des sillons longiludinaux qui n’alleignent pas le milieu. Ecusson arrondi, lisse. Elytres en ovale court, fort bombées, un peu plus larges à la base que le pronolum, avec les angles huméraux marqués; dilatées, arrundies sur les côtes, avec lenr plus grande largeur au tiers, atténuées par derriere et arrondies au bout; étroitement rebordées dans leur pourtour el sur le liers postérieur le long de la suture; parsemées de très-petits points pililères écartés. Prosternum saillant, élargi par derrière, tronqué à la base et ne dépassant pas les hanches antérieures, noir de poix. Mésosternum finemenl rebordé dans son pourtour, plus long que large, arrondi en devant, tronqué droit par derrière et bien séparé du métasternum. Palles robustes, d'un rouge ferrugineux assez clair, même les hanches; cuisses renflèes en massue. - Long., 3 mill. - Larg., 1,6 mill.

Algérie, Bône. (M. Perris.)

VIII. HYLAIA (jìxi⿱亠⿻⿰丿亅八, de forêt).

Chevrol. Guér., Archir. Ent. I. 274, Pl. XIII. 1857.

Ceramis (Kispujes, terre à potier).

Gerst., Endom. 220, 18. 1858.

Ovale, convexe, atténuée postérieurement. Tête enfoncée 
jusqu'aux yeux globuleux, forlement granulée ; front abaissé, anguleux en devant, avec l'insertion antennaire sous le rebord près des yeux; épistome convexe, tronqué au bout ; labre court, bilobé.

Antennes robustes; 1 -3 articles obconiques, allongés ; 4-8 courts, larges; 9-11 formant une massue forte, peu serrée;

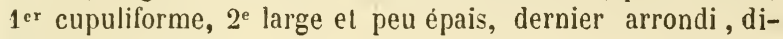
latés en dedans.

Pronotum plus large que long, convexe sur le dos, biéchancré en devant, avec les anglos assez avancés, obtus ; arrondi sur les côtés, rétréci par derrière, avec les angles aigus; tronqué à la base et bordé au milieu d'un profond sillon, qui se termine à un enfoncement longitudinal. Ecusson semi-circulaire. Elytres à peine plus larges que le pronolum à la base, arrondies latéralement, très-atténuées par derrière, terminées en pointe, arrondies séparément.

Mandibules très-grandes, dépassant le labre, beaucoup plus larges que dans les Lycoperdina, coudées presque droit en dehors et terminées par une longue pointe aiguẻ, munies d'une petite dent tout à la base. Lobe externe des mâchoires un peu plus long que large, arrondi au bout; l'interne plus court, étroit.

Palpes maxillaires dépassant le lobe externe; dernier article allongé, aiguisé en alène, presque de la longueur des deux précédents ensemble.

Menton en carré transversal, dilaté en angle sur les côtés, puis rétréci à la base, presque tronqué droit en devant, avec les angles saillants. $2^{\text {e }}$ article des palpes labiaux court, cupuliforme; dernier épais, subcylindrique, un peu plus long que large, tronqué au bout.

Prosternum caché par les hanches, qui sont contiguës. Nésosternum en carène mince et tranchante, présentant une échancrure à la base pour recevoir la pointe du métasternum qui est rebordée de manière à s'avancer entre les hanches, lesquelles sont reçues de chaque côlé dans une échancrure circulaire du métasternum. Hanches postérieures très-distantes entre elles.

Cuisses épaissies peu à peu vers l'extrémité; jambes presque droites, faiblement et insensiblement élargies. $1^{\mathrm{er}}$ article des tarses un peu plus long que le $2^{\circ}$. 
Ailes bien développées.

Caractères sexuels inconnus.

Ce genre, qui a de grands rapports de forme avec les Leiestes, les Lycoperdina el les Dapsa, se distingue des uns par son pronotum rétréci par derrière, son mésosternum en cárène mince et étroite, et surtout par ses premiers articles des tarses bilobés; des seconds par sa massue antennaire bien accusée, son mésosternum mince et fort long, ses élytres non enfoncées à la suture; enfin des derniers par ses élytres atténuées vers le bout, et son mésosternum trèsmince et très-élevé.

A. Rouge en dessus, pronotum marqué d'une grosse tache triangulaire noire; élytres arec une large bande et l'extrémité noires.

1. Hylaia podagriea Guér., Arch. Entom. I. 274. Pl. 13, f. 27a. 1857. - Gers'xk., Endom. 223, note (Ceramis).

Elongalu angusta, parce punclulata, flaro-pubescens, rufa, nitida; macula antica pronoli subcordati convexi, scutello parro, lata fascia transiersa ante mediam et apice nigris.

Allongée, convexe, subparallèle, rouge ferrugineux foncé, luisante, avec une tache sur le front, les yeux, une grande tache triangulaire sur le dos du pronotum, une large bande transverse sur le milieu des élytres el leur extrémité noires, peu densément punctuée, garnie de poils gris-jaune. Front plan, transversal court, anguleux en devant; yeux globuleux. Antennes assez longues, robustes: $1^{\text {er }}$ article courbé épais, 2-3 obconiques, assez longs el égaux, 4-8 courts, serrés, granuleux; les 3 derniers dilatés surtout en dedans, transverses, courts: $1^{\text {er }}$ cupuliforme, $2^{\text {e }}$ plus court, $3^{\text {c }}$ arrondi. Pronotum beancoup plus large que long, bombe sur le dos antérieur, s'abaissant dans son pourtour, largement échancré en devant avec les angles avancés oblus, ar: ondi, puis rétréci sur les tés avec un étroit rebord élevé, presque droit à la base avec les angles aigus; un sillon marginal profond au milieu du bord postérieur, limité de chaque côté par un fort enfoncement longitudinal qui remonte presque jusqu'au inilieu; la tache noire dorsale occupe tout l'espace 
compris entre les yeux el les $4 / 5$ postérieurs. Écusson en demi-cercle. Bilytres à peine plus larges que le pronotum à la base, beancoup plus longues que larges, bombees, vues en-dessus, paraissant subparallèles an milieu, mais vues de côté un peu dilatées arrondies au tiers, puis insensiblement rétrécies par derrière, obtusément arrondies au bout, étroitement rebordées depuis l'angle huméral jusqu'à l'angle sutural ; suture un peu élevée en carène et bordée d'une strie enfoncée à partir du tiers postérieur; noires, ornées d'une large tache triangulaire rouge occupant l'épaule et coupant l'élytre en diagonale, puis d'une large bande commune transverse commençant vers le tiers postérieur, élargie à la suture, ou bien rouges avec une large bande égale à la moitié des élytres, coupée droit par derrière, mais s'avançant angulairement vers l'écusson et l'extrémité noirs. Pattes allongées; cuisses un peu renflées. - Long , 3 mill. - Larg., 1 mill.

Turquie d'Asie, Batoum (M. Reiche).

Cette gentille espèce se reconnaît aisément à sa forme subparallèle et à sa coloration noire à tache et à bande rouge.

A' Pronstum d'un rouge et d'un noir uniforme.

2. Hylaia rubricollis Dahl., Coléopt. Vers 80. 1823 (Lycoperdina). - Germ., Faun. Ins. Eur. Fasc. 23. Pl. 18. - Guér., Arch. Ent. I. 274. PI. 13 , f. $26 a$ et $b$. - Gerstæk., Endom. 222, 1 (Ceramis).

Nigra, oblongo-ovata, convexa, subtiliter punctata, flavo-pubescens, subnitida, capile, antennis, prolhorace, pedibus abdominisque apice rufis, pronoto subcordato, latcribus subcrenulatis, elytris apice dilutioribus, humeris clevatis.

liouge lerrugineux foncé, avec les élytres, le postpectus et les 4 premiers segments de l'abdomen noirs; pubescente de gris-jaune, assez luisante, finement, mais distinctement ponctuée. Front presque plan, avec de très-petits points épars, anguleux en devant; yeux globuleux. Antennes presque de la longueur de la moitie du corps, épaisses; $1^{\text {er }}$ article ovale, $2^{\mathrm{e}}$ obconique, ainsi que le $3^{\mathrm{e}}$ qui est de moilié plus long, 4-8 arrondis, beaucoup plus larges que longs ; 3 derniers 
formant une massue très-dilatée surtout en-dedans, 9-10 cupuliformes beaucoup plus larges que longs, celui-ci le plus court, le dernier arrondi au bout. l'ronotum beaucoup plus large que long, bombé sur le dos antérieurement, bisinué en devant avec un pelit angle bien marqué au milieu et les angles antérieurs creusés, arrondis, avec un étroil rebord élevé ; dilaté en avant sur les côtés, puis obliquement rélıéci par derrière, presque droit à la base avec une petite sinuosité de chaque côté au niveau d'une courte el profonde impression longitudinale servant de limite au silion qui longe la base; angles postérieurs aigus et assez pointus. Écusson semi-circulaire. Élytres plus larges que le pronotum, coupées droit à la base, 2 fois aussi longues que larges, avec les angles huméraux bien marqués et le calus saillaul, bombées el comme gibbeuses sur le dos, étroitement rebordees, dilatées arrondies sur les côtés avant le milieu, atténuées par derrière et terminées en pointe arrondie séparément. Paltes assez longues; cuisses un peu renflées vers le milieu. Long., 2,8 mill. - Larg., 1,2 mill.

Styrie, Bannat, France, Fontainebleau (II. Chevrolat).

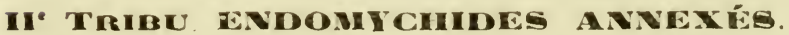

Tarses à $3^{e}$ article libre et visible.

\section{LEIESTES (irifris, voleur).}

Redt., Faun. Austr. 200, 188. 1\$49. - Guér., Arcliv. I. 276, pl. XIII, fig. 29. - Gerstæk., Endom. 389, 34. - Cryptophagus Gyl., Ins. Suec. I. 178. - Lycoperdina Gyl., Ins. Suec. IV. 221.

Corps allongé, subelliptique, poli el luisant. Tête assez large, enfoncée dans le prothorax, tombant obliquement par devant Yeux arrondis, peu saillants, distants. Epistone coupé droit, transverse, séparé du front par un sillon arqué entre les antennes. Labre légèrement arrondi par devant. Mandi- 
bules larges et robustes, avec la pointe courte fendue, protondément entaillées au bord interne et munies dans celte entaile d'une lamelle courte el large, triangulaire, frangée de poils. Mâchoires petites et étroites, leur hampe mince, cornée, les deux lobes coriaces; l'externe seulement un peu plus long que l'interne, élargi par devant, largement arrondi au bout el longuement barbu ; linterne étroil, tronqué obliquement au boul où il est garni de quelques soies épaisses. Palpes maxillaires courts et serrés; $2^{\text {e }}$ article en forme de coupe, plus large que long; 3 e court, en carré transverse; dernier ovale allongé, rétréci vers le bout, qui est brièvement tronqué. Meuton courl el large, élargi par derrière, arrondi sur les côtés, avec une saillie en forme de dent en devant; languetle cornée comme le menton, avec l'extrémité apicale nembraneuse, à peine plus longue que large, tronquée droit par devant, arrondie sur les côtés, rétrécie en cœur par derrière. Palpes labiaux grands el épais; $2^{\mathrm{e}}$ arlicle trèslarge el de moitié moins long que large, dernier court et ovale, épais, largement tronqué au bout.

Antennes assez fortes, à peine plus longues que le tiers du corps, insérées sous un petil rebord frontal, au-devant des yeux et assez distantes, régulièrement de 11 articles : $1^{\mathrm{er}}$ épais el ovale, $2^{\mathrm{e}}$ el $3^{\mathrm{e}}$ obconiques, presque d'égale longueur, un peu allongés; 4-8 graduellement plus larges que longs; massue de la longueur des 5 articles précédents, ses 2 premiers articles courts et transverses, le $2^{\mathrm{e}}$ presque deux fois aussi large et aussi long que le $1^{\mathrm{er}}$, le dernier ovale, tronqué obliquement en dehors.

Pronolum en carré transverse, convexe, rétréci et largement échancré par-devaut, avec les angles peu saillants, obtus, abaissés; bien régulièrement rebordé sur les côtés, qui sont arrondis antérieurement puis parallèles; presque coupé droil el bordé d'un profond sillon à la base, avec les angles droits, et de chaque côté d'un large enfoncement triangulaire limité en dehors par un pli tranchant et fort élevé.

Ecusson en demi-cercle. Elytres à peine plus larges à la base que le pronolum, plus de deux fois aussi longues que larges, dilatées, arrondies sur les côlés, graduellement et légèrement rétrécies à partir du premier tiers, arrondies au ABEILLE, v. 1868. 
bout; chaque élytre entourée d'un étroit rebord bien marqué; bosse lıumérale saillante; ponctuation peu régulière. Bord pectoral antérieur coupé droit en devant; prosternum non saillant, pénétrant en pointe très-aiguẻ entre les hanches antérieures qui se touchent. Mésosternum allongé, étroit, acuminé en devant, avec les bords latéraux tranchants et légèrement élevés; rétréci un peu par derrière el tronqué à sa base Avance antérieure du postpectus appointie presque en triangle aigu entre les hanches, qui sont assez rapprochées. IIanches postérieures transverses, un peu plus distantes que les intermédiaires.

Abdomen de 5 segments; $1^{\text {er }}$ un peu plus court que les suivants ensemble, $5^{\mathrm{e}}$ assez long, arrondi.

Pattes médiocres; cuisses courtes et larges; jambes étroites, légèrement et graduellement élargies au bout; tarses des $2 / 3$ de la longueur les jambes, grêles; $1^{\mathrm{er}^{\mathrm{r}}}$ article un peu plus long que le $2^{\mathrm{e}}$, tons deux garnis en dessous de poils qui sont tress-longs, surtout au bout du $2^{\mathbf{e}}$; article ongulaire assez fort, égal en longueur aux trois précédents.

Le o se distingue de la $\&$ par les jambes intermédiaires entaillées en demi-cercle vers le milieu du côté interne et armées, à chaque bout de l'entaille, d'une petite dent mince, l'une dirigée en dedans, l'autre par derrière.

La seule espèce d'Europe vit sous l'écorce des arbres.

Ce genre a des rapports de forme arec les Mycetina, Lycoperdina et Hylaic, et pour la coloration et la taille arec ce dernier.

Son prosternum est construit comme dans le genre Hylaia, ses lıanches antérieures sont contiguës, son mésosternum est allongé, non en carène étroite, mais en bande rebordée et rétrécie à ses deux bouts; ses antennes sont plus grêles, et sont terninées par une massue à $1^{\text {er }}$ article plus petit el à dernier obliquement tronqué ; enfin, son pronotum a les deux sillons longitudinaux en cavité triangulaire profonde et large, et sa surface est presque glabre.

Il a également le prosternum comme dans le sous-genre Golgia, les antennes un peu semblables, quaique moins robustes, mais le mésosternum et le pronotum sont bâtis sur un tout autre plan.

Enfin la taille, la forme allongée, la struclure du proster- 
num et du mésosternum, la longueur relative des articles des antennes el les sillons prothoraciques le distinguent des Mycetina.

1. Leiestes seminigra Gyll., Ins. Suec. I. 178, 16. 1808 (Cryptophagus); - IV. 221, 4 (Lycoperdina). - Redt.. Faun. Austr. 200.-Guér., Arch. Ent. I. 276, PI. XIII, fig. $29 a b c$. - Gerstæk., Endom. 391, 1.

Oblonga, convexiuscula, glabra, nitida, rufa, elytris abdomineque nigris: scutello, margine basali pronoti et pectore castaneis; pronoto utrinque late et profunde excavalo.

Allongée, subparallèle, polie et luisante, d'un rouge ferrugineux vif, avec les élytres, le postpcctus et l'abdomen d'un noir profond, quelquefois d'un brun de poix transparent de roux. Tête assez large, légèrement convexe, avec une trèslégère impression de chaque côté presque sur le vertex et quelques petits points épars; yeux noirs, ronds, peu saillants, très-distants; épistome bien séparé du front par un sillon arqué au même niveau. Antennes assez longues ; $\mathbf{1}^{\text {er }}$ article renflé, gibbeux ; 2-3 obconiques, plus longs que larges, les suivants plus larges que longs, très-courts, égaux entre eux; les trois derniers un peu plus gros, également transverses, allant en grossissant ; dernier ovoïde, tronqué obliquement. Pronotum de moitié plus large que long. en carré transverse, Łombé sur le dos et très-vaguement pointillé, parallèle jusqu'au tiers antérieur où il est rétréci en arc vers le devant, qui est largement échancré et bordé d'une fine strie interrompue et dont les angles sont abaissés, peu saillants et obtus; étroitement rebordé sur les côtés avec la marge noirâtre, coupé presque droit el rembruni à la base, longé par un profond sillon, qui s'abaisse en dedans de chaque angle dans un large et profond enfoncement triangulaire, abruplement rebordé en dehors; angles droits. Ecusson en demi-cercle, large, lisse, brun plus ou moins ferrugineux. Eiytres en ovale tronqué et enfoncé à la base, régulièrement convexes, un peu plus larges que le pronotum à la base, faiblement arquées sur les côtés, ' rétrécies et arrondies au bout, bien rebordées dans leur pourtour en 
dehors comme le long de la suture; points assez forts et peu serrés. Mésosternum aliongé, rehordé fortement, acuminé en devant. Nétasternum avancé en pointe arrondie et rebordé. Pattes d'un rouge ferrugineux clair ; cuisses courtes et fort renflées: jambes élargies au bout; $\delta$ munies sur le milieu du bord interne d'une petite dent aigue suivie d'une entaille. - Long., 3 mill. - Larg., 1,3 mill.

Cette jolie espèce a l'aspect de l'Hylaia rubricollis, la même distribution de couleurs, à peu près la même taille; mais l'absence de villosité, les tarses plus grêles, la structure des antennes et du mésosternum l'en distinguent aisément.

Elle est largement répandue en Europe: Suède; Allemagne; Autriche, Croatie; Pussie, Crinée; elle se trouve rarement en France, Fontainebleau, et clle parait manquer en Angleterre.

2. Criestes montana Mots., Mosc. Bull. 1845. 111, 326.

Un peu plus grande et plus allongée que $L$. scminigra, d'un bleu foncé, avec la tête et le prothorax noirs, plus ou moins rougeâtres sur les cỏtés et à la base. (Ex Mots.)

Montagnes du Caucase.

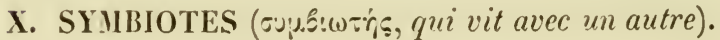

Redt., Faun. Austriaca. 198, 184.1849 ; - 2e éd. 400.-Gerstæk., Endom. 398, 37. - Dur., Gen. II. 221. Pl. LIV, 270. 1859. - Nicrochondrus ( Wollast., Ins. Mad. 196, 67. 1854.

Ovale-oblong, convexe, obtus par devant, rétréci et arrondi par derrière, luisant, finement pubescent. Tête courte et large, enfoncée dans le prothorax, inclinée; front légèrement convexe, limité en devant par une fine strie transverse; yeux arrondis, très-distants, abaissés. Epistome en carré large; labre à peine sinué, avec les angles arrondis, ciliés. Nandibules formées d'une pièce basale courte, arrondie, et d'une allongée, assez épaisse, tronquée au bout et divisée en trois dents courtes; leur bord interne est à 
peine entaillé, avec une lamelle membraneuse assez longue et large, garnie par devant de poils sétoîdes longs, et par derrière de soies de plus en plus courtes. Mâchoires à hampe courte, subtriangulaire, cornée; lobe externe pyriforme, arrondi, garni au bout de poils touffus longs el épais; lobe interne beaucoup plus court, fort étroit, linéaire, longuement barbu au bout. Palpes maxillaires courts et serrés, de 4 articles: $1^{\text {er }}$ petit, $2^{\text {e }}$ et $3^{\text {e }}$ d'égale longueur, subcordiformes, dernier de moitié plus long, ovale en pointe. Mlenton corné, transversal, coupé ủroit aux deux bouts, élargi angulairement sur les côtés vers la base; languette aussi transversale, légèrement dilatée arrondie par devant, presque cornée, avec une ėtroite bordure apicale membraneuse paraissant un peu sinuée et ciliée de poils courts: le bord antérieur de la partie cornée est garni de fortes soies écartées. Palpes labiaux de 3 articles : $1^{\text {er }}$ très-petit, $2^{\text {e }}$ court et transverse, dernier grand, arrondi en sphère, tronqué transversalement au bout.

Antennes grêles, à peine plus longues que le tiers du corps, insérées au bord du front, tout près et un peu en dedans des yeux, assez distantes, puluescentes, de $\mathbf{1 1}$ articles: $1^{\text {er }}$ épais, subcylindrique; $2^{\mathrm{e}}$ de moitié plus court, mince, allongé, les suivants très-courts, serrés l'un contre l'autre; massue grande, de 3 articles de la longueur des 6 à 7 articles précédents, graduellement élargis, les deux preniers articles transverses, le dernier ovale, terminé en pointe.

Pronotum en carré transversal, au moins deux lois aussi large que long, parallèle de la base jusqu'au-delà du milieu, rétréci et arrondi en devant, avec les angles peu saillants et obtus; coupé droit en devant, bisinué à la base, avec les angles assez aigus et un fort sillon marginal entre les sillons longitudinaux qui sont courts, larges, assez profonds et bordés en dehors d'un pli mince; fortement bombé sur le dos, avec le bord latéral tranchait, rebordé, faiblement crénelé. Ecusson petit, en demi-cercle. Elytres de la largeur du prothorax à la base, ovales, également convexes, élargies sur les côtés avec un mince rebord retroussé, alténuées par derrière et arrondies au bout, marquées d'une strie le long de la suture.

Prosternum élevé en carène étroile, linéaire, parallèle, 
avec la base obluse, dépassant les hanches el s'appuyant sur la pointe du mésosternum. Celui-ci plus large, également saillant, enfoncé au milieu avec les bords latéraux tranchants, en triangle, élargi et tronqué par derrière. Métasternum grand, formant une avance obtuse, rebordée entre les hanches, s'appuyant contre la base du mésosternum, marqué de chaque côté, derrière les hanches, d'une paire de boutons ou de verrues enfoncées. 4 hanches antérieures globuleuses, les intermédiaires un peu plus distantes; postérieures transversales, encore plus écarlées

Abdomen de 5 segments : $\mathcal{A}^{\text {er }}$ long, aussi long que les 3 suivants ensemble; ceux-ci coupés droit, égaux entre eux, dernier un peu moins court, en arc.

l'altes courtes el comprimées; cuisses assez robustes, légerement élargies au milien; jambes étroites, s’élargissant un peu vers le bout. Tarses de / articles grêles; $1-3$ à peu près de même longucur et de mème épaisseur, munis en dessous et particulièrement au bout d'un pinceau de longs poils; dernier subcylindrique, aussi long que les 3 précédents ensemble.

On n’aperçoit aucune différence sexuelle anx pattes, mais dans le $\sigma^{*}$ le $5^{\text {e }}$ segment abdominal est court et large, coupé droit par derriere, el suivi d'un $6^{\text {e }}$ segment saillant, en triangle obtus, tandis que dans la $q$ il est plus étroit, un pen plus long, arrondi par derrière.

Les espèces connues sont de petite taille et vivent sous les végétaux pourris, et aussi en sociélé avec les fourmis.

Jacquelin Duval, frappé des rapports qui lient ce genre aux Cryptophages et aux Mycetca, en avait composé une petite famille qu'il avait placée dans le voisinage des premiers. Sans méconnaître l'air de parenté que présentent leurs faciès avec les Atomaria, je préfère les rapprocher des Endomychus, à l'exemple du savant monographe de celte famille, II. Gerstæker, et les leur associer comme petit groupe aberrant. La structure des antennes, l'agencement du prosternum el du mésosternum, la forme générale du corps, les sillons du pronotum et enfin leurs tarses de 4 articles, sont à mes yeux d'un grand poids. Par là on évitera une nouvelle anomalie dans ce système tarsal, battu en 
brèche de tous côtés, et qui cependant offre un secours précieux pour le groupenent facile des coléoptères.

1. Symbiotes latus Redt., Faun. Austr. 198. 1849; - 2eéd. 371. - Gerstæk., Endom. 400, 1.

Oblongo-ovatus, subparallelus, ferrugineus, flavo-pubescens, nitidus; elytris vix dilatatis, striato-punctatis, sub sulcatis; pronoti disco convexo, subtiliter punctulato; antennis crassiusculis.

Ovale-oblong, largement obtus par devant, atténué et arrondi par derrière, convexe, d'un ferrugineux plus ou moins clair, quelquefois presque brunâtre, luisant, densément pubescent de jaune. 'Tête presque aplatie, sans impression sensible, très-finement ponctuée; yeux noirs. Antennes assez fortes; massue aussi longue que les 7 articles précédents; leur $1^{\mathrm{er}}$ en triangle court, $2^{\mathrm{e}}$ en carré transverse un peu plus large, dernier pyriforme, plus long. Pronotum près de 2 fois $1 / 2$ aussi large que long, distinctement mais légèrement élargi de la base vers le milieu, avec les angles poslérieurs un peu retirés, convexe sur le dos el garni de petits points fins mais bien visibles; bord postérieur légèrement arqué au milieu et rebordé d'un sillon parallèle, sinué de chaque côté au niveau des sillons longitudinaux, qui sont en triangle et bordés en dehors par un pli mince, rendu plus saillant par un enfoncement sur le bord externe, et qui ne remontent pas jusqu'au milieu; bord antérieur comme tronqué, beaucoup plus étroit que la base, avec les angles obtus peu saillants; bord latéral creusé dans sa longneur, avec la marge élevée, mince et crénelée. Ecusson court, arrondi. Elytres à peu près de la largeur du pronotum à la base, à peine arrondies derrière l'épaule avec la bosse humérale bien marquée, atténuées peu à peu par derrière, distinctement et régulièrement striées-ponctuées, avec les stries creusées légèrement et les interstries couverts sur la moitié antérieure de nombreux points irréguliers; la strie suturale s'éloigne de la suture en devant et se contourne en arc vers la base; la pubescence jaune est assez longue. Dessous finement pointillé. -Long , 2 mill. - Larg., 1 mill. Celle espèce se trouve en France et en Allemagne; mais 
elle est encore peu connue et doit être plus largement étendue en Europe. Elle n'est pas rare et se trouve par places en très-grand nombre.

2. Symbiotes pyomans Hampe, Ent. Zeits. 1850. 353, 15. -Wollast., Canar. Cat. 153, 258. 1854-Redt., Faun. Austr. 2 e éd. 371. - Gerstæk., Endom, 401. - Duv., Gen. II. 231. Pl. LII, f. 270. 1859. - Domuum Wollast., Ins. Mad. 197. 157, Pl. IV, 2. 1854 (Microchondrus); - Cat. Mader. 71. 1857.

Ovalus, convexior, ulrinque altemualus, ferrugineus, dense pubescens, nitidus, untennis gracilibus; pronoti disco valde convexo, rix punctulato; elytris dilatatis, subtiliter et parum striato-punclatis.

Egal en taille aux plus pelits individus du Latus, mais d'une autre forme, plus convexe, régulièrement ovalaire, à peine moins rétréci par devant que par derrière, variant de même pour la couleur du jaune lerrugineux clair au brunâtre; pubescence plus dense el plus grise. Tête trèsfinement et à peiue visiblement pointillée, sans impression. Antennes comme dans le précédent, mais massue plus étroite el plus courte, aussi longue seulement que les six articles précédents. Pronotum sensiblement plus étroit et plus long que dans le Latus, seulement 2 fois aussi large que long, non élargi aı milieu sur les côtés, mais presque parallèle jusqu'au tiers antérieur; bord latéral peu abaissé et finement crénelé; les sillons longitudinaux de chaque côté largement raccourcis avant le milieu; dos beaucoup plus fortement convexe, couvert d'un pointillé si fin qu'on peut à peine le reconnaître à un fort grossissement. Ecusson non ponclué. Elytres en ovale court, dilatées-arrondies vers le milieu, un peu plus rétrécies par derrière, d'environ un quart plus courtes que dans le Latus; le dessus est aussi ponctué-strié, mais les stries ne sont pas enfoncées, leurs points sont beaucoup plus fins et plus indistincts et elles sont moins marquées, parce que les interstries sont, sur la moitié antérieure, couverts très-densément de presque aussi gros points; en regardant de côté, la ponctuation se réunit en petites rides transversales. La pubescence des élytres est plus épaisse et plus grise, el elle ne paraît alignée que sur 
les côtés. La poitrine est polie et luisante; l'adbomen est très-finement ponctué et très-finement velu. - Long , 1,5 mill. - Larg., 0,7 mill.

France, Allemagne, Sardaigne; Madère, Palma.

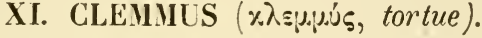

Hampe, Zeit. Stet. 1850. 353, 14.

Ovale arrondi, convexe, ferrugineux, luisant, ponctué, garni de longs poils fauves.

Tête courte et large, enfoncée dans le prothorax jusqu'aux yeux qui sont peu saillants, mais fort écarlés l'un de l'autre. Front plan, coupé droit et bien séparé en devant de l'épistome, qui est en carré transverse. Labre petil, arqué. Parties de la bouche comme dans les Iycetcea.

Antennes longues, insérées à nu sur le bord du front audevant des yeux $; 1^{\text {er }}$ article très-grand, $2^{\text {e }}$ assez long mais mince, 3-8 très-grêles, serrés; massue abruptement épaissie, de 3 articles, grosse et peu serrée, plus longue que les 6 articles précédents; $1^{\text {er }}$ el $2^{\text {e }}$ articles en triangle large, le dernier ovale obtus.

Pronotum très-court et large, arrondi au milieu de la base et sinué de chaque côté vers les angles qui sont rentrés, obtus et appuyés sur la base des élytres en dedans de l'épaule, fortement rebordé sur les côtés, qui vont en se courbant et se rétrécissant jusqu'aux angles de devant, lesquels sont arrondis et peu saillants; largement éclıancré, mais peu profondément, au bord antérieur. On voit de chaque côté un profond sillon arqué, bien limilé extérieurement, parallèle au bord latéral, qui va jusqu'au bord antérieur en s'atténuant; le sillon transverse n'existe pas. Ecusson en triangle enfoncé.

Elytres larges, arrondies, convexes, plus larges à la base que le prothorax, fortement dilatées-arrondies sur les côtés, avec un étroit rebord élevé bien net; atténuées vers le bout et terminées en pointe aiguë, finement rebordées le long de la suture dans leur moitié postérieure; bord infléchi large, 
plan, avec les bords élevés, un peu rétréci par derrière près du bout oủ il cesse en formant un angle distinct.

Bord pectoral antérieur coupé droit et laissant libre les parties progéniales; prosternum saillant, subparallèles, rebordé entre les hanches, qu'il sépare largement et qu'il depasse; obtusément arrondı à la base el appuyé dans une fossette pratiquee sur le bord antérieur du mésosternum; celui-ci transverse, cuupé droit par derrière. Métasternum deux fois plus long et encore plus large, à peine échancré de chaque côté pour les cavités cotyloïdes, qui sont creusées dans le $1^{\text {er }}$ segiment de l'abdomen.

Celui-ci de 5 segments: $1^{\text {er }}$ presque de la longueur des 3 suivants réunis, qui sont courts, linéaires, transverses; dernier en triangle, fovéolé.

Pattes grẻles, ne dépassant pas le bord des élytres. Ilanches antérieures globuleuses, peu distantes à leur insertion: ir:termédiaires également globuleuses, rapprochées des anlérieures et un peu plus distantes entre elles; postérieures transverses, grère plus écartées que les intermédiaires. Cuisses courtes, ovales, renflées au milieu; jambes grèles, un peu plus longues, à peine épaissies vers le milieu et a:ténuées au bout. Tarses allongés, filiformes, de 4 articles: 1-3 bien distincts, grêles; dernier long, armé de 2 fins crochets.

Cet insecle a de grands rapports avec les Vycctcta pour la structure des antennes, du prosternum et du pronotum; mais il a une forme générale très-différente: il est presque arrondi à la nıanière des $S c y m n u s$, au lieu d'être en ovaleoblong et alténué par derrière, et ses élytres sont vaguement ponctuées et non striées-ponctuées. En outre, ses sillons prothoraciques parailèles, son bourrelet marginal épaissi en devant, son mésosternum plus large que long, et la disposition remarquable de son bord infléchi ne permeltent pas de le réunir arec ce genre, comme le pensait Jacq. Duval.

1. Clemmus troglodytes Hampe, Stett. Zeit. 1850. 353 (Symbiotes). - Duv., Génér. 11. Pl. LIV , 269. 1859 (Symbiotes). 
Subrotundatus, convexus, subnitidus, rufo-ferrugineus, flavo longius pubesccns; antennis tenuibis, pronoto brevi, lateribus et sulcis arcuatis, antice angustiori; clytris apice acuminutis.

Ovale arrondi, convexe, assez luisant, d'un roux ferrugineux, avec les antennes, les parties de la bouche et les pattes d'un jaune påle, garni de longs poils jaunes. Tête large; front plan et lisse, tronqué droit en devant et bien séparé de l'épistome qui lorme un carré transverse. Yeux assez gros, ronds, noirs, fort éloignés l'un de l'autre. Antennes longues, insérées à nu sur le bord du front au-devant des yeux $; 1^{\text {er }}$ article très-grand, $2^{\mathrm{e}}$ assez long, mais mince, 3-8 très-grêles, serrés; massue brusquement épaissie, grosse et peu serrée, plus longue que les 6 articles précedents; $1^{\text {er }}$ el $2^{\mathrm{e}}$ articles en triangle large, dernier ovale oblus. P'ronotum beaucoup plus large que long, convexe, arrondi et rebordé au milien de la base jusqu'au sillon longitudinal, sinué de chaque côté au-devant de l'angle postérieur qui est obtus el appuyé sur la base des élytres, arqué sur les côtés avec un sillon marginal profond entier, limilé par un bourrelet qui va en s'épaississant par devant, très-rétréci et largement échancré en devant, avec les angles arrondis: sillons longitudinaux profonds, en arc parallèle au sillon marginal, attenués antérieurement et alteignant le bord antérieur. Elytres bombées, plus larges que le pronotum, dilatées arrondies régulièrement sur les côlés, avec un rebord élevé mince, un peu atténuées et un peu obliques au bout, avec l'angle sutural de chacune très-aigu; le bord infléchi large, creusé longitudinalement, se lermine brusquement un peu avaut la pointe. Prosternum assez saillant et reborde entre les hanches qu'il sépare et dépasse, obtusément tronqué au bout. Jésosternum beaucoup plus large que long, marqué d'une impression pour recevoir la base du prosternum. Abdomen de 5 segments; $1^{\text {er }}$ double des suivants, 2-1 égaux entre eux et courts, $5^{\text {e }}$ un pell plus long, arrondi, impressionné au bout. Paltes grêles; tarses filiformes, longs. - Long., 2 mill. - Larg., 1 mill.

Croatie. 


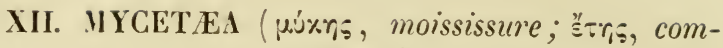
pagnon).

Steph., Manuel. Brit. 124. 1829. - Illust. Brit. Fnt. Mandib. III. 80. 1830. - Redt., Faun. Austr. 197, 183. - Gerstæk., Endom. 402, 38. - Duv., Gén. II. $2201^{\circ}$, Pl. LV, f. 271. 1859. - Cryptophagus Gyl., Ins. Suec. I. 164 ; - IV, 292.

Ovale allongée, distinctement alténuée en pointe obtuse par derrière, assez convexe, ferrugineuse, luisante, poncluée, couverte à sa surface de poils épars.

Tête large, peu enfoncée dans le prothorax, inclinée; yeux petits, ronds, latéraux; épistome lien séparé du front par un sillon étroil, coupé droit par devant. Labre transverse, arrondi de chaque côté. Mandibules à pointe large, fendue el munie d'une petite dent; entaillées au bord interne d'une échancrure garnie d'une lamelle membraneuse étroite par devant, fort élargie par derrière el longuement ciliée. Màchoires à hampe courte cornée, à 2 lobes coriacés, l'externe plus corné à la base, légèrement élargi par devanl, arrondi et garni de longues soies touffues au bout; l'interne proportionnellement plus court, linéaire et aussigarni de longs poils au bout, qui est tronqué. Palpes maxillaires assez petits el menus; ze article allongé, cupuliforme; $3^{\text {e }}$ courl, transverse; dernier long, étroit el fortement subuliforme. Menton deux fois aussi large que long, dilaté arrondi de chaque cóté par derrière, bisinué par devant, avec une légère courbure au inilieu et les angles en saillie dentiforme; languelte aussi longue que large, un peu plus rélrécie par derrière, échancrée en devant avec un appendice frangé de poils fins de chaque côté, presque entièrement cornée, bordée au bout d'une étroile bande membraneuse. Palpes labiaux de 3 articles; $2^{\mathrm{e}}$ grand, transversal, arrondi presque en demi-cercle à son bord postérieur; $3^{\mathbf{e}}$ épais, en ovale court et largement tronqué au bout.

Antennes insérées au bord du front, un peu en dedans des yeux et à une assez grande distance l'une de l'autre, à peu près du tiers de la longueur du corps, menues, de 11 arlicles: $1^{\text {er }}$ très-renflé, en ovale court; $2^{\text {e }}$ beaucoup plus long et plus tort que les suivants, 2 fois $1 / 2$ aussi long 
que large, 3-5 aliongés, $6^{\text {e }}$ presque carré, 7-8 globuleux ; massue de la longueur des 5 articles précédents, petite, dilatée peu à peu; $1^{\text {er }}$ artícle à peine de moitié de la longueur du $22^{\mathrm{e}}$, tous deux transverses; dernier un peu plus long que large, presque carré.

Pronotnm transversal, deux fois aussi large que long, convexe sur le dos, légèrement bisinué et rebordé d'un sillon à la base avec les angles obtus, arrondi en arc sur les côtés avec le bord étroitement relevé, subdentelé et cilié, rétréci en devant avec les angles peu saillants, moins avancés que le bord antérieur, quoique marqués par une échancrure; sillons lorgitudinaux bordés en dehors d'une carène, suivant une courbe concentrique à celle du bord latéral et aboutissant à la marge antérieure. Ecusson très-court, arrondi. Elytres faiblement élargies jusqu'au tiers, alors distinctement, presque obliquement rétrécies par derrière et terminées ensemble en pointe arrondie, avec la marge tranchante; convexes et grossièrement ponctuées-striées sur leur surface. Ailes manquent.

Hanches antérieures séparées par une saillie prosternale qui les dépasse par derrière. Mésosternum élargi par devant, rétréci entre les hanches intermédiaires et coupé droit par derrière. $1^{\text {er }}$ segment de l'abdomen à peine plus long que les deux suivants ensemble, $5^{\mathrm{e}}$ plus long et arrondi dans la $\Varangle$, court, tronqué et suivi d'un $6^{e}$ saillant dans le $\delta^{\star}$.

Cuisses épaissies avant l'extrémité. Jambes étroites, légèrement et peu à peu élargies vers le bout. $1^{\mathrm{er}}$ article des tarses un peu plus court que le $2^{\mathrm{e}}$; celui-ci allongé, avancé en pointe au-dessous du $3^{e}$, les deux garnis en dessous de poils qui paraissent des plus longs au bout; $3^{\mathrm{e}}$ petit et trèscourt, quoique dégagé des précédents en dessus; article ongulaire subcylindrique, devenant à peine plus large par devant, aussi long que les trois premiers ensemble.

La seule espèce connue d'Europe vit dans les lieux humides, remplis de moisissures, surtout dans les maisons; on la trouve en grand nombre dans les coins dont les murs sont à l'abri de la lumière. J'en ai rencontré en quantité dans une vieille racine de sureau, perforée d'une foule de petits trous assez profonds, évidemment creusés par l'insecte, d'oủ ils sortaient et paraissaient éclos depuis peu.

ABEILLE, v. 1868. 
Ce genre a les plus grands rapports avec les symbiotes : même furme, même taille et même couleur blonde, même structure des antennes, du steruum, de l'abdomen et des paltes; néanmoins il est facile à en distinguer par le pronotum régulièrement arqué sur les côtés avec les angles postérieurs rentrés, courts et obtus, et les sillous longitudinaux limités en dehors par une carene trancliante el formant un arc concentrique jusqu'au bord antérieur, par ses élytres marquées de lignes de gros points profonds et garnies de longs poils hérissés, et par la forne du mésothorax.

1. Hycetaea hirsa Marsh., Coléopt. Brit. I. 124, 29. 1802 (Silpha).-Gyll., Ins. Succ. I. 184, 23. 1808 (Cryplophagus). - Steph., Illust. Brit. Ent. III. 66, 7 (Atomaria). - Man., Brit. 127. 1030. - Curt., Brit. XI. pl. 502. - Redt., Austr. 197 et $2^{e}$ éd. 371. - Gerst., End. 404. 1. - Dur., Gén. II. pl. LV, f. 271. 1859. - Subterranea F. Syst. El. I. 318, 34 (Dermestes)? (Tedt.). - Fumata Steph., Illust. III. 81, 1. pl. XVII, 1. 1830, et Man. Brit. 127, 1029.

Oblongo-ovala, convexu, mufo fervuginea, flavo picta; pronoto punctalo, margine laterali crenulato elevaloque, sulcis arcuatis antice convergentibus; elytris postice attemuatis, regulariter e't validis punctis seriatis.

Ovale allongée, médiocrement convexe, rouge ferrugineux clair, luisante, pubescente de poils jaune d'or. Tête finement el densément poncluée, sans impression. Antennes plus claires, d'un ferrugineux plus jaune. Yeux petits, noirs. Pronotum deux fois aussi large que long, arrondi sur les côlés, plus rétréci devant que derrière, avec les angles postérieurs presque droits; marge exlerne relevée, iranclıante, subdentelée et ciliée ; longée d'un sillon limilé d'une carène, alqué en dedans, mais dont la courbe s'éloigne du borl en devant, de manière à pouvoir rejoindre celui du côté opposé et former avec lui un demi-cercle, s'il ne s'urrêlait pas au bord antérieur; base bordée d'un sillon bien marqué, peu profond ; dos également convexe, un peu plus distinclement et moins densément ponclué que la têle, densément pubescent. Ecusson extraordinairement court, près de 4 fois plus large que long, tronqué presque droit par derrière. Elytres allongées et ovales, convexes, un peu plus larges à la 
base que le prothorax, dilatées-arrondies au tiers, rétrécies fortement par derrière, arrondies ensemble au bout, et en angle assez aigu séparément; marquées de lignes de gros points assez rapprochés el garnis d'une pubescence jaune d'or roide, dirigée par derrière; ces poils sont plus longs dans les rangées de points alternes $1,3,5$, etc., que dans les intermédiaires, et par là même plus distinctement marqués. Le dessous est coloré comme le dessus, la ponctuation de la poitrine est forte et serrée, celle de l'abdomen trèsfine et très-serrée. Le prosternum est peu élevé, parallèle, tronqué au bout avec les bords élevés sur les côtés. Les pattes sont d'un jaune ferrugineux clair. - Long , 1,8 mill. - Larg., 0,7 mill.

Le $\sigma^{x}$ se distingue de la $q$ par la forme du corps plus étroite, les élytres plus rétrécies par derrière el un $6^{\mathrm{e}}$ segment abdominal saillant sortant du $5^{\mathrm{e}}$, qui est court et obtus; le $5^{\mathrm{e}}$ segment de la $q$ est plus large et obtusément arrondi au bout.

Commune et en grand nombre dans les ruches d'abeilles ; répandue vraisemblablement dans toute l'Europe.

Les premiers étals de la vycctca hirla ont été décrits et figurés dans les Annales de la Société entomologique 1849, 315 , pl. IX, II (Cryptophagus) par mon regrettable ami Blisson. La larve a une grande ressemblance pour la forme avec celle des Endomychus et des Lycoperdina. Le corps est composé de 13 anneaux, y compris la tête; le $1^{\text {er }}$ segment diu thorax est beaucoup plus long que les 2 suivants réunis, dont il a presque la largeur; ceux de l'abdomen sont presque d'égale longueur, et se rétrécissent peu à peu par derrière, de sorte que le dernier est seulement deux fois aussi large que long; le bord postérieur de ce dernier est profondément échancré au milieu. Le dessus de tous les segments est, comme dans les Endomychus, garni de petits granules élevés; leurs bords latéraux, au contraire, sont munis de petils appendices allongés en massue. Antennes de 3 articles courts, qui s'atténuent peu à peu vers le bout. Il doit y avoir 2 oce!les de chaque côté de la tête. Pattes courtes, finissant par un article tarsal long, comme dans les Endomychus. 
Note 1. - En examinant les mâchoires de l'Aulacochcilus violaceus, nous avons été induit en erreur sur la forme de cet organe. Nous avions cru voir le lobe maxillaire interne terminé par un fort crochet corné simple, et l'externe par un crochet extrêmement petit. Au contraire, il résulte de nouvelles observations de M. Fairmaire que le lobe interne seul est muni de deux forts crochets aigus, égaux entre eux, tandis que le lobe externe est inerme; seulement, comme les deux crochets sont accolés, on ne peut les distinguer si l'on n'a eu soin de les examiner obliquement. Cette remarque est, du reste, conforme aux observations antérieures de M. Lacordaire (V. p. 3, I. 9 ; p. 44, I. 3, et p. 45, I. 9).

Note 2. - Dans un article sur les Triplax de la collection et des ouvrages de Stephens, M. Waterhouse (Transac. of the entom. Soc. of London, $3^{\text {e }}$ série, 1862-64, p. 129) a publié des remarques synonymiques dont la plupart nous étaient connues; nous n'indiquons ici que celles dont nous n'avions pas eu connaissance.

D'après ce mémoire, le Triplax castanea de Stephens est bien le T. russica L. très-immature; quant au Silpha castanea Marsh., dont la description était donnée d'après un type de la collection de Shaw, il parait très-douteux qu'il appartienne à la même espèce, Marsham donnant au T. russica 3 lignes de longueur et 2 seulement à son Silpha caslanea (V. p. 18, I 9, et p. 29, I. 39).

La description donnée par Stephens du T. bicolor, insecte étranger à l'Angleterre, est suivant . 1. . Waterhouse, simplement copiee sur Gyllenhal. Sur les 3 individus portant le nom de bicolor dans la collection Stephens, 2 sont des $T$. cenea noircis par la graisse (bicolor Marsh.; types); le $3^{\text {e }}$ se rapporte au ruficollis Lacord., et, par une étrange confusion, a servi de modèle à la fig. 4 , pl. XVII, t. III des Illustrations, sous ce même nom de bicolor (V. p. 28, l. 15 et 23, el p. $32,1.9$,

Note 3.-Ainsi que nous l'avions présumé (V. p. 37, I. 9 ), le Tritoma Menetriesi Fald. n'appartient pas au genre Triplax. D'après Notschulsky (Bul. Mosc. 1845. 110, 322) cette espèce est la Podagrica punctatostriata Mots. qui habite les Alpes du Caucase.

L. B. 


\section{CATALOGUE}

DE

\section{LA FAMILLE DES ENDOMYCHIDES.}

\section{ENDOMYCHIDES PROPRES.}

\section{Axcylopes Costa Fn. Nap. 50. 14 .}

1 melanocephalus 0I. Ent. VI. 08. 1073. Sic.

v. pictus Wiedm. Zool. II. 78.

2. Елдомхсниs Panz, Germ. 1795. 175.

1 coccineus I. Fn. Suec. 1735. 166. Eur.

4-maculatus de G. V. 1755. 301. v. coccineus Kryn. Mosc. 32. 178. 2 armeniacus Mots. Mosc. mém. 35. 321. Cauc.

Scovit:i Fald. Cauc. II. 37. 411.

3. Mycetina Muls. Sulc. 46. 15.

1 cruciata Schal. Hal. 1783. 273.

Eur. Méd.

lithoplitus Herb. Fuesl. 1783.37. v. binotata Dahl. Col. 23. 80 .

2 apicalis Mots. Mosc. mém. 35. 321. TN.

4. Lycoperdina Lat. Gén. IIl. 07. 73.

1 succincta L. S. N. 1767.573. Fur. Sib.

v. fusciata F. S. El. I. 01.505. 1. pallida Gebl. Mosc. 41. 623. Sib. 2 bovistæ F. E. S. II. 1792. 20. Eur. Afr.

3 penicillata Mars. 68. 96. Alg.

4 validicornis Gerst. End. 58. 217. Sard.

5 marginalis Gebl. Ledeb. 30. II. 227. Sib.

6 humeralis Wollst. Can. 64. 432. Ténérif.

5. Dapsa Lat. Reg. 29. V. 159.

1 denticollis Germ. Fn. III. 17.8. A v. nigricollis Dahl. Vers. 23. 80 .
2 edentata Woll. Can. 64. 432. Can.

3 trimaculata Mots. Mosc. Mém.35. 322. FERC.

4 barbara Luc. Alg. 42. 552. Alg.

5 subpunctata Mars. 68. 57. Alg.

6 sellata Mars. 68. 58. Bône.

7 pallescens Mars. 68. 59. Alg.

8 limbata Mots. Mosc. Mém. 35 . 323. C.

9 caucasica Mots. Mosc. 45. 111. C. 6. Pouynus Muls. Sulc. 46. 10. 1 nigricornis Muls. Sulc. 46. 10. F.

7. Perrisia Mars. 68. 63.

1 brevis Per. Fr. 64. 303. Bône. 8 Hruala Chevl. Guér. Arch. I.

57. 27亿.

Ceramis Gerst. End. 58. 220.

1 podagrica Guér. Arch. Fnt. I. 57 274. N.

2 rubricollis Dahl. Vers. 23. 80. FA.

\section{ENDOMYCHIDES ANNEIES.}

9 Leiestes Redt. Fn. 49. 200.

1 seminigra Gyl. Suec. I. 08. 178. Eur.

2 monlana Mots. Mosc. 45. 111. C. 10 Sүмвюотеs Redt. Fn. 49. 198. Microchondrus Woll. Mad. 34. 196. 1 latus Redt. Fn. 49. 198. Eur.

2 pygmæa IIamp. Stet. 50. 353.

FAI Mad.

domuum Wollst. Mad. 5/.157.

11 Clemuos Hamp. Stet. 50. 353.

1 troglodytes Hamp. Stet. 50. 353. Croat.

12 Mycetea Steph. Man. 29. 124.

1 hirta Marsh. Brit. I. 02.124. Eur. subterranca F. S. El. I. 01. 318. fumala Steph. III. III. 81. 


\section{TABLE ALPHABÉTIQUE}

\section{DES GENRES ET DES ESPE்CES.}

Pages. Ancylopus Costa $1^{\circ} \ldots . . .18$ apicalis Mots. Mycetina 2. . 36 armeniacus Mols. Endomyc. 2. 29 barbara Lnc. Dapsa 4. . . . 56 binotata Costa Mycetina 1. . 35 bovista F. Lycoperdina 2... 44 brevis Per. Perrisia 1.... 65 Caucasica Mots. D. psa 9. . 61 Ceramis Gerst. $8^{\circ}$... 66

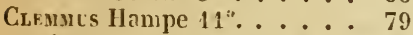
coccincus L. Endomych. 1 . 25 cruciata Sclial. Mycetina 1. . 34 Dapsa Latr. 5". . . . . 49 denlicollis Germ. Dapsa 1 . 52 domuum Wollst. Symbiotes 2. 78 edentata WVollst. Dapsa 2. . 53 Exдonссис Panz. 2\%... 22 fasciata F. Lycoperd. 1. . . 42 fumata Steph. Mycetaea 1... 84 Golgia Muls. 4\%..... 38 hiita Marsh. Mycetæa 1. . . 84 humeralis Wollst. Lycoperd. 6.49 Hriara Cherl. $8^{\circ}$..... . 66 immaculata Latr. Lycoperd. 2. 44 latus Redt. Symbioles 1. . . 77 Leinstes Redt. 9\%..... 70 limbata Motء. Dapsa 8. . . 60 lithophilus Herbst Mycetina 1. 35 Lycoperdina Latr. $4^{\circ}$. . . 38 marginalis Gebl. Lycoperd 5. . 48
Pages

melanocephalus Costa Ancyl. 120 Microchondrus Guér. 10\%. . 74 montana Mots. Leiestes 2. . 74 МrсетÆA Steph. 12.... 82 Mrcetuna Muls. $3^{\circ}$.... 32 nigricollis Dahl. Dapsa 1 . . 52 nigricornis Muls. Polym.1. . 62 pallescens Mars. Dapsa 7. . 59 pallida Gebl. I ycoperd. 1 . . 43 penicillata Mars. Iycoperd. 3 . 46 Perrisia Mars. $7^{\circ}$..... 63 pictus WVieám. Ancyl. 1... 22 Polymus Muls $6^{\circ}$..... 61 podagrica Guér. Hylaia 1. • 68 pygmieus Hampe. Symbiotes 2. 78 4-maculalus de G. Endom. 1. 26 4-pustulata k. Lycoperd. 1. . 41 rubricollis Dahl. Hylaia 1. . 69 Scovitzi Fald. Endomych. 2. . 29 sellata Mars. Dapsa 6. . . 58 seminigra Gyl. Leiestes 1 . . 73 subpunctata Mars. Dapsa 5. . 57 subterinea F. Mycetæa 1. . 84 succincta L. I.ycoperdina 1. . 41 Syubiotes Redi. 10". ... 74 thoracicus Charp. Endom. 3. . 31 trimaculata Mots. Dapsa 3. . 5 54 troglodytes Hanıpe Clemmus 180 validicornis Gerst. Lycoperd.4. 47 









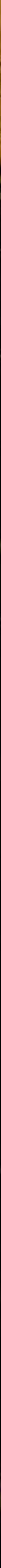

